Valorisation

of waste streams

from by-product

to worm biomass
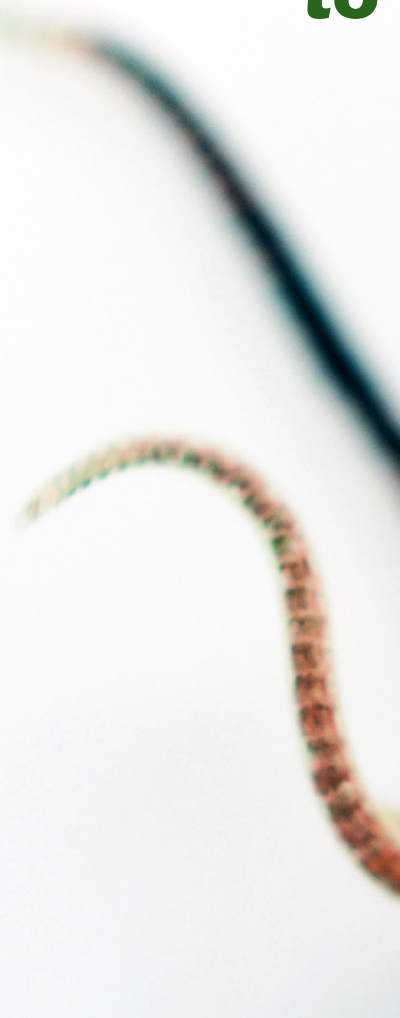

.

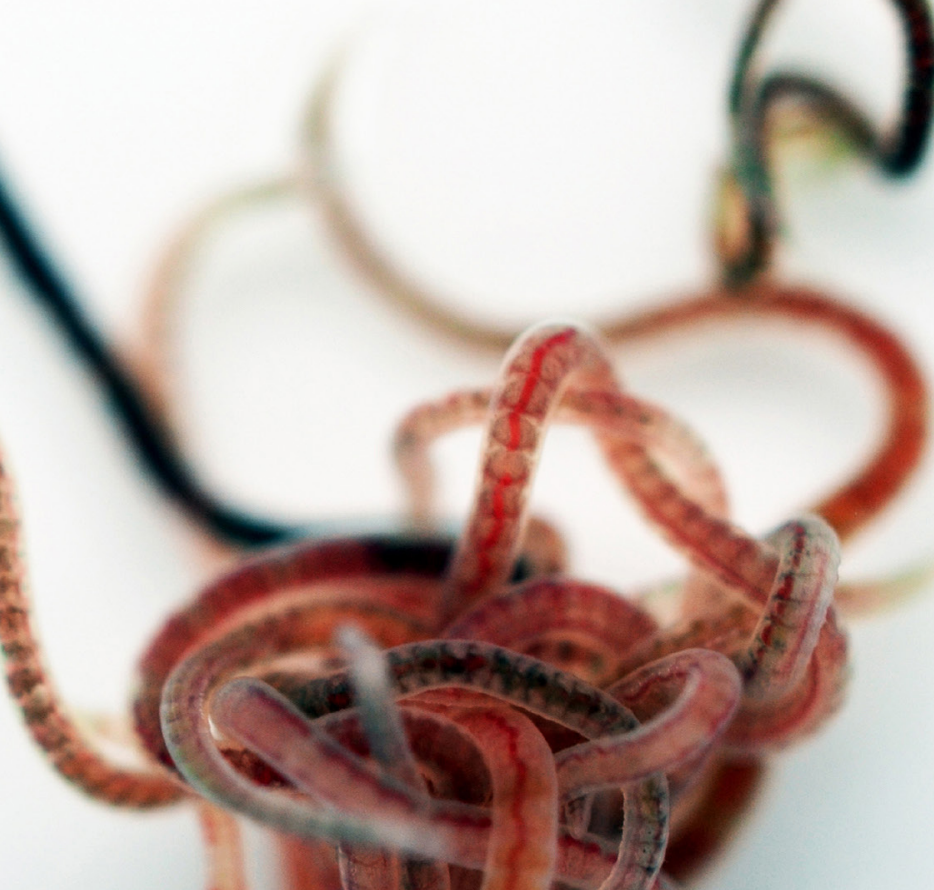

\section{C.}

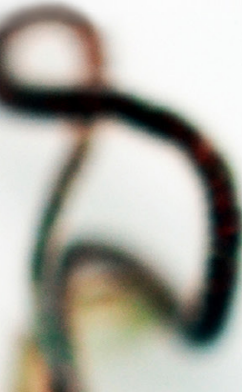

You are cordially

ted to attend the public

defense of my PhD thesis

Valorisation

of waste streams

from by-product

to worm biomass

Friday, 15 of December at 11:00,

The Aula, Generaal Foulkesweg 1, Wageningen

The defense will be followed

by a short reception at

Bob Laarhoven

b.laarh

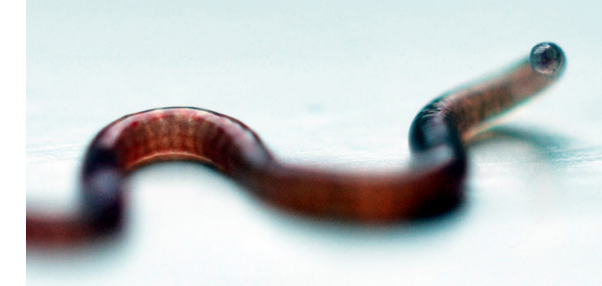

Paranymphs

Jos van Dalfsen

osvanDalfsen@wetsusn

Jan-willen Schoonen JanWillemSchoonen@wetsus n 


\section{Propositions}

1. Growth of Lumbriculus variegatus is mainly determined by the protein content of the diet.

(this thesis)

2. Worm density in a worm production reactor can be improved if the carrier directly around the centralized food compartment provides more void space.

(this thesis)

3. Legal acceptance of novel feed and food alternatives should be regulated on the basis of its biomass quality and not on the basis of its origin.

4. Maximizing animal and plant production results in a low resilience to any kind of disturbance and production failure on the longer term.

5. A bio-based economy can only flourish when we accept that sustainable solutions are often inferior with respect to production, efficiency and cost.

6. Courses in bio-inspired designs "bionica" should be compulsory to all economic- and beta students.

7. It's better as a dog owner to leave dog poo on the public lawn if the alternative is to remove it with the use of unsustainable nonbiodegradable plastic bags or pollute the local ditch or rainwater drainage system with it.

Propositions belonging to the thesis: Valorisation of waste streams, "From by-product to worm biomass".

Bob Laarhoven

Wageningen, 15 december 2017 


\section{Valorisation of waste streams from by-product to worm biomass}




\section{Thesis committee}

\section{Promotor}

Prof. Dr C.J.N. Buisman

Professor of Biological Recovery and Re-use Technology

Wageningen University \& Research

\section{Co-promotors}

Dr B.G. Temmink

Assistant professor at the sub-department of Environmental Technology

Wageningen University \& Research

Dr H.J.H. Elissen

Researcher, Applied Arable and Vegetable Research

Wageningen University \& Research

\section{Other members}

Prof.Dr W.H. Hendriks, Wageningen University \& Research

Prof. Dr M.K. de Kreuk, Delft University of Technology

Prof. Em. Dr.J.J. Videler, University of Groningen

Dr A.H.M. Terpstra

This research was conducted under the auspices of the Graduate School for Socio- Economic and Natural Sciences of the Environmental (SENSE) 


\title{
Valorisation of waste streams from by-product to worm biomass
}

\author{
Bob Laarhoven
}

\section{Thesis}

submitted in fulfilment of the requirements for the degree of doctor

at Wageningen University

by the authority of the Rector Magnificus,

Prof. Dr A.P.J. Mol,

in the presence of the

Thesis Committee appointed by the Academic Board

to be defended in public

on Friday 15 December 2017

at 11 a.m. in the Aula. 


\section{Bob Laarhoven}

Valorisation of waste streams — from by-product to worm biomass, 142 pages.

PhD thesis, Wageningen University, Wageningen, the Netherlands (2017) With references, with summary in English

ISBN 978-94-6343-811-7

DOI https://doi.org/10.18174/424548 


\section{Table of contents}

$\begin{array}{lll}\text { Chapter } 1 & \text { General introduction } & 7\end{array}$

Chapter 2 Agar sediment test for assessing the suitability of organic waste streams for recovering nutrients by the aquatic worm Lumbriculus variegatus

Chapter 3 The carbon to nitrogen ratio in isoenergetic wheat based diets controls the growth rate of the aquatic worm Lumbriculus variegatus

Chapter $4 \quad$ Aquatic worm density and production in a new reactor concept using a gravel column loaded with secondary food waste

Chapter 5 Growth and fatty acid profile of aquatic worms cultured on various waste streams

Chapter 6 General discussion and outlook

Acknowledgments

About the author 


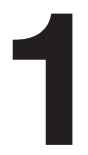

General introduction 


\subsection{From food waste to worm based fish feed}

There is a rising demand for feed resources to keep up with the increasing production of livestock, in particular for aquaculture. Over $75 \%$ of natural fish stocks are fully exploited or even overexploited (Miller et al., 2008; Pike and Barlow, 2003; Shepherd et al., 2005). The hunger for feed resources is most pronounced in aquaculture, which heavily depends on the use of fish oil/ meal from wild fish (Naylor et al., 2009; Tacon and Metian, 2015) whilst resource availability is on its decline.

With an $8 \%$ annual growth rate, aquaculture is the fastest growing food production sector in the world (FAO, 2008). It can only be sustainable if it is supported by a similar increase in feed production. This had led to several developments to reduce and replace the amount of fishmeal/ oil in fish diets by plant based ingredients originating from by-products or from crops specifically cultured for this purpose. Although plant oils and proteins are available in bulk amounts, their application in fish feed is questionable as it induces more pressure on land-use due to increased agricultural production and competes with present use as food or feed. This drives several alternative feed source developments which are based on the use of residual streams. Novel feed ingredients based on residual stream conversion can in general be subdivided into two major classes: (1) Single cell protein, mainly from yeast, microalgae and bacteria (Naylor et al., 2009; Tlusty et al., 2017) and (2) Terrestrial insect production (Barragan-Fonseca et al., 2017; Popoff et al., 2017). These novel feed ingredients have the potential to be more sustainable than fish and plant based proteins/oils if they can be effectively produced from residual nutrients, waste streams or low value by-products from e.g. food or agro industries.

Aquatic macro invertebrates also possess great potential to be used as a fish feed. They are a natural diet for most freshwater and marine fish and are rich in proteins, lipids, vitamins and minerals, and often leave a small ecological footprint as they feed on low value streams like detritus and algae residues (Henry et al., 2015). With the exception of the marine ragworm (Nereis virens), processing other aquatic organisms for farmed fish feed has only been applied on a very small and local scale. However, this group of organisms thus far has not been considered for mass production as aquaculture feeds (Lietz, 1987).

Organic waste sludges from food industries or from municipal wastewater treatment plants (WWTPS) are generally a rich source of bio-molecules, which can be upgraded to feed by aquatic worms. The production of freshwater worms of the species Lumbriculus variegatus (Oligochaeta, Lumbriculidae, common name blackworms, Fig 1.1) using safe and low-grade organic waste streams could be a full and sustainable replacement of fishmeal (Elissen et al., 2015). Lumbriculus variegatus (Lv) is able to convert these (suspended) substrates into biomass which has a composition that closely resembles the composition of fish meal (Table 1.1) and 
meets all of the nutritional requirements for healthy growth of (juvenile) fish such as rainbow trout (Mount et al, 2006). Unlike single fish feed ingredients like common used plant or animal proteins,

Lv biomass contains most essential amino acids and poly-unsaturated $\omega 3 / \omega 6$ fatty acids

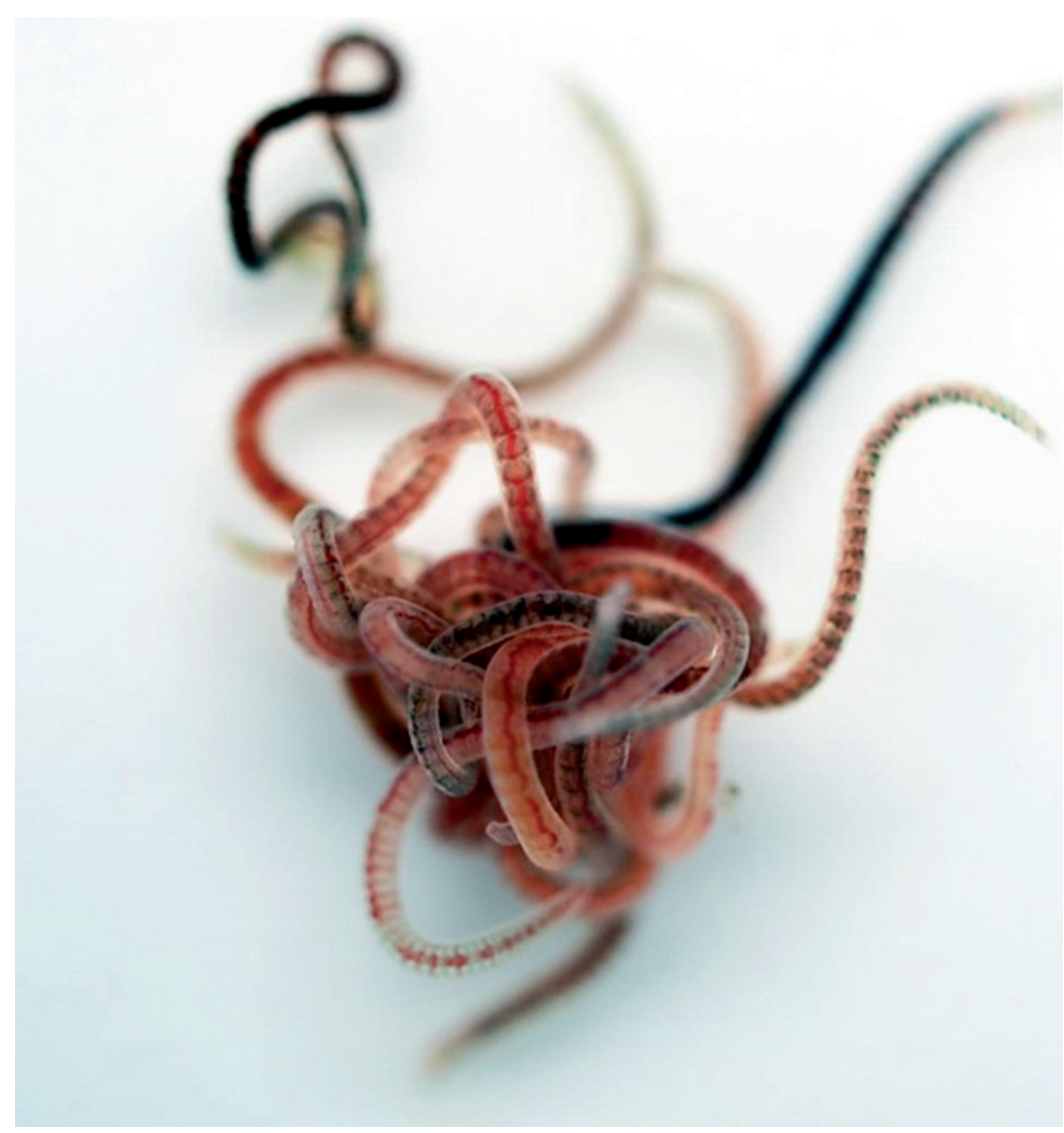

Figure 1.1 A close-up of clustering freshwater worms Lumbriculus variegatus. Worms are approximately 1 to 1.5 millimetres in diameter and on average about 6 centimetres long. The front part of the worm appears is darker in most individuals. 
Table 1.1 The nutritional composition of sewage sludge, aquatic worms grown on this sludge and a typical high quality fish meal. ${ }^{A}$ (Elissen et al., 2010), ${ }^{\mathrm{B}}(\mathrm{FAO}, 2012)$

\begin{tabular}{llll}
\hline Nutrient \% of dry matter & Sewage $^{\mathrm{A}}$ sludge & Aquatic $^{\mathbf{A}}$ worms $^{\circ}$ & Fishmeal $^{\mathrm{B}}$ \\
\hline Crude protein & $34-43$ & $62-66$ & $60-68$ \\
Crude fat & n.d. & $8-24$ & $6-13$ \\
Ash & $14-22$ & $9-11$ & $11-28$ \\
Carbohydrates & $23-26$ & $13-18$ & - \\
Calcium & - & $0.2-0.3$ & $1.8-7.8$ \\
Phosphorus & $1.6-1.7$ & $1.4-2.1$ & $1.9-4.0$ \\
Lysine & - & 5.1 & 4.8 \\
Methionine & - & 1.3 & 1.7 \\
Threonine & - & 3.2 & 2.6 \\
\hline
\end{tabular}

For valorisation of waste streams into feed by aquatic worms, as proposed in this thesis, these streams cannot contain contaminants that present a health risk such as organic micropollutants, heavy metals and pathogens as are often associated with sewage sludge. Two classes of biowaste can be distinguished: food grade and non-food (technical) grade. The quality of the waste stream determines the application potential and value chain options for the worm biomass and its refinery products (Fig 1.2). This results in a total of six potential product classes: (1) Feed grade whole biomass, either live, (freeze)dried or frozen to be used as aquaculture feed, (2) Proteins for feed, (3) Fatty acids and lipids for feed, (4) Biomass as organic fertilizer, (5) Technical proteins for e.g. paint and adhesives, (6) Oleo-chemicals for e.g. soaps and detergents. 


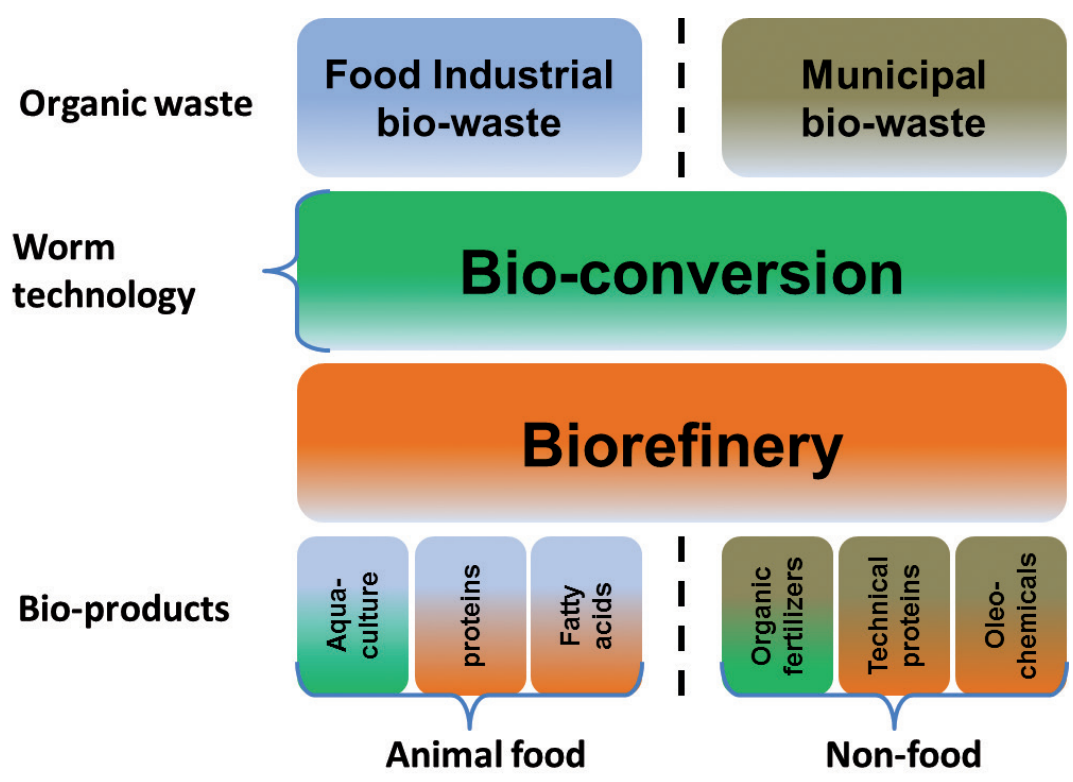

Figure 1.2 Worm production concept based on food industrial and municipal waste with food and non-food value chains (Elissen, 2007; Hendrickx, 2009).

\subsection{History of use of the freshwater worm Lumbriculus variegatus}

The aquatic worm Lv is known for its capacity to grow on a variety of substrates like natural sediments rich in organic matter (Leppänen and Kukkonen, 1998c), food industry sludges and fish food (Elissen et al., 2015). It can be used for the reduction and compaction of sewage sludge and, if cultivated on safe waste streams, nutrients and nutritional components can be recovered from its biomass (Elissen, 2007; Hendrickx et al., 2009). The consumption of (suspended) sludge particles results in a dry matter reduction of between $25-50 \%$ and in worm faeces that are about $60 \%$ more compact than the original waste sludge. Both reduction and compaction of the solids in sewage sludge can contribute to a reduction in excess sludge processing costs (Elissen et al., 2015). Reproduction of this worm is by simple year-round division (architomy), which in combination with the high sludge consumption rate and high stress tolerance makes it suitable for a controlled (reactor) application.

Aquatic worms such as the sediment dwelling LV and free-swimming worms belonging to the Aelosomatidae and Naidinae (Tubificidae) have been studied for their sludge reduction capacity, mainly by research groups in The Netherlands (de Valk et al., 2017; Janssen et al., 1998; Janssen et al., 2002; Ratsak, 1994; 2001; Rensink and Rulkens, 1997; Tamis et al., 2011) and in China (Huang et al., 2007; Liang et al., 2006a; Liang et al., 2006b; Wei and Liu, 2005; Wei et al., 2003a). It is generally accepted that the application of free swimming worms in full-scale WWTPs 
is extremely difficult because of large (seasonal) population fluctuations. Currently, several reactor designs are available for sludge reduction using aquatic worms in order to gain some more control on applying worms for sludge reduction (Emamjomeh et al., 2017).

A controlled and robust application based on the sessile species Lv was proposed by Elissen (2007) and was translated to a reactor concept by Hendrickx (2009). Key element in this concept is a carrier material for the worms, which also functions as a separation layer between waste stream (worm food) and water compartment (Fig. 1.3).



Figure 1.3 Reactor concept for waste sludge reduction by Lumbriculus variegatus as proposed by (Elissen et al., 2006).

When the sludge compartment is partly depleted form oxygen the worms start to position themselves between the two compartments in order to realize their simultaneous need for feed and respiration. The anterior part of the worm is positioned in the substrate itself for feeding and its posterior part is exposed into the water compartment for respiratory exchange through the skin (see inset picture of the carrier material in Fig. 1.3). The worm is supported by the carrier material itself. Due to this positioning, the worms will consume the waste sludge and release the residual matter as faecal pellets into the water compartment. The advantage of using this reactor concept in comparison with other reactor designs is that sludge dosage and faecal pellet collection can be separated from each other while maintaining a stable worm density. This results in a controlled method for sludge reduction. However, if the primary goal is to produce worm biomass for feed purposes, the use of clean sludges/suspensions should be considered and attention should be paid to the limited growth that occurs when worms are immobilised by the carrier material. 


\subsection{Goals and thesis outline}

The two main goals of this thesis are: (1) to assess the potential of organic waste streams and by-products for Lv production as a fish feed and (2) to develop a (cost) effective bioreactor for this purpose.

A quantitative and qualitative evaluation of the effect of different substrates for worm growth is not possible without a standardized growth setup. Growth can only be compared on substrate level if worm growth conditions are stable and independent of the food source, and if food availability is not limiting. In Chapter $\mathbf{2}$ such a set-up is described. A combination of agar and sand was applied to optimize food uptake and growth of the worms. The effects of agar gel, sand, and food quantity were studied and evaluated for different food sources. In Chapter $\mathbf{3}$ this standardized setup was used for a study focussing on the effect of carbon to nitrogen $(\mathrm{C} / \mathrm{N})$ ratios of the food on worm growth and reproduction. This was carried out with isoenergetic wheat based diets. In Chapter $\mathbf{4}$ a new worm reactor concept was evaluated. A vertical tubular reactor containing a centralized food compartment and surrounding gravel layer mimicking the natural habitat of the worms was developed. Secondary (biological) sludge from a potato starch processing industry was used as clean and cheap food source. The results were compared to the previous reactor design with respect to worm growth rate, density and production and nutrient recovery. In Chapter $\mathbf{5}$ worm growth, reproduction and biomass quality were evaluated using more waste streams and by-products of bacterial, animal and plant origin. For this purpose the standardized setup mentioned above was used. In addition, it was discussed which diet composition and food sources would be most suitable for large scale production of Lv. In Chapter 6 performance parameters (worm growth rate, density and biomass production rate) of the newly developed gravel layer reactor were used as the input for a feasibility study of large scale worm production on secondary sludge from the potato industry. In addition, future value chains and lines of research were discussed to gain more insight in worm growth and reproduction and application of the worm biomass as a fish feed. 


\section{References}

Barragan-Fonseca, K., Dicke, M. and van Loon, J., 2017. Nutritional value of the black soldier fly (Hermetia illucens L.) and its suitability as animal feed-a review. Journal of Insects as Food and Feed: 1-16.

de Valk, S., Khadem, A.F., van Lier, J.B. and de Kreuk, M.K., 2017. Unravelling the protein preference of aquatic worms during waste activated sludge degradation. Environmental Technology: 1-8.

Elissen, H.J.H., 2007. Sludge reduction by aquatic worms in wastewater treatment with emphasis on the potential application of Lumbriculus variegatus. PhD thesis Thesis, Wageningen University, the Netherlands, Wageningen, $192 \mathrm{pp}$.

Elissen, H.J.H., Hendrickx, T.L.G., Temmink, H. and Buisman, C.J.N., 2006. A new reactor concept for sludge reduction using aquatic worms. Water Research 40: 3713-3718.

Elissen, H.J.H., Hendrickx, T.L.G., Temmink, H., Laarhoven, B. and Buisman, C.J.N., 2015. Worm-it: converting organic wastes into sustainable fish feed by using aquatic worms. Journal of Insects as Food and Feed 1: 67-74.

Elissen, H.J.H., Mulder, W.J., Hendrickx, T.L.G., Elbersen, H.W., Beelen, B., Temmink, H. and Buisman, C.J.N., 2010. Aquatic worms grown on biosolids: Biomass composition and potential applications. Bioresource Technology 101: 804-811.

Emamjomeh, M.M., Tahergorabi, M., Farzadkia, M. and Bazrafshan, E., 2017. A Review of the Use of Earthworms and Aquatic Worms for Reducing Sludge Produced: An Innovative Ecotechnology. Waste and Biomass Valorization: 1-15.

FAO, 2008. World Review of Fisheries and Aquaculture Available at: ftp://ftp.fao.org/docrep/fao/011/i0250e/ i0250e01.pdf. Accessed 1 July

FAO, I.C.A.a., 2012. Animal Feed Resources Information System. Available at: http://www.feedipedia.org/ node/208. Accessed 17 july 2017.

Hendrickx, T.L.G., 2009. Aquatic worm reactor for improved sludge processing and resource recovery. PhD thesis Thesis, Wageningen University, the Netherlands, Wageningen.

Hendrickx, T.L.G., Temmink, H., Elissen, H.J.H. and Buisman, C.J.N., 2009. Aquatic worms eating waste sludge in a continuous system. Bioresource Technology 100: 4642-4648.

Henry, M., Gasco, L., Piccolo, G. and Fountoulaki, E., 2015. Review on the use of insects in the diet of farmed fish: Past and future. Animal Feed Science and Technology 203: 1-22.

Huang, X., Liang, P. and Qian, Y., 2007. Excess sludge reduction induced by Tubifex tubifex in a recycled sludge reactor. Journal of Biotechnology 127: 443-451.

Janssen, P.M.J., Rulkens, W.H., Rensink, J.H. and Roest, H.F.v.d., 1998. The potential for metazoa in biological wastewater treatment. Sludge Management. WQI: 25-27.

Janssen, P.M.J., Verkuijlen, J. and van der Roest, H.F., 2002. Slibpredatie door inzet van oligochaete wormen. Pilotonderzoek naar slibreductie op de rwzi Bennekom. Report 2002-17 (in Dutch with English abstract), STOWA, the Netherlands. 
Leppänen, M.T. and Kukkonen, J.V.K., 1998c. Relative importance of ingested sediment and pore water as bioaccumulation routes for pyrene to oligochaete (Lumbriculus variegatus, Müller). Environmental Science and Technology 32: 1503-1508.

Liang, P., Huang, X. and Qian, Y., 2006a. Excess sludge reduction in activated sludge process through predation of Aeolosoma hemprichi. Biochemical Engineering Journal 28: 117-122.

Liang, P., Huang, X., Qian, Y., Wei, Y. and Ding, G., 2006b. Determination and comparison of sludge reduction rates caused by microfaunas' predation. Bioresource Technology 97: 854-861.

Lietz, D.M., 1987. Potential for aquatic oligochaetes as live food in commercial aquaculture. Hydrobiologia 155: 309-310.

Miller, M.R., Nichols, P.D. and Carter, C.G., 2008. n-3 Oil sources for use in aquaculture--alternatives to the unsustainable harvest of wild fish. Nutrition research reviews 21: 85-96.

Naylor, R.L., Hardy, R.W., Bureau, D.P., Chiu, A., Elliott, M., Farrell, A.P., Forster, I., Gatlin, D.M., Goldburg, R.J. and Hua, K., 2009. Feeding aquaculture in an era of finite resources. Proceedings of the National Academy of Sciences 106: 15103-15110.

Pike, I. and Barlow, S., 2003. Impact of fish farming on fish stocks. Fish Farmer 26: 14-16.

Popoff, M., MacLeod, M. and Leschen, W., 2017. Attitudes towards the use of insect-derived materials in Scottish salmon feeds. Journal of Insects as Food and Feed: 1-8.

Ratsak, C.H., 1994. Grazer induced sludge reduction in wastewater treatment. PhD thesis

Vrije Universiteit, the Netherlands

Ratsak, C.H., 2001. Effects of Nais elinguis on the performance of an activated sludge plant. Hydrobiologia 463: 217-222.

Rensink, J.H. and Rulkens, W.H., 1997. Using metazoa to reduce sludge production. Water Science and Technology 36: 171-179.

Shepherd, C., Pike, I. and Barlow, S., 2005. Sustainable feed resources of marine origin. European Aquaculture Society Special Publication 35: 59-66.

Tacon, A.G.J. and Metian, M., 2015. Feed Matters: Satisfying the Feed Demand of Aquaculture. Reviews in Fisheries Science \& Aquaculture 23: 1-10.

Tamis, J., van Schouwenburg, G., Kleerebezem, R. and van Loosdrecht, M.C.M., 2011. A full scale worm reactor for efficient sludge reduction by predation in a wastewater treatment plant. Water Research 45 : 5916-5924.

Tlusty, M., Rhyne, A., Szczebak, J.T., Bourque, B., Bowen, J.L., Burr, G., Marx, C.J. and Feinberg, L., 2017. A transdisciplinary approach to the initial validation of a single cell protein as an alternative protein source for use in aquafeeds. PeerJ 5: e3170.

Wei, Y. and Liu, J., 2005. The discharged excess sludge treated by Oligochaeta. Water Science and Technology 52: 265-272.

Wei, Y., van Houten, R.T., Borger, A.R., Eikelboom, D.H. and Fan, Y., 2003a. Comparison performances of membrane bioreactor and conventional activated sludge processes on sludge reduction induced by Oligochaete. Environmental Science and Technology 37: 3171-3180. 




Agar sediment test for assessing the suitability of organic waste streams for recovering nutrients by the aquatic worm Lumbriculus variegatus

Published as: Laarhoven B, Elissen H.J.H, Temmink H, Buisman C.J.N (2016). Agar Sediment Test for Assessing the Suitability of Organic Waste Streams for Recovering Nutrients by the Aquatic Worm Lumbriculus variegatus. PLoS ONE 11(3) 


\section{Abstract}

An agar sediment test was developed to evaluate the suitability of organic waste streams from the food industry for recovering nutrients by the aquatic worm Lumbriculus variegatus (Lv). The effects of agar gel, sand, and food quantities in the sediment test on worm growth, reproduction, and water quality were studied. Agar gel addition ameliorated growth conditions by reducing food hydrolysis and altering sediment structure. Best results for combined reproduction and growth were obtained with $0.6 \%$ agar-gel $(20 \mathrm{ml}), 10 \mathrm{~g}$. fine sand, $40 \mathrm{~g}$. coarse sand, and $105 \mathrm{mg}$ fish food (Tetramin). With agar gel, ingestion and growth is more the result of addition of food in its original quality. Final tests with secondary potato starch sludge and wheat bran demonstrated that this test is appropriate for the comparison of solid feedstuffs and suspended organic waste streams. This test method is expected to be suitable for organic waste studies using other sediment dwelling invertebrates. 


\subsection{Introduction}

The freshwater worm Lumbriculus variegatus (Lv) (Oligochaeta, Lumbriculidae) is a natural fish food and can be employed for the reduction and compaction of municipal wastewater sludge. However, application of produced worm biomass, as livestock feed poses a significant risk due to the presence of heavy metals, micro pollutants, and pathogens (Elissen et al., 2010; Hendrickx et al., 2009a). Worm biomass, therefore, should be produced from safe waste streams such as byproducts from food industries. To evaluate worm growth performance on different organic waste streams, the growth and reproduction of LV on these streams should be quantified in relation to a standard food substrate. This paper describes the development of an standardized agar sediment test for this purpose.

The characteristics described below show that Lv is a promising species for recovering high value nutrients (particularly protein) from food byproducts to produce worm biomass for application as a high-quality commercial feed source; in particular, as aquaculture feed (Elissen et al., 2015; Tacon and Metian, 2008)

Lv has a gross nutritional value similar to other fish diets such as brine shrimp and trout chow and satisfies fish nutrition guidelines with respect to proteins and essential amino acids (Mount et al., 2006). Lv dry weight (14-16 \% of the wet weight) contains 62-66 \% protein, 11-12 \% lipids, 4-9\% ash and 7-12 \% fatty acids (Elissen et al., 2010; Hansen et al., 2004). Reproduction of Lv occurs by simple year-round division (architomy), and worm populations can double their biomass every two weeks (Phipps et al., 1993). They also possess a high tolerance for temperature fluctuations with an optimum between 15 and $25^{\circ} \mathrm{C}$ and optimum oxygen levels are between 2.3 and 8.1 $\mathrm{mg} \mathrm{O}_{2} / \mathrm{L}$ (Airas et al., 2008; Hendrickx et al., 2009b). It has not been identified which range of food sources Lv is capable of utilizing, although its nutritional requirements probably do not vary from other sediment-feeding invertebrates such as macro benthos which feed on complex mixtures of decomposing organic matter, algae, and microorganisms (Moore, 1979; Vos et al., 2000). Accordingly, in nature, Lv dominantly ingests subsurface sediments containing the digestible organic fraction which is associated with this sediment (Leppänen and Kukkonen, 1998c). In many laboratory cultures, Lv feeds on fish food such as Tetramin ${ }^{\circledR}$ whereas, for sludge treatment, it feeds on a complex mixture of biopolymers and bacteria(Hendrickx et al., 2009a).

Food type should be the only variable when comparing different food sources as a substrate for Lv production. Such a test should comprise ideal food uptake conditions with limited food hydrolysis combined with a fixed sediment composition and structure as well as the continuous refreshment of overlying water (Ankley et al., 1993). For the development of a standardized growth test for assessing a variation of potential food sources, it is essential to understand that many factors have a(n) (in)direct impact on worm growth and reproduction. This includes 
sediment type (particle size, organic fraction); food source (concentration, composition, particle size); and (pore) water quality (Airas et al., 2008; Ankley et al., 1993; Egeler et al., 2010; Groh et al., 2010; Lasier, 2009; Leppänen and Kukkonen, 1998b).

Laboratory tests employing Lv have been developed especially for toxicology and bioaccumulation studies (Van Geest et al., 2010) and activated sludge reduction (Buys et al., 2008). However, for testing food byproducts, these tests are likely to prove ineffective as water quality (e.g. ammonia and oxygen levels) will be negatively affected by their degradation products. Also standard sediment-bioaccumulation tests specify that Lv should not be fed during the 28-day exposure (Burkhard et al., 2015) in order to maintain water quality and to avoid any disturbance in contaminant bioavailability.

For inhibiting the transfer of soluble food compounds from the sediment into the overlying water and to promote direct feeding, we propose utilizing agar gel to trap food components inside the sediment. This is similar to the application of agar in microbial cultures where the agar gel is used as a fixed gel medium and often mixed with nutrients essential for growth. Agar is also able to replace soil and water in laboratory tests for Enchytraeidae (potworms) (Römbke and Moser, 2002).

Agar can be consumed by the earthworm Perionyx excavatus, substantiating that direct uptake occurs (Pokarzhevskii et al., 2000). Under normal experimental conditions, it is unlikely to be digested by Oligochaeta as the polymer only becomes unstable when heated above $90{ }^{\circ} \mathrm{C}$ and exposed to a $\mathrm{pH}$ exceeding the range of 5.5 - 8. Degradation by agarases can be neglected as these are normally not present in food products not related to marine environments or active under freshwater conditions (Phillips and Williams, 2009).

The objective of this study was to develop a laboratory test procedure for a reliable comparison of growth and reproduction of Lv on a variety of food sources. TetraMin ${ }^{\circledR}$ fish food was exploited as a food by-product model during the test development since it contains a balanced mixture of nutrients that dissolve and break down over a period of time, suitable for long-term worm culture. Finally, secondary potato starch sludge and wheat bran, were employed in the test as examples of real food byproducts, to ensure its practical applicability, substantiating that this new agar-based test is a reliable method for evaluating the suitability of different food byproducts for producing worm biomass. 
Table 2.1 The effect of specific combinations of agar gel, sand, and food on final worm numbers and changes in total wet weight (wt \%).

\begin{tabular}{|c|c|c|c|c|c|c|c|c|}
\hline \multirow[b]{2}{*}{ Exp. } & \multirow[b]{2}{*}{ Test } & \multicolumn{2}{|c|}{ Agar } & \multicolumn{2}{|c|}{ Sand } & \multirow{2}{*}{$\begin{array}{c}\text { Food } \\
\text { Amount } \\
\text { (mg) }\end{array}$} & \multicolumn{2}{|c|}{ Final worm } \\
\hline & & $\begin{array}{l}\text { Conc. } \\
\text { (wt \%) }\end{array}$ & $\begin{array}{l}\text { Amount } \\
\text { (g) }\end{array}$ & Fraction & $\begin{array}{c}\text { Amount } \\
\text { (g) }\end{array}$ & & $\begin{array}{c}\text { Number } \\
(\#)\end{array}$ & $\begin{array}{l}\text { Weight } \\
\text { (wt \%) }\end{array}$ \\
\hline \multirow[t]{7}{*}{1} & 1 & 0.0 & 0 & $\mathrm{C}$ & 90 & 0 & 99 & -16.1 \\
\hline & 2 & 0.8 & 30 & none & 0 & 0 & 56 & -14.4 \\
\hline & 3 & 0.8 & 30 & C & 90 & 0 & 92 & 2.5 \\
\hline & 4 & 0.8 & 30 & C & 90 & 420 & $51.0(3.0)$ & $-13.6(3.6)$ \\
\hline & 5 & 0.8 & 30 & C & 90 & 840 & $47.5(1.5)$ & $-16.1(7.5)$ \\
\hline & 6 & 1.0 & 30 & C & 90 & 420 & $55.5(2.5)$ & $3.7(2.1)$ \\
\hline & 7 & 1.0 & 30 & $\mathrm{C}$ & 90 & 840 & $50.5(0.5)$ & $-4.1(1.4)$ \\
\hline \multirow[t]{12}{*}{2} & 1 & 0.0 & 0 & C & 90 & 420 & 67 & 9.9 \\
\hline & 2 & 0.0 & 0 & C & 90 & 1050 & 46 & -12.2 \\
\hline & 3 & 0.0 & 0 & $\mathrm{~F} / \mathrm{C}$ & $22.5 / 67.5$ & 420 & 62 & 9.1 \\
\hline & 4 & 0.0 & 0 & $\mathrm{~F} / \mathrm{C}$ & $22.5 / 67.5$ & 1050 & 50 & 3.3 \\
\hline & 5 & 0.6 & 30 & C & 90 & 420 & 65 & 41.3 \\
\hline & 6 & 0.6 & 30 & C & 90 & 1050 & 54 & 7.5 \\
\hline & 7 & 0.6 & 30 & F/C & $22.5 / 67.6$ & 420 & 59 & 40.6 \\
\hline & 8 & 0.6 & 30 & $\mathrm{~F} / \mathrm{C}$ & $22.5 / 67.6$ & 1050 & 52 & 11.1 \\
\hline & 9 & 0.8 & 30 & C & 90 & 420 & 64 & 22.8 \\
\hline & 10 & 0.8 & 30 & C & 90 & 1050 & 53 & 8.2 \\
\hline & 11 & 0.8 & 30 & $\mathrm{~F} / \mathrm{C}$ & $22.5 / 67.7$ & 420 & 76 & 44.5 \\
\hline & 12 & 0.8 & 30 & $\mathrm{~F} / \mathrm{C}$ & $22.5 / 67.7$ & 1050 & 54 & 19.1 \\
\hline \multirow[t]{12}{*}{3} & 1 & 0.0 & 0 & $\mathrm{~F} / \mathrm{C}$ & $10 / 40$ & 0 & 104 & -20.6 \\
\hline & 2 & 0.0 & 0 & $\mathrm{~F} / \mathrm{C}$ & $10 / 40$ & 105 & 56 & 3.3 \\
\hline & 3 & 0.0 & 0 & $\mathrm{~F} / \mathrm{C}$ & $10 / 40$ & 140 & 76 & 5.2 \\
\hline & 4 & 0.0 & 0 & $\mathrm{~F} / \mathrm{C}$ & $10 / 40$ & 210 & 50 & -6.1 \\
\hline & 5 & 0.6 & 20 & $\mathrm{~F} / \mathrm{C}$ & $10 / 40$ & 0 & 97 & -8.8 \\
\hline & 6 & 0.6 & 20 & $\mathrm{~F} / \mathrm{C}$ & $10 / 40$ & 105 & 79 & 38.3 \\
\hline & 7 & 0.6 & 20 & $\mathrm{~F} / \mathrm{C}$ & $10 / 40$ & 140 & 52 & 28.7 \\
\hline & 8 & 0.6 & 20 & $\mathrm{~F} / \mathrm{C}$ & $10 / 40$ & 210 & 50 & -10.8 \\
\hline & 9 & 0.8 & 20 & $\mathrm{~F} / \mathrm{C}$ & $10 / 40$ & 0 & a & a \\
\hline & 10 & 0.8 & 20 & $\mathrm{~F} / \mathrm{C}$ & $10 / 40$ & 105 & 64 & 22.1 \\
\hline & 11 & 0.8 & 20 & $\mathrm{~F} / \mathrm{C}$ & $10 / 40$ & 140 & 61 & 29.4 \\
\hline & 12 & 0.8 & 20 & $\mathrm{~F} / \mathrm{C}$ & $10 / 40$ & 210 & 50 & 17.5 \\
\hline
\end{tabular}

Sand fractions used: coarse sand $(\mathrm{C})$ and fine sand (F). Test 4-7 measured in duplicate; range is given between brackets $( \pm)$. Initial worm number $=50$ (all tests). Average total start weight Exp.1: $365 \mathrm{mg}$ (min-max, 362-367), Exp. 2: 399 mg (min-max, 330-476), Exp.3: 391 mg (min-max, 350-422). Exp.3, aTest 9: Worm losses due to experimental error 


\subsection{Materials and Methods}

\subsubsection{Experimental design}

Experiments 1, 2, and 3 were performed with different combinations of agar, sand and TetraMin ${ }^{\circledR}$ as food (Table 2.1) in order to select a test setup most suitable for growth and reproduction of Lv over a 21 day timeframe. A final test of 25 days (Experiment 4) with Tetramin, secondary potato starch sludge (starch production, Novidon, the Netherlands) and wheat bran (Cargill, the Netherlands) was performed to study growth, reproduction and suitability of the selected test setup for further use with a genuine food byproduct. In the selected agar test setup, an oxygen profile was determined and a food hydrolysis test was conducted to examine the effect of agar on oxygen concentrations and ammonium production.

The duplicates in Experiment 1 confirmed that the maximum standard deviation within one single test combination was at most $7.5 \%$. Therefore further combinations tested in experiments 2 and 3 were not tested in duplicate to increase the number of tested combinations. In addition, the final experiment was done in duplicate, to further validate the repeatability in growth and reproduction. Based on the results of Experiment 1, pretreatment of the agar gel and sand addition was improved for Experiments 2 and 3, and the water renewal rate was increased. Additional details are indicated in the information described below.

\subsubsection{Test organisms}

L.variegatus from a recirculating aquaculture system was retained in $16.0 \mathrm{~L}$ plastic flow-through tanks. Culture tanks were each fitted with two $1.5 \mathrm{~cm}$ thick PVC mats. These mats had an open structure which provided sufficient support for 300 to $500 \mathrm{~g}$ of live worms per tank. The cultures were nourished three times per week with fish food flakes (TetraMin ${ }^{\circledR}$ or trout food). Water temperature was maintained at $19^{\circ} \mathrm{C}$ and filtered over a nitrifying filter to prevent ammonia and nitrite levels above $0.4 \mathrm{mg} / \mathrm{L}$. Prior to entering the tanks, the water was aerated to ensure oxygen levels above $6 \mathrm{mg} / \mathrm{L}$ in the tanks. Water refreshment rate was approximately $2.5 \mathrm{~h}^{-1}$. Approximately every second week, $30 \%$ of the water was replaced by tap water. Fully developed worms from cultures experiencing positive growth and no indications of recent fragmentation (front and hind parts without thickening or blunt ends) or abnormalities were selected and purged overnight in clean tap water to remove their remaining gut content. At the beginning of Experiments 1 - 4, 50 worms were selected for each test, and their total wet weight was determined (0.3-0.4 g per test). 


\subsubsection{Test beaker and system configuration}

A controlled temperature and water flow system with 12 plastic flow-through beakers was utilized to test the different agar/sand/food combinations (Table 2.1). Each beaker had a working volume of $770 \pm 8 \mathrm{~mL}$ and a bottom surface area of $57 \mathrm{~cm} 2$. Water was continuously discharged with a drain pipe positioned approximately $2 \mathrm{~cm}$ above the artificial sediment (at the $150 \mathrm{~mL}$ mark). The beakers were submerged in a temperature controlled bath at $19 \pm 1^{\circ} \mathrm{C}$ and retained in dark conditions until sediment replacement and/or sampling occurred. Water was supplemented at a flow rate of 2.17 $\mathrm{ml} / \mathrm{min}$ in Experiment 1 and $4.34 \mathrm{ml} / \mathrm{min}$ in Experiment 2 - 4, resulting in refreshment rates of 4 and 8 day-1, respectively. The water $\left(\mathrm{pH}\right.$ 8.3-8.5, hardness $\left.92 \mathrm{mg} \mathrm{CaCO}_{3}\right)$ was a blend of tap water (Leeuwarden, the Netherlands) and softened water. The water was disinfected with UV-C light to prevent inoculation of the beakers with microorganisms. It was then supplied on the surface of each beaker by a needle dispenser, creating a constant flow of small droplets.

\subsubsection{Sand, agar medium and food use}

Two different quartz gravels were utilized. Pre-treated acid washed sand (ALFA (AESAR)) with particle size 0.1-0.35 mm obtained from WWR International (the Netherlands) will be referred to as fine sand (F). Quartz filter sand with particle size 0.71-1.25 $\mathrm{mm}$ will be further referred to as coarse sand (C). It was obtained from Wildkamp ${ }^{\circledR}$ (the Netherlands), rinsed with hot water, and combusted at $550^{\circ} \mathrm{C}$ for 2 hours to eliminate organic compounds. Various agar concentrations were pre-prepared by mixing Agar (BD Bacto ${ }^{\mathrm{TM}}$ Agar) with demineralized water, after which the mixture was autoclaved at 120 ${ }^{\circ} \mathrm{C}$ for 20 minutes to dissolve the agar. Prior to use, Tetramin flakes were finely ground to create the food particles suitable for unmediated worm ingestion. Yeast extract BBL (BBL 211929) was added as a source of minerals and vitamins. In Experiment 1, all food enriched beakers contained $15 \mathrm{mg}$ (dry weight) yeast extract each; in Experiment 2 - 4, 20 mg yeast was added for each gram of food.
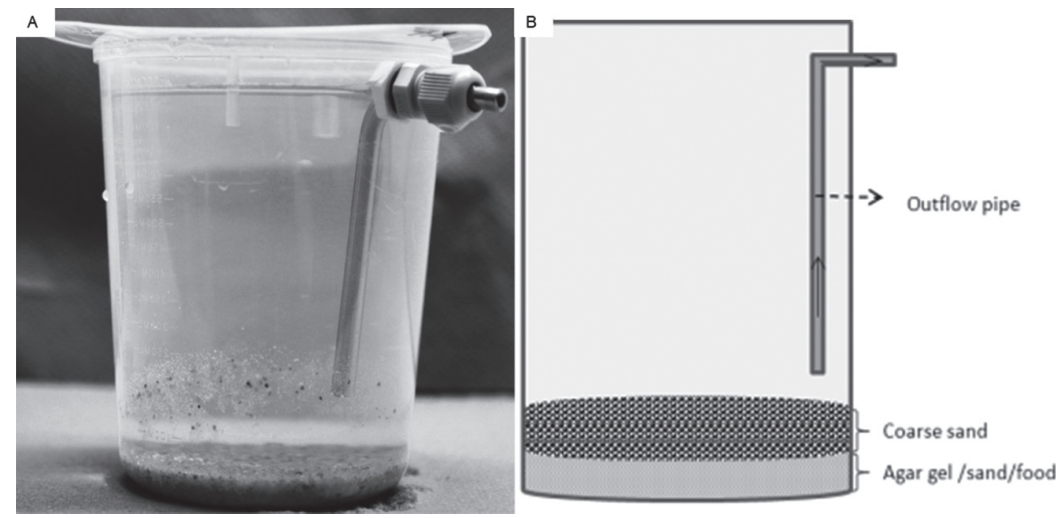

Figure 2.1 (A) Picture of experimental beaker including artificial sediment. (B) Schematic overview of the artificial sediment structure used in Experiments 2, 3 and 4. 
In Experiment 1, $90 \mathrm{~g}$ coarse sand was employed with or without agar gel (Table 2.1). For beakers containing an agar layer, the gel (30 g) was first poured into the test beakers and cooled before sand was added on top. For each combination with food (0,420 and $840 \mathrm{mg}$ ), the food was incorporated into the agar and water mixture prior to autoclaving.

In Experiment 2, the agar gel was treated differently than in Experiment 1. After autoclaving, the gel was cooled and briefly blended to break up the tension of the gel and make it less viscous. Subsequently, $30 \mathrm{~g}$ of pre-blended agar gel was mixed with the food (420 and $1050 \mathrm{mg}$ ) and part of the sand. Both coarse and fine sand were utilized. The first mixture contained only $90 \mathrm{~g}$ coarse sand (C/90; Table 2.1) which was applied by mixing $45 \mathrm{~g}$ sand with food and/or agar gel and adding $45 \mathrm{~g}$ sand on top of this mixture. The second mixture consisted of a total of $22.5 \mathrm{~g}$ fine and $67.5 \mathrm{~g}$ coarse sand (F/22.5 + C/67.5; Table 2.1) and was prepared by initially mixing $22.5 \mathrm{~g}$ fine and $22.5 \mathrm{~g}$ coarse sand with food and/or agar gel. This created an artificial sediment layer wherein interstitial space was filled with agar gel and $45 \mathrm{~g}$ coarse sand was subsequently added on top (Fig 2.1).

In Experiment 3, only one mixture of sand was used, and the total amount of sand was reduced to $50 \mathrm{~g}: 10 \mathrm{~g}$ of fine sand and $10 \mathrm{~g}$ of coarse sand were mixed with only food $(0,105,140$ or 210 mg), $20 \mathrm{~g}$ agar gel, or both. As a final step, $30 \mathrm{~g}$ course sand was added on top. The same preblended agar gel of Experiment 2 was employed in Experiment 3.

In Experiment 4, the same combination and settings utilized in Test 6 (Exp. 3) were used with three different diets all tested in duplicate. To standardize the organic loading between the three applied diets, chemical oxygen demand (COD) and total nitrogen were measured according to Standard Methods(APHA, 1998) using Hach Lange ${ }^{\circledR}$ test kits. Tetramin, secondary potato starch sludge and wheat bran respectively contain $1.33,1.25 \mathrm{~g}$ and $1.07 \mathrm{COD} / \mathrm{g}$ dry weight and 0.075 , 0.059 and $0.023 \mathrm{~g}$ total nitrogen $/ \mathrm{g}$ dry weight. For both, an amount representing $140 \mathrm{mg}$ COD was added comprising $105 \mathrm{mg}$ and $131 \mathrm{mg}$ for Tetramin and wheat bran respectively and 6 to 10 $\mathrm{ml}$ of fresh sludge. The diets were tested over 25 days starting with 50 worms each. The entire sediments including the food substrate were replaced three times per week. Wheat bran was tested at a later stage using worms from a different batch with a higher individual weight.

\subsubsection{Water quality measurements.}

Once per week, dissolved oxygen (DO) concentrations and $\mathrm{pH}$ were measured in situ prior to artificial sediment replacement using a $\mathrm{Hach}^{\circledR}$ Luminescent Dissolved Oxygen probe (LDO) and a pH electrode (WTW ${ }^{\circledR}$, Senti ${ }^{\circledR}$ Plus). To ensure precise and stable measurements at 0-2 mm above the sediment surface, these probes were inserted into the test beaker with a custommade probe holder. Once per week, DO and $\mathrm{pH}$ concentrations were also measured in the 
incoming water, and total ammonium nitrogen (TAN) concentration was determined with Hach Lange $^{\circledR}$ test kits (HACH LANGE LCK304). For this purpose, samples were extracted at 0-2 mm above the surface of the sediment with a $5 \mathrm{ml}$ syringe and needle.

\subsubsection{Investigation of food hydrolysis and oxygen profile in optimized test setup}

To examine the differences in breakdown of Tetramin under test conditions with and without agar gel, $420 \mathrm{mg}$ of food was incorporated into $80 \mathrm{ml}$ of water or agar gel $(0.6 \% \mathrm{w} / \mathrm{w})$ which corresponds to the additions in the optimized beaker setup. Both mixtures were sealed in a $100 \mathrm{ml}$ syringe, depleted of remaining air, and incubated for two days at a temperature of $19^{\circ} \mathrm{C}$. Finally, a sample was withdrawn from each syringe, diluted, and analysed for TAN.

In order to study the DO levels within and above the sediment in more detail, an oxygen micro sensor (PreSense ${ }^{\circledR}$, Sensor type PSt1) was used. Two beakers with an optimized test setup similar to Test 6 (Exp. 3) and containing 50 worms each were used. The test beakers were removed from the temperature controlled bath prior to measurement. Measurement began when the sensor was slowly inserted in the sediment and gradually moved upwards in moderate increments varying between 0.4-2 mm. Sensor position was determined and controlled with the use of a digital caliper which was connected to the sensor probe. The positions of the caliper and sensor probe were stabilized by a solid aluminum frame surrounding the test beaker to minimize vibrations during repositioning of the sensor.

\subsubsection{Replacement of artificial sediment and worm handling}

To minimize bacterial growth and associated food degradation, complete sediments including the food were replaced three times per week in all experiments. The test beakers were withdrawn from the temperature controlled bath, and approximately $70 \%(\mathrm{v} / \mathrm{v})$ of the overlying water was removed. The beaker was gently shaken to fragment the sediment layer which incited most worms to perform their typical escape reflex (Drewes, 1999) into the overlying water. This reflex made it possible to collect the worms by pouring off the overlying water. Repeating this three times resulted in complete removal of the worms from the sediment. The collected worms were cleaned by flushing them with clean water, and all of the sediments were thoroughly inspected for remaining worms. The worms were placed directly into clean test beakers with new sediments and $200 \mathrm{ml}$ of water. Once per week, total worm wet weight was measured with a pre weighted fine mesh, and total number of worms were determined by counting the worms using a glass pipette. Prior to weighing, worms were collected on top of the mesh, and paper towels were gently pressed against the back of the mesh for 10 seconds to absorb adherent water. 


\subsection{Results and Discussion}

\subsubsection{Experiment 1: single and combined effects of agar and sand}

In this experiment, it was expected that the absence of food would result in a reduction of total weight and in a consistent number of worms. When food was included in the agar gel, increases in total weight and worm numbers were expected. In all of the tests with agar, it was observed that the worms were not capable of penetrating the agar layer. The absence of faecal pellets and reductions in total weight between 4.1 and $16.1 \%$ in Tests 4,5 and 7 (Table 2.1) demonstrate that food uptake was probably limited for all combinations containing food and agar gel.

Tests 1 and 3, characterized by the absence of food in combination with coarse sand or a combination of agar and coarse sand, unexpectedly resulted in a more significant increase in worm numbers than in Test 2 with the omission of sand (Fig 2.2). The major portion of this increase occurred during the first week of the test, and the worm weight was reduced considerably in test1, 2 and was negligible in Tests 3 (Table 2.1).

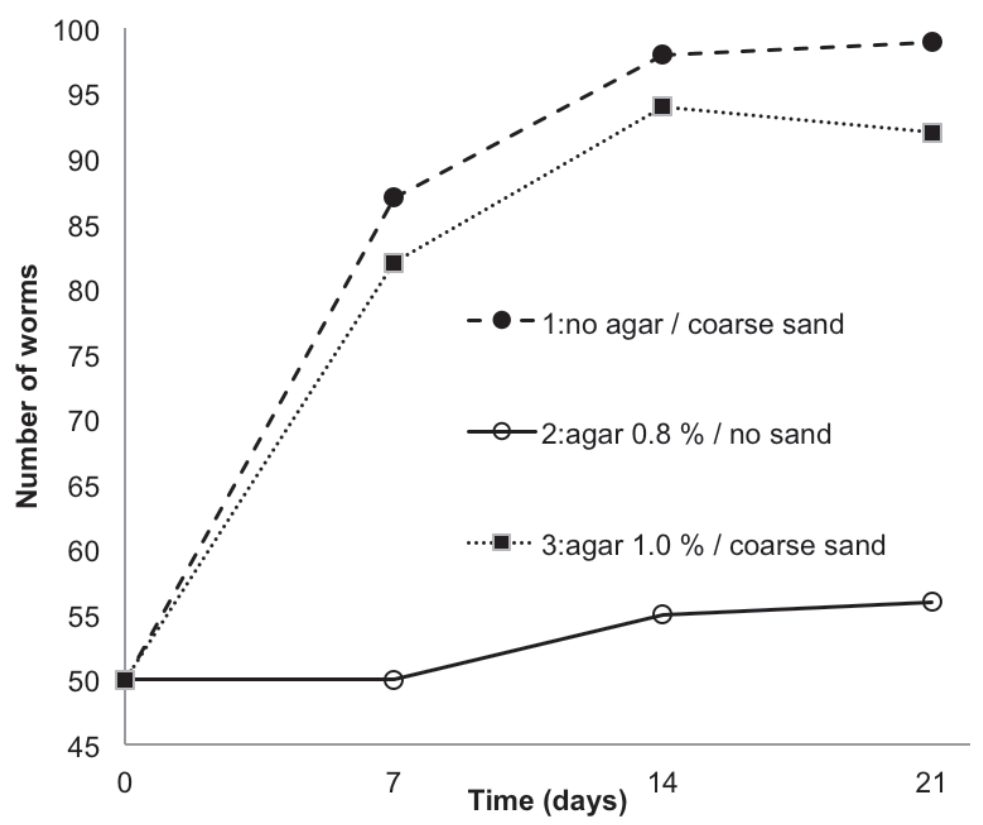

Figure 2.2 Experiment 1: Change in worm numbers during 21 days for three test combinations without food. For agar gel and coarse sand $30 \mathrm{~g}$ and $90 \mathrm{~g}$ were used, respectively. 
Test 6, with a combination of $1.0 \%$ agar gel, $90 \mathrm{~g}$ coarse sand, and $420 \mathrm{mg}$ food only exhibited a moderate weight increase between $2 \%$ and $6 \%$. With 50 worms initially, the final worm numbers in all of the tests that included food varied between 46 and 58 worms due to mortality and reproduction, respectively.

Within two days from the beginning of the tests, all beakers containing food displayed an opaque stagnant layer above the sediment with elevated TAN levels, i.e. tests with $420 \mathrm{mg}$ food and 840 mg food exhibited concentrations of 0.6-1.0 and 1.1-2.2 $\mathrm{mg} \mathrm{NH}_{4}{ }^{+} \mathrm{N} / \mathrm{L}$, respectively.

In a control beaker without worms but including $30 \mathrm{ml}$ of $1.0 \%$ agar, $90 \mathrm{~g}$. of coarse sand, and $840 \mathrm{mg}$ of food, levels were in the same range as in the other beakers with $840 \mathrm{mg}$ food and worms (1.6-1.7 $\mathrm{mg} \mathrm{NH}_{4}{ }^{+} \mathrm{N} / \mathrm{L}$ ), demonstrating that ammonium release is primarily related to the added food amount in the test and is less influenced by worm presence. In addition, all of the tests that included food exhibited a decrease in DO from \pm 7.6 to lower than $1 \mathrm{mg} / \mathrm{l} \mathrm{O}_{2}$ close to the sediment, and a pH decrease from 8.3 to approximately 7.4.

In Experiment 1, no suitable combinations were found that promoted both worm growth and reproduction. Elevated TAN levels and an emergence of an opaque stagnant layer above the sediment indicated that heat pretreatment of the food had stimulated undesired food hydrolysis. Changes were made to improve the accessibility and consumption of agar and the food particles encapsulated by the agar. In Experiment 2, it was decided to employ only 0.6 and $0.8 \%$ agar-gels which were stirred and shaken after solidification to lower the viscosity and surface tension. To minimize the dissolution and decomposition of food due to elevated temperature exposure, food particles were mixed with the agar-gel only after it was cooled and stirred, creating a suspension of food particles in the agar-gel.

In addition, to stimulate the worms' consumption of small particles, fine sand was added and mixed with coarse sand and agar-gel. Based on algae consumption data, it was ascertained that Lv is capable of consuming particles up to $200 \mu \mathrm{m}$ (Moore, 1978). As there were no clear variances in Experiment 1 in total wet weight or worm numbers between tests with 420-840 mg of food, it was also decided to apply a broader range of food amounts. The water renewal rate was doubled from 4 to 8 day- 1 to remove more ammonium and provide additional oxygen.

\subsubsection{Experiment 2: the effect of agar gel, sand and two different food levels}

In all test beakers in which this new agar gel pretreatment was applied, worms were able to penetrate the entire sediment (Fig 2.3). A microscopic examination of the deposits on the top of the coarse sand layer revealed that faecal pellets were produced containing gel and fine sand confirming that active consumption had occurred. Growth and reproduction were found for all of the combinations with agar. 


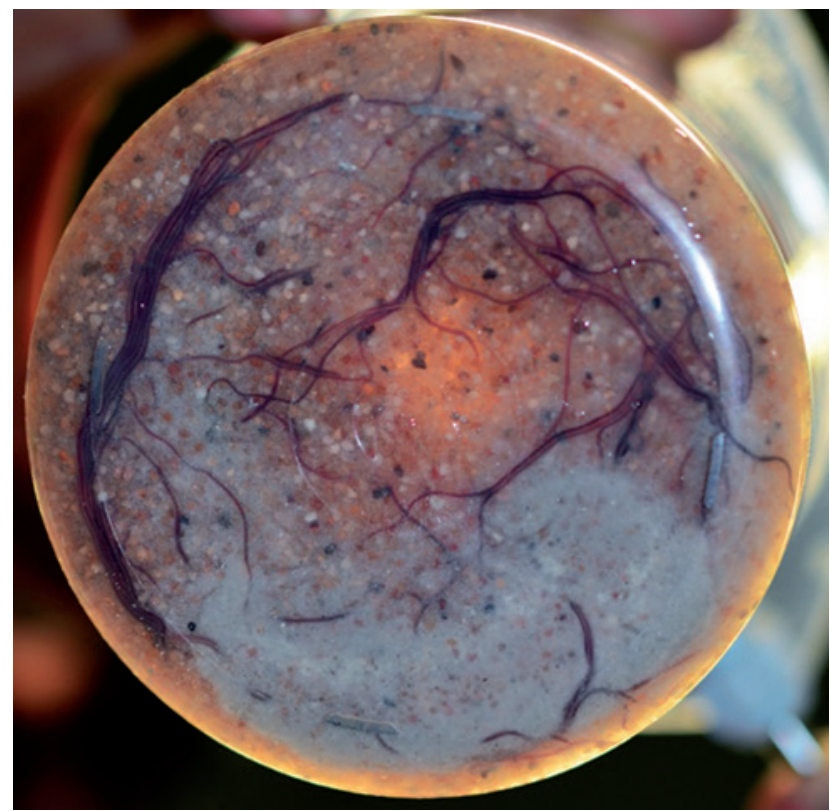

Figure 2.3 Bottom view of test beaker containing an agar layer combined with a mixture of sand and food which is penetrated by worms.

All combinations containing agar gel demonstrated more increase in total weight than combinations without agar. No variance was observed between the $0.6 \%$ and $0.8 \%$ agar gel (Table 2.1). Differences in the total weight increase and number of worms were primarily associated with the food amount and the addition of agar gel but less with the use of different sand types or agar gel concentrations. Increase in worm weight and numbers were determined at low food amounts as can be observed when comparing tests with $420 \mathrm{mg}$ opposed to tests with $1050 \mathrm{mg}$ of food. With the latter food level, a positive trend in total weight was observed for the coarse-fine sand type and greater agar concentrations.

The effects of agar, sand and food on $\mathrm{DO}$ and $\mathrm{pH}$ (S 2.1) were not evident due to significant variations in these measurements. An overall trend of lower TAN levels in tests with agar gel was observed compared to tests without agar. Tests with elevated food amounts exhibited higher TAN levels than tests with low food amounts. The sand type and agar concentration only seemed to play a minor role. Elevated TAN levels again correlated with an opaque layer just above the sediment surface in the beakers wherein agar gel was omitted (Test 1-4), exhibiting a thicker opaque layer. With an addition of agar gel, thin or no distinct opaque layers were formed or were even nonexistent in beakers with less food $(420 \mathrm{mg})$, revealing that this is associated with the amount of added food. A pH decrease within all test beakers was ascertained similar to Experiment 1. It appears that $\mathrm{pH}$ diminishes more acutely with the absence of agar gel, but this could not be further established. 
Lower TAN levels in tests with gels were plausibly caused by less food degradation. Despite doubling of the water renewal rates, DO levels above the sediment surface remained very low compared to the levels in Experiment 1.

\subsubsection{Experiment 3: Different agar gel concentrations combined with lower food levels}

In Experiment 3, the effects of agar addition and concentration (0.6 and $0.8 \%$ ) were studied with lower food levels of $0,105,140$, and $210 \mathrm{mg}$ which were intended to reduce the negative effect on reproduction and growth that had been found at the higher food levels in Experiment 2. Several other changes were made to improve the conditions for feed uptake: 1) a thinner coarse sand layer to increase access to the layer of food containing gel; 2) a decrease in the gel to food ratio (w/w); and 3) the use of a fixed mixture of coarse and fine sand.

Reproduction in the absence of food (Test 1 and 5) was elevated and accompanied by a reduction of the total weight (as previously observed in Tests 1 and 3, Exp. 1). Tests with food demonstrated no reproduction at the highest food level of $210 \mathrm{mg}$ (Tests 4, 8, and 12) in combination with negative growth in Tests 4 and 8 and positive growth in Test 12. A low to moderate reproduction response was ascertained at the 105 and $140 \mathrm{mg}$ food levels compared to tests without food. At the two lowest food levels, a more than $22.1 \%$ growth (in 21 days) was determined in the presence of agar gel. No obvious effects of agar gel or its concentration on reproduction could be determined. However, visual observation established that the addition of agar gel results in an improved worm distribution as well as improved conditions for food uptake as the worms penetrated the entire sediment layer.

The effects of agar and food on TAN, DO and pH were remarkably variable. Nevertheless, TAN levels increased with the amount of food and were reduced in the presence of agar gel. The lowest TAN levels were observed in the absence of food. In all of the test beakers containing food, $\mathrm{pH}$ decreased from an average inflow $\mathrm{pH}$ of 8.4 (SD, 0.14) to values below 7.4 near the sediment. In the test without food (Tests 1, 5 and 9), the $\mathrm{pH}$ decrease was more moderate. In general, higher levels of food lead to a greater decline in $\mathrm{pH}$ and a more clearly defined opaque layer above the surface of the sediment. 


\subsubsection{Effect of sand on reproduction and growth}

Sand stimulates worms to reproduce (Experiments 1 and 3). However, Experiment 3 demonstrated that combining sand with food initially reduced reproduction. Experiment 2 showed that a mixture of fine and coarse sand induced up to $10 \%$ more worm weight with the greatest food addition than in coarse sand alone. Apparently, fine sand has a positive effect on growth at elevated food levels. However, reproduction did not vary between the two sand/sediment types. The effect of sand on growth and reproduction of Lv is not yet fully understood. An additional study indicated that reproduction of Lv in natural sediments is lower in sandy sediments with low organic carbon (Leppänen and Kukkonen, 1998a). In the same study, reproduction was determined to be worm size dependent with larger worms reproducing more frequently. It is believed that, in our tests with only sand, reproduction was the result of the absence of organics which may have incited a stress induced reproduction response. In the beakers with food, reproduction was often delayed, indicating that the worms must achieve a certain size before reproduction occurred. This is in accordance with observations that specific culture conditions will determine at what size the animal will reproduce during the test (Leppänen and Kukkonen, 1998b). Factors mentioned to be of influence on the minimum size for reproduction are food availability, food quality, and water quality. The ingestion of sand by Lv has been substantiated to be significant for the uptake of hydrophobic compounds (Leppänen and Kukkonen, 1998c). Therefore, a certain minimum amount of fine sand that is small enough for ingestion should be added to increase the bioavailability of hydrophobic compounds.

Standardized invertebrate bioassays are generally initiated with animals of a defined age- or stagestructure to control for individual variability in the measured response (Ingersoll et al., 2000). As the reproductive strategy of Lv creates significant difficulty for age or stage selection, the directly induced reproduction in sediments without food that was observed in our experiments could also be used prior to testing to improve overall standardization in bioassays.

\subsubsection{Experiment 4: Validation of optimized test setup}

A test combination of $0.6 \%$ agar-gel $(20 \mathrm{ml}), 10 \mathrm{~g}$ fine sand, $40 \mathrm{~g}$ coarse sand and $105 \mathrm{mg}$ Tetramin, combined with a water renewal rate of 8 day- 1 was most effective and used for further experiments. Fig 2.4 shows that both Tetramin and secondary potato starch sludge diets supported reproduction and growth for the entire test period. The graph depicts that reproduction begins on day 11 for both diets. The total wet weight increase was initially higher due to individual growth in the absence of reproduction. After day 11, the overall growth rate decreased with the initiation of reproduction. Potato sludge supported a higher overall growth rate and reproduction than Tetramin. In contrast to Tetramin and secondary potato starch sludge diets, worms cultivated on wheat bran showed a small increase in total weight and a 
reproduction that almost stopped after day 11. This test that started with a larger initial weight and a nitrogen poor diet showed that both initial weight and the quality of the diet can influence the overall response.

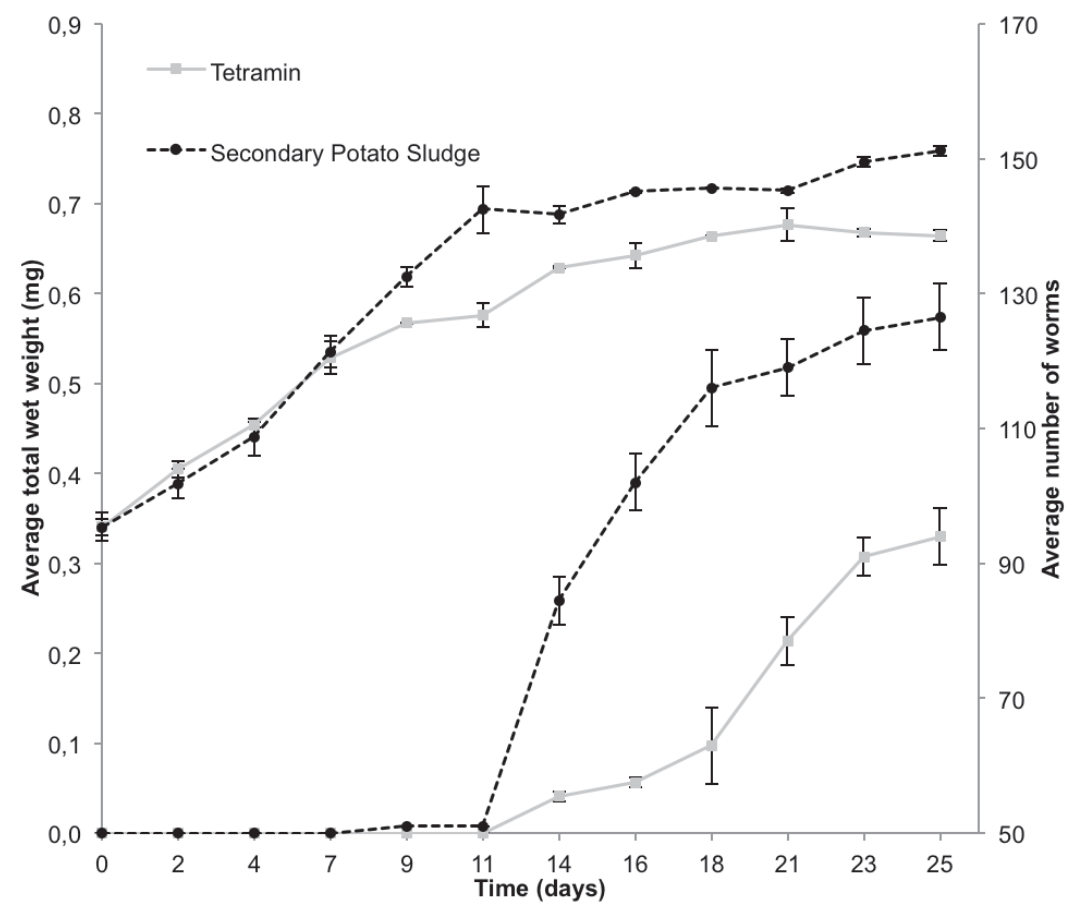

Figure 2.4 Increase in L. variegatus live weight and number in an optimized growth setup. Setup contains 0.6 $\%$ agar-gel (20 ml), $10 \mathrm{~g}$. fine sand, $40 \mathrm{~g}$. coarse sand and $140 \mathrm{mg}$ COD for three different diets (Tetramin, secondary potato sludge and wheat bran). Numbers of worms (right axis) are represented by the three lowest lines and increase in total wet weight (left axis) by the three upper lines. Error bars; average of two biological replicates \pm standard deviation.

Standard deviation within the tested diets never exceeded $7.0 \%$ for total wet weight and 8.9 $\%$ for the number of worms. TAN, DO, and $\mathrm{pH}$ values were similar to those under the selected standard conditions from Test 6 of Experiment 3 (data not shown). The final increase in worm numbers and increase in total weight differed clearly between Tetramin, Potato sludge and wheat bran diets. Increase in worm numbers were respectively 44, 76.5 and 68 and increase in total weight were respectively $0.32,0.42$ and $0.06 \mathrm{~g}$ (25 days). Results demonstrate that the diet has a dominant effect on growth rate and reproduction. When sediments are replaced three times per week, this combination of agar, sand, and food was appropriate to monitor growth and reproduction for a test of at least 25 days. 
Based on Experiment 3, it is believed that food was not limiting when $105 \mathrm{mg}$ Tetramin was added. To determine the optimum food level for testing, a food saturation growth curve should be established such as those that have been established for early instar chironomid larvae(Vos et al., 2000). In that study it was demonstrated that maximum specific growth rates strongly depend on food composition and quality. It is surmised that different food types, food levels, and food renewal times, therefore, will result in different LV growth rates. It is recommended to add less food in the standard setup to prevent possible ammonium accumulation when a COD/N $(\mathrm{w} / \mathrm{w})$ ratio below 18 (Tetramin) is utilized.

Growth rates between 0.02-0.05 d-1 were achieved in Tetramin in a previous study investigating the feeding behavior of Lv (Williams, 2005). Similar growth rates were observed in Experiments 2 and 3 for several combinations of agar, sand, and food. In the selected combination for long term testing (exp. 4), growth rates $(t=0-25)$ of 0.027 and $0.032 \mathrm{~d}^{-1}$ were achieved for Tetramin and secondary potato sludge, respectively. The initial growth rates ( $t=0-7$ days) in Tetramin and potato sludge were, respectively, 0.063 and 0.065 and are in the same range as the initial growth rates ascertained in waste activated sludge of 0.05-0.11 d-1 (Buys et al., 2008).

In the latest sediment bioaccumulation test with Lv, a maximum wet weight increase of $48 \%$ within 28 days (calculated growth rate approximately 0.014) was found (Burkhard et al., 2015). Comparing the growth rates between the sediment bioaccumulation tests and the new agar sediment test showed that growth rate was almost doubled in the latter test (growth rate of 0.027 instead of 0.014). Although the agar-sediment test is different in several aspects (e.g. the use of agar, incubation temperature, photoperiod, sediment composition and replacement) we expect that the large difference in growth rate is dominantly explained by the difference in food dosing. In the agar sediment test $105 \mathrm{mg}$ Tetramin was fed three times a week to a beaker of $770 \mathrm{ml}$, housing $340 \mathrm{mg}$ of Lv in contrast to only $6 \mathrm{mg}$ Tetramin dosed three times a week to a beaker of $300 \mathrm{ml}$, housing $250 \mathrm{mg}$ worms in the sediment bioaccumulation test.

\subsubsection{Determination of food hydrolysis and oxygen profile in an agar sediment test setup}

The decomposition of Tetramin under test conditions with and without agar was examined. Food decomposition in water was greater than in agar gel, resulting in concentrations of 10

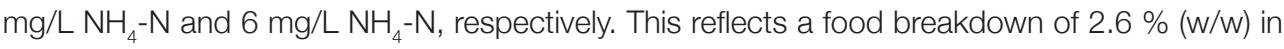
water and $1.5 \%(\mathrm{w} / \mathrm{w})$ in agar gel, indicating that food hydrolysis is diminished when agar-gel is applied. Tests incorporating agar gel in Experiments 2 and 3 generally exhibited lower TAN levels above the sediment, substantiating that protein degradation inside the agar-sediment layer is more gradual than in the absence of agar gel. The agar gel most likely slows down the diffusion of oxygen, resulting in a slower breakdown of the food. 
The oxygen levels of two beakers containing worms under conditions identical to Test 6 in Experiment 3 (Fig 2.5) indicate that, at the interface between the sediment and the overlying water, an intense shift in the oxygen level appears from anoxic to levels up to a maximum of $7 \mathrm{mg} / \mathrm{L}$. However, as it was required to remove the beakers from the controlled temperature and flow system prior to measurement, water mixing occurred, and the gradients demonstrated a significant variation. The oxygen gradient in beaker 2 is, therefore, unlikely to reflect the stable gradient during testing, and it is more plausible that a steep and stable oxygen gradient develops over a period of time such as beaker 1 continued to partially exhibit. The opaque layers in Experiments 2 and 3 support the development of this stable layer near the bottom which, over a period of time, leads to oxygen depletion. To avoid these low oxygen concentrations above the sediment, mixing could be induced by cooling the incoming water to less than the beaker temperature.

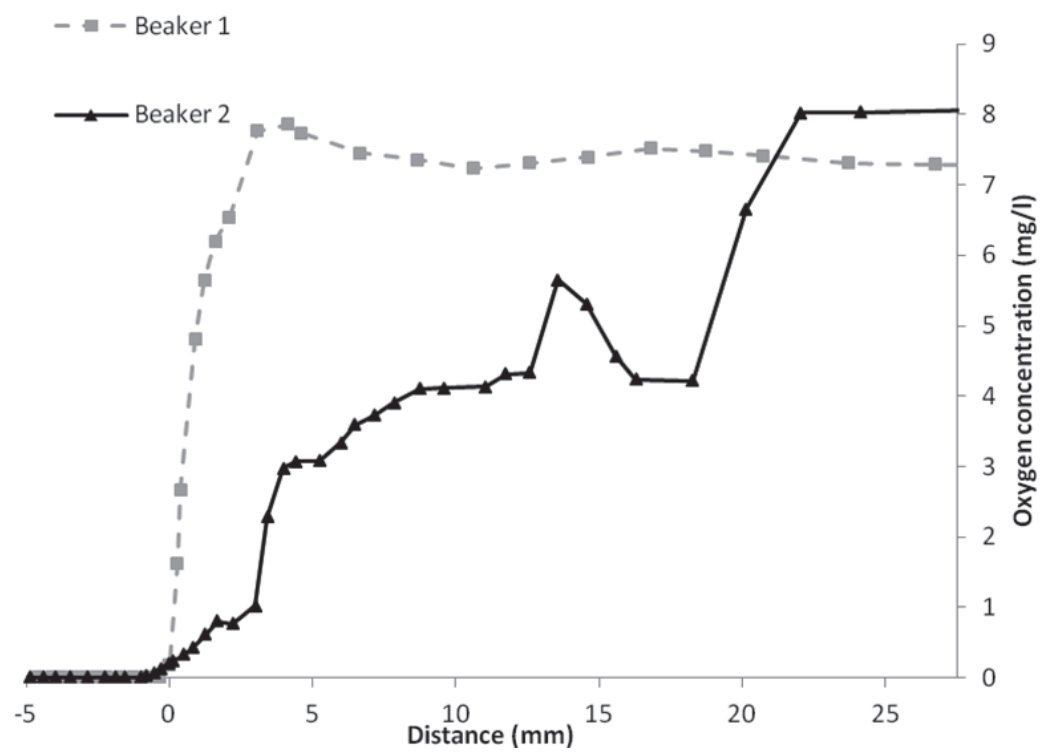

Figure 2.5 Oxygen profile of two optimized beakers in an identical setup. Both setups contain $0.6 \%$ agar-gel $(20 \mathrm{ml}), 10 \mathrm{~g}$. fine sand, $40 \mathrm{~g}$. coarse sand and $105 \mathrm{mg}$ TM, including 50 worms, incubated for two days prior to measurement. Negative distance refers to measurements in the sediment itself. Transition from sediment to water is indicated by $0 \mathrm{~mm}$; the water outflow is situated around $22 \mathrm{~mm}$ distance. 
Maintaining elevated DO concentrations at the substrate level improves worm growth and survival but also increases endogenous decomposition of the food as demonstrated in activated sludge tests with Lv (Buys et al., 2008). A study regarding the effect of DO on Lv fed with waste sludge showed that oxygen concentrations affect food consumption rates (Hendrickx et al., 2009b). The most significant consumption rates were found at levels above $8.1 \mathrm{mg} / \mathrm{L} \mathrm{O}_{2}$, and the lowest food consumption rates were found below $2.5 \mathrm{mg} / \mathrm{L} \mathrm{O}_{2}$. Constant low DO levels led to a reduction in growth and eventually worm death. In our study, DO levels proximate to the sediment in the food containing beakers were far below $2.5 \mathrm{mg} / \mathrm{L}$ with no indications of mortality. This was almost certainly due to the worms having unhindered access to oxygen rich water by protruding their tails above the oxygen depleted layer.

The food hydrolysis test and the oxygen profile establish that food decomposition of the gel enclosed food particles was slowed down by low oxygen levels inside the gel layer. As the sediment layer in the final test setup is oxygen deficient, food decomposition occurs primarily under anaerobic conditions which retards endogenous breakdown as is also found for the decay of activated sludge under anoxic conditions (Kim and Hao, 1990).

Assuming that high oxygen levels in the sediment promote sediment dwelling activities of the worms, this is likely to increase the feed intake and thus resulting in a higher growth rate. An elevated DO level in the sediment could at the same time accelerate the breakdown of the food substrate itself resulting in a negative influence on growth and growth conditions. Therefore the influence of higher DO levels in the sediment on growth rate remains unclear and should be further evaluated.

\subsubsection{Effect of agar gel and food amount on worm growth and ammonia}

Agar gel addition provided appropriate conditions for growth when combined with a low food level. Worm numbers were not impacted by adding agar gel. TAN concentrations were greater when an overdose of food was added; therefore, food amounts should be retained within a certain range to minimize the effect of ammonia on growth. Toxicity of ammonia in the proposed setup is minimized by keeping ammonia concentrations below $1 \mathrm{mg} / \mathrm{l}$ at a pH between $7-8$ by applying regular substrate changes, continuous water refreshing, and minimal food additions analogous with $105 \mathrm{mg}$ Tetramin. By maintaining this regime, effects of low ammonia levels on growth are expected to be absent or insignificant, as a former study showed an LC50 (10 days) of $93.5 \mathrm{mg} / \mathrm{L}$ and $15.1 \mathrm{mg} / \mathrm{L}$, respectively, at pH 7 and 8 (Schubauer-Berigan et al., 1995).

The improved growth conditions for Lv by adding agar gel are thus caused by a reduction in food hydrolysis and, most likely, also due to increasing the interstitial space of the sediment. This makes the sediment easier accessible to the worms for food consumption. In the optimized 
beaker setup (Test 6, Experiment 3); the total pore volume without agar gel was $9 \pm 1 \mathrm{ml}$. This volume is increased by more than $200 \%$ when $20 \mathrm{ml}$ of agar gel is added which results in a greater interstitial volume and, herewith, in lower food and TAN concentrations in sediments with agar gel. Due to this volume expansion, worms can more easily access and penetrate the entire sediment layer. The higher sediment dwelling activity of the worms also intensifies exposure to sediment and agar gel embedded food particles.

\subsubsection{Assessment of organic waste streams for worm culture purposes}

How Lv growth performance determined with the agar sediment test can be extrapolated to worm production on a larger scale was not further quantified in this study. It is expected however that this performance is a good indicator whether if a waste stream can be applied for large scale Lv cultivation or not.

Besides food availability and food quality (evaluated in the agar sediment test) the most important factors improving worm growth on a reactor level are: high dissolved oxygen concentrations , low ammonia levels a temperature that should be between $15-25^{\circ} \mathrm{C}$ (Hendrickx et al., 2009b). On a reactor level some microbial ingrowth and food breakdown can be expected resulting in slightly changed food qualities that may have a positive or negative effect on biomass production. Thus, the test is suitable to compare different food sources for their suitability for large scale LV cultivation but not to predict actual biomass production.

\subsubsection{Long term use of the optimized test setup}

Under the controlled conditions applied in Experiment 4 (0.6 \% agar-gel $(20 \mathrm{ml}) / 10 \mathrm{~g}$. fine $/ 40 \mathrm{~g}$. coarse sand with a food addition similar to $105 \mathrm{mg}$ Tetramin), the test setup can be used for long term monitoring of growth and reproduction with no food limitation or density effects. As food decomposition is reduced with agar-gel, food uptake and the subsequent growth of the worms are more directly the result of addition of food in its original quality.

Regular sediment replacements were performed to prevent bacterial ingrowth and associated food breakdown. Long term stability of the food-agar complex over a period longer than two days has not yet been studied and still remains to be investigated. However, with the regular sediment replacements and the use of agar gel, this standardized setup seems to be most suitable to compare growth and reproduction among an extensive variety of organic waste and food byproducts. 


\subsection{Conclusions}

A novel test for assessing the suitability of food by-products to produce aquatic worm biomass was successfully developed. Growth and reproduction response of Lv can be studied in time with this test. A selected combination of sand, agar gel, and food combined with regular sediment replacements results in less protein decomposition and a higher sediment dwelling activity. The benefit of agar gel application is that ingestion and resulting growth are more directly the result of addition of food in its original quality. This test method is expected to be suitable for a variety of food related studies using other sediment dwelling invertebrates. For waste and byproduct applications from food industries, both organic loading and ammonium should be controlled as high levels influence growth and reproduction of worms in a negative way. To study the bio recovery, this test has his limitations as the current system design does not allow for a reliable quantification of mass fluxes e.g. for $\mathrm{N}$ or COD because of their low concentrations and high water renewal rates.

\section{Acknowledgements}

The authors thank Peter Rappoldt (MSc) from Wageningen University and Research Centre (the Netherlands) for his valuable contributions towards the performance of Experiment 4. This work was performed in the cooperation framework of Wetsus, centre of excellence for sustainable water technology (www.wetsus.nl). The authors would like to thank the participants of the research theme "Aquatic worms" for the fruitful discussions and their financial support. 


\section{References}

Airas, S., Leppänen, M. and Kukkonen, J.V.K., 2008. Effects of temperature and oxygen concentration in sediment toxicity testing. Ecotoxicology and Environmental Safety 70: 475-482.

Ankley, G.T., Benoit, D.A., Hoke, R.A., Leonard, E.N., West, C.W., Phipps, G.L., Mattson, V.R. and Anderson, L.A., 1993. Development and evaluation of test methods for benthic invertebrates and sediments: Effects of flow rate and feeding on water quality and exposure conditions. Archives of Environmental Contamination and Toxicology 25: 12-19.

APHA, 1998. Standard methods for the examination of water and wastewater. 20th edition. American Public Health Association, Washington, DC.

Burkhard, L., Hubin-Barrows, D., Billa, N., Highland, T., Hockett, J., Mount, D., Norberg-King, T.J., Hawthorne, S., Miller, D. and Grabanski, C., 2015. Sediment Bioaccumulation Test with Lumbriculus variegatus: Effects of Feeding. Archives of Environmental Contamination and Toxicology 68: 696-706.

Buys, B.R., Klapwijk, A., Elissen, H. and Rulkens, W.H., 2008. Development of a test method to assess the sludge reduction potential of aquatic organisms in activated sludge. Bioresource Technology 99: 8360-8366.

Drewes, C.D., 1999. Helical swimming and body reversal behaviors in Lumbriculus variegatus (Annelida: Clitellata: Lumbriculidae). Hydrobiologia 406: 263-269.

Egeler, P., Henry, K.S. and Riedhammer, C., 2010. Potential effects of food addition to sediment on test conditions in sediment toxicity tests. Journal of Soils and Sediments 10: 377-388.

Elissen, H.J.H., Hendrickx, T.L.G., Temmink, H., Laarhoven, B. and Buisman, C.J.N., 2015. Worm-it: converting organic wastes into sustainable fish feed by using aquatic worms. Journal of Insects as Food and Feed 1: 67-74.

Elissen, H.J.H., Mulder, W.J., Hendrickx, T.L.G., Elbersen, H.W., Beelen, B., Temmink, H. and Buisman, C.J.N., 2010. Aquatic worms grown on biosolids: Biomass composition and potential applications. Bioresource Technology 101: 804-811.

Groh, S., Claus, E., Manz, W., Möhlenkamp, C., Immermann, R.D. and Blübaum-Gronau, E., 2010. Influence of increasing sediment organic matter on reproduction and growth of the benthic oligochaete Lumbriculus variegates. Einfluss organischer substanz auf die reproduktion, biomasse und akkumulation hydrophober schadstoffe in lumbriculus variegatus 22: 99-106.

Hansen, J.A., Lipton, J., Welsh, P.G., Cacela, D. and MacConnell, B., 2004. Reduced growth of rainbow trout (Oncorhynchus mykiss) fed a live invertebrate diet pre-exposed to metal-contaminated sediments. Environmental Toxicology and Chemistry 23: 1902-1911.

Hendrickx, T.L.G., Temmink, H., Elissen, H.J.H. and Buisman, C.J.N., 2009a. Aquatic worms eating waste sludge in a continuous system. Bioresource Technology 100: 4642-4648.

Hendrickx, T.L.G., Temmink, H., Elissen, H.J.H. and Buisman, C.J.N., 2009b. The effect of operating conditions on aquatic worms eating waste sludge. Water Research 43: 943-950.

Ingersoll, C.G., Burton, G.A., Dawson, T.D., Dwyer, F.J., Ireland, D.S., Kemble, N.E., Mount, D.R., NorbergKing, T.J., Sibley, P.K. and Stahl, L., 2000. Methods for measuring the toxicity and bioaccumulation 
of sediment-associated contaminants with freshwater invertebrates. 2nd edition. Report EPA 600/R99/064, United States Environmental Protection Agency, US.

Kim, M.H. and Hao, J.H., 1990. Comparison of activated sludge decay under aerobic and anoxic conditions. Research Journal of the Water Pollution Control Federation 62: 160-168.

Lasier, P.J., 2009. Alternative substrates for culturing the freshwater oligochaete lumbriculus variegatus. North American Journal of Aquaculture 71: 87-92.

Leppänen, M.T. and Kukkonen, J.V.K., 1998a. Factors affecting feeding rate, reproduction and growth of an oligochaete Lumbriculus variegatus (Müller). Hydrobiologia 377: 183-194.

Leppänen, M.T. and Kukkonen, J.V.K., 1998b. Relationship between reproduction, sediment type and feeding activity of Lumbriculus variegatus (Müller): implications for sediment toxicity testing. Environmental Toxicology and Chemistry 17: 2196-2202.

Leppänen, M.T. and Kukkonen, J.V.K., 1998c. Relative importance of ingested sediment and pore water as bioaccumulation routes for pyrene to oligochaete (Lumbriculus variegatus, Müller). Environmental Science and Technology 32: 1503-1508.

Moore, J.W., 1978. Importance of algae in the diet of the oligochaetes Lumbriculus variegatus (Müller) and Rhyacodrilus sodalis (Eisen). Oecologia 35: 357-363.

Moore, J.W., 1979. Influence of food availability and other factors on the composition, structure and density on a subarctic population of benthic invertebrates. Hydrobiologia 62: 215-223.

Mount, D.R., Highland, T.L., Mattson, V.R., Dawson, T.D., Lott, K.G. and Ingersoll, C.G., 2006. Use of the oligochaete, Lumbriculus variegatus, as a prey organism for toxicant exposure of fish through the diet. Environmental Toxicology and Chemistry 25: 2760-2767.

Phillips, G.O. and Williams, P.A., 2009. Handbook of hydrocolloids. Woodhead publishing in food science and technology. CRC [etc.], Boca Raton [etc.].

Phipps, G.L., Ankley, G.T., Benoit, D.A. and Mattson, V.R., 1993. Use of the aquatic oligochaete Lumbriculus variegatus for assessing the toxicity and bioaccumulation of sediment-associated contaminants. Environmental Toxicology and Chemistry 12: 269-279.

Pokarzhevskii, A.D., Van Straalen, N.M. and Semenov, A.M., 2000. Agar as a medium for removing soil from earthworm guts. Soil Biology and Biochemistry 32: 1315-1317.

Römbke, J. and Moser, T., 2002. Validating the enchytraeid reproduction test: organisation and results of an international ringtest. Chemosphere 46: 1117-1140.

Schubauer-Berigan, M.K., Monson, P.D., West, C.W. and Ankley, G.T., 1995. Influence of pH on the toxicity of ammonia to Chironomus tentans and Lumbriculus variegatus. Environmental Toxicology and Chemistry 14: 713-717.

Tacon, A.G.J. and Metian, M., 2008. Global overview on the use of fish meal and fish oil in industrially compounded aquafeeds: Trends and future prospects. Aquaculture 285: 146-158.

Van Geest, J.L., Poirier, D.G., Sibley, P.K. and Solomon, K.R., 2010. Measuring bioaccumulation of contaminants from field-collected sediment in freshwater organisms: A critical review of laboratory methods. Environmental Toxicology and Chemistry 29: 2391-2401. 
Vos, J.H., Ooijevaar, M.A.G., Postma, J.F. and Admiraal, W., 2000. Interaction between food availability and food quality during growth of early instar chironomid larvae. Journal of the North American Benthological Society 19: 158-168.

Williams, P.M., 2005. Feeding behaviour of Lumbriculus variegatus as an ecological indicator of in situ sediment contamination. PhD thesis Thesis, University of Stirling, UK, Stirling, $256 \mathrm{p} \mathrm{pp}$ 


\section{Supporting Information}

S 2.1 Final worm numbers and increase in total wet weight over a three week period for each combination employed in Experiments 2 and 3. Data includes Weekly TAN, Oxygen and pH. Sand fractions used: coarse sand (C) and fine sand (F). Initial worm number $=50$ (all tests). Average total start weight Exp. 2: 399 mg (min-max, 330-476), Exp.3: 391 mg (min-max, 350422). Exp.3, Test 9: Worm losses due to experimental error Weekly TAN, Oxygen and pH for each combination (average $\pm S D$ ), $(n=3)$. ${ }^{*}$ loss of approximately 25 worms due to experimental error. 







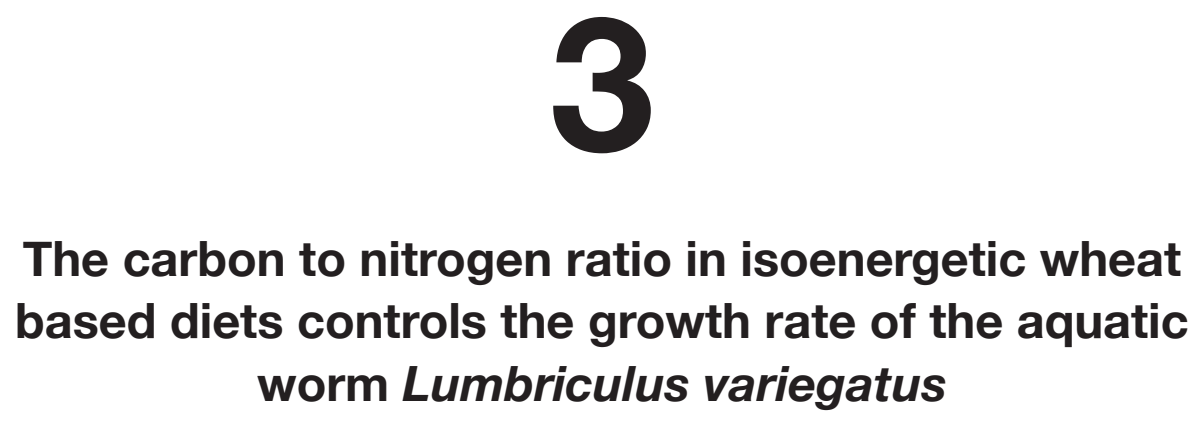

Published as: Laarhoven B, Elissen H.J.H, Buisman C.J.N, Temmink H (2016). The carbon to nitrogen ratio in isoenergetic wheat based diets controls the growth rate of the aquatic worm Lumbriculus variegatus. Journal of Insects as Food and Feed 2(4): 225-231. 


\section{Abstract}

The aquatic worm Lumbriculus variegatus (Lv) contains high levels of proteins and can provide an excellent fish food. Large-scale production of Lv on low value organic substrates, such as by-products produced during wheat processing, therefore can be a promising and sustainable concept for the aquaculture industry. Growth and reproduction of Lv on different combinations of wheat based derivatives was studied at fixed isoenergetic levels (expressed by the chemical oxygen demand of the food), but at different carbon to nitrogen $(\mathrm{C} / \mathrm{N})$ mass ratios under controlled conditions in specifically designed test-beaker tests. Growth and reproduction rates were compared to those on Tetramin ${ }^{\circledR}$, a substrate known to give excellent growth of Lv. Although Lv did exhibit a growth response on single as well as on mixed wheat fractions, growth was mainly controlled by the $\mathrm{C} / \mathrm{N}$ ratio of the diets. Lower $\mathrm{C} / \mathrm{N}$ ratios of typically 6-7 gave a much better performance than high $\mathrm{C} / \mathrm{N}$ ratios of approximately 20. It was discussed this is probably caused by Lv relying on the presence of proteins for their carbon and energy source. Although growth and reproduction rates were not as high as on the control diet, the results are promising for the development of a worm biomass production system operating on by-products from the wheat processing industry.

Key-words: Lumbriculus variegatus, aquatic worm, wheat, gluten, aquaculture, food 


\subsection{Introduction}

Because of its fatty acid and amino acid composition the freshwater worm Lumbriculus variegatus (Lv) (Oligochaeta, Lumbriculidae) is an excellent fish food (Elissen et al., 2015; Mount et al., 2006). It contains high levels of protein and like most other sediment-feeding invertebrates is capable of growing on complex mixtures of decomposing organic matter, algae, and microorganisms (Moore, 1978). For this reason production of Lv biomass on safe, low value organic substrates could add a lot of value to the aquaculture sector. Suitable substrates can be found among byproducts and waste streams originating from the food industry where food quality and content are carefully monitored and controlled.

According to the FAO, European food and agricultural production of terrestrial plant based resources is dominated by wheat, sugar beet, potatoes, maize and barley with wheat the most important one with an annual production of 195 million tons (FAOSTAT, 2012). If by-products generated during wheat processing could be efficiently assimilated by Lv, large-scale, safe and sustainable worm biomass production comes within reach. Direct inclusions of wheat based by-products in aquaculture feeds are feasible to some extent but comes with nutritional and technical challenges(Apper-Bossard et al., 2013; Draganovic et al., 2013); complete fishmeal replacement is not feasible for carnivorous fish species like salmon and trout. The conversion of

wheat by-products by Lv biomass could perhaps improve the indirect use of those plant based resources in aquaculture feeds.

How growth (biomass yield and production rate) of Lv is affected by the quantity and elemental composition of its food has not yet been studied. More insight in the effect of food composition on growth can improve selection of organic (waste) substrates that are suitable for Lv production. Aquatic invertebrates such as Lv may react in many ways to foods of different composition (C/N/P ratio), source (bacterial, plant or animal) and quantity by changing their feeding rate, production efficiency and growth and reproduction rate. The possibility to grow Lv on different crude wheat sources like gluten, wheat germ oil and starch and their effect on worm growth and reproduction rate was investigated. To be able to compare the results between different wheat sources experiments were performed under fixed, high isoenergetic food levels to minimize food limitation. The effect of the foods' macro and elemental composition, in particular the C/N ratio, on worm growth will be discussed because this is very important for a selection of suitable byproducts and waste streams enabling large-scale aquatic worm production. 


\subsection{Materials and Methods}

\subsubsection{Experimental design}

Experiment 1 (without additional phosphorus) and 2 (with additional phosphorus) were performed with different combinations of wheat based derivatives and different types of saccharides (Table 3.1).

Table 3.1 Composition of resources used in diet experiment 1 and 2. Chemical oxygen demand (COD), total nitrogen $(\mathrm{N})$ and total phosphorus $(\mathrm{P})$ all are expressed in $\mathrm{g} / \mathrm{kg}$ dry matter $( \pm \mathrm{RSD})$.

\begin{tabular}{|c|c|c|c|c|c|c|c|c|c|}
\hline Food source & Exp & $\begin{array}{l}\text { COD } \\
(\mathrm{g} / \mathrm{kg})\end{array}$ & & $\begin{array}{l}N \\
(\mathrm{~g} / \mathrm{kg})\end{array}$ & & COD/N & & $\begin{array}{l}P \\
(\mathrm{~g} / \mathrm{kg}) \\
\end{array}$ & \\
\hline TetraMin ${ }^{\circledast}$ (Control) & 1,2 & 1330 & (47) & 75.0 & $(1.35)$ & 18 & $(0.7)$ & 13.5 & $(0.24)$ \\
\hline Crude wheat starch & 1 & 1120 & (39) & 1.9 & $(0.03)$ & 602 & (23.7) & n.a & \\
\hline Crude wheat gluten & 1 & 1210 & (42) & 40.7 & $(0.73)$ & 30 & $(1.2)$ & n.a & \\
\hline Wheat germ oil & 1 & 3091 & (108) & 0.3 & $(0.01)$ & 9721 & (383) & n.a & \\
\hline Wheat native starch & 2 & 1210 & (42) & 1.9 & $(0.03)$ & 651 & (25.6) & 1.1 & $(0.02)$ \\
\hline Maltodextrin & 2 & 1010 & (35) & 1.9 & $(0.03)$ & 546 & (21.5) & 1.0 & $(0.02)$ \\
\hline Glucose & 2 & 896 & (31) & $<0.05$ & $(0.00)$ & $>17920$ & (705) & 0.0 & $(0.00)$ \\
\hline Vital wheat gluten & 2 & 1320 & (46) & 129.0 & (2.32) & 10 & $(0.4)$ & 1.4 & $(0.03)$ \\
\hline Hydrolized wheat gluten & 2 & 1360 & (48) & 129.0 & (2.32) & 11 & $(0.4)$ & 1.6 & $(0.03)$ \\
\hline Yeast (micronutrient inclusion) & 1,2 & 1020 & (36) & 114.0 & (2.05) & 9 & $(0.4)$ & 12.7 & $(0.23)$ \\
\hline
\end{tabular}

Worm growth and reproduction were monitored on single fractions or mixtures of these fractions. Each diet (Table 3.2) was tested in duplicate for 56 days and diets were replaced three times a week to avoid the effect of food depletion caused by worm consumption and bacterial degradation. Wheat derivatives combination (Table 3.2) were mixed on the basis of their COD/N ratios and not on the basis of their carbon ratios as carbon analysis was only performed on the final composed diets used in experiment 1 and 2. In experiment 1, combined diets except for diet 5 were constituted targeting an overall COD/N of 50. In experiment 2, each combination of wheat based derivatives was mixed to constitute, a high and a low $\mathrm{C} / \mathrm{N}$ ratio version by targeting a COD/N ratio of either 50 or 17 . Sodium dihydrogen phosphate (Sigma -Aldrich, SKU: S9638) was added to each diet in experiment 2 to maintain similar high phosphorus levels in all diets matching the levels seen in the control diet. For the addition of dihydrogen phosphate the low phosphorus levels of the single fraction were neglected, only the COD/P ratio of the control diet (109) and the COD values of each test diet were used for this matter. 
Food was dosed isoenergetically using chemical oxygen demand (COD) as an indication for energy content. Isoenergetic food dosing makes it possible to compare the growth only on the basis of the diets $\mathrm{C} / \mathrm{N}$ and $\mathrm{C} / \mathrm{P}$ ratios. Using $\mathrm{COD}$ in feed studies is uncommon but there is a direct relationship between energy in terms of Joules or $\mathrm{kWh}$ and COD. The conversion factor for that is: $1.47 \times 10^{7}$ joules energy production per kg COD oxidized or $3.86 \mathrm{kWh} / \mathrm{kg}$ COD (McCarty et al., 2011). Tetramin ${ }^{\circledR}$ fish food was used as a control diet as it was proven to be a suitable diet to support growth of Lv and other aquatic worms (Ducrot et al., 2007; Elissen et al., 2015).

Preliminary tests with the control diet showed that no further increase in growth rate occurred above $100 \mathrm{mg}$ COD per test beaker and that growth rate slowed down above $140 \mathrm{mg}$ COD per beaker (Laarhoven et al., 2016). Therefore, $127 \mathrm{mg}$ COD per test beaker for all diets was used as a maximum food dose representing food saturation. To prevent mineral and vitamin limitation, 19 mg yeast extract (BBL 211929, Bacto ${ }^{\text {TM }}$ Yeast Extract; Technical, Becton, Dickinson and Company, Franklin Lakes, NJ.USA) was added for each gram of food.

\subsubsection{Pretreatment of wheat fractions and diet formulation}

Different gluten and starch fractions were provided by the industrial wheat milling industry (Cargill, Bergen op Zoom) and wheat germ oil (Jacob Hooy \& Co BV, Limmen, the Netherlands) was purchased from a local retail shop. Maltodextrin and glucose were purchased from WWR $^{\circledR}$. (Radnor, PA, USA) Gluten and starches were frozen at $-20^{\circ} \mathrm{C}$ for temporary storage and freeze dried (Modulyo freeze dryer; Edwards High Vacuum International, Crawley, UK) to remove moist. Prior to diet formulation and chemical analysis, samples were finely ground to create food particles suitable for unhindered worm ingestion and blended as stated in Table 2 to obtain a wide variation of $\mathrm{C} / \mathrm{N}$ ratio in the diets.

\subsubsection{Test organisms}

Lv from a recirculating culture system were retained in plastic flow-through tanks. The cultures were fed three times per week with the Tetramin ${ }^{\circledR}$ control diet. Water temperature was maintained at $19^{\circ} \mathrm{C}$ and circulated over a nitrifying filter to prevent ammonia and nitrite levels above $0.4 \mathrm{mg} / \mathrm{L}$. Prior to entering the tanks, the water was aerated to ensure oxygen levels above $6 \mathrm{mg} / \mathrm{L}$. Fully developed worms from cultures experiencing growth with no indications of recent fragmentation or abnormalities were selected and purged overnight in clean tap water to remove their gut content. In experiment 1 and 2, 75 and 50 worms were used respectively. 


\subsubsection{Test beaker and system configuration}

A controlled temperature and water flow system with plastic flow-through beakers (working volume of $770 \pm 8 \mathrm{~mL}$ and a bottom surface area of $57 \mathrm{~cm}^{2}$ ) was used (Fig 3.1). Each test beaker contained $0.6 \%$ agar-gel $(20 \mathrm{ml}), 10 \mathrm{~g}$ fine sand (0.1-0.35 mm grain size), $40 \mathrm{~g}$ coarse sand (0.71-1.25 mm grain size) and $127 \mathrm{mg}$ COD of each diet supplied as a finely ground dry powder. The diets were mixed with sand and agar gel to provide suitable conditions for food uptake while reducing (microbial) food hydrolysis at the same time. Water was continuously discharged with a drain pipe positioned approximately $2 \mathrm{~cm}$ above the artificial sediment. The beakers were submerged in a temperature controlled bath at $19 \pm 1{ }^{\circ} \mathrm{C}$ and retained in dark conditions until sediment replacement and/or sampling. Water was supplemented at a flow rate of $4.34 \mathrm{ml} /$ min, resulting in refreshment rates of 8 day $^{-1}$. The water $\left(\mathrm{pH} 7.2\right.$, hardness $\left.77 \mathrm{mg} \mathrm{CaCO}_{3}\right)$ was a mixture of $70 \%$ tap water (Leeuwarden, the Netherlands) and $30 \%$ softened water. The water was disinfected with UV-C light to prevent inoculation of the beakers with microorganisms and was aerated to keep oxygen at saturated levels. The $\mathrm{pH}$ was controlled by dosing HCL (37 \%) with the use of a pH controlled dose pump (StepDos O8S, KNF Neuberger Inc., Trenton, NJ, USA). Water was supplied on the surface of each beaker by a needle dispenser, creating a constant flow of small droplets.
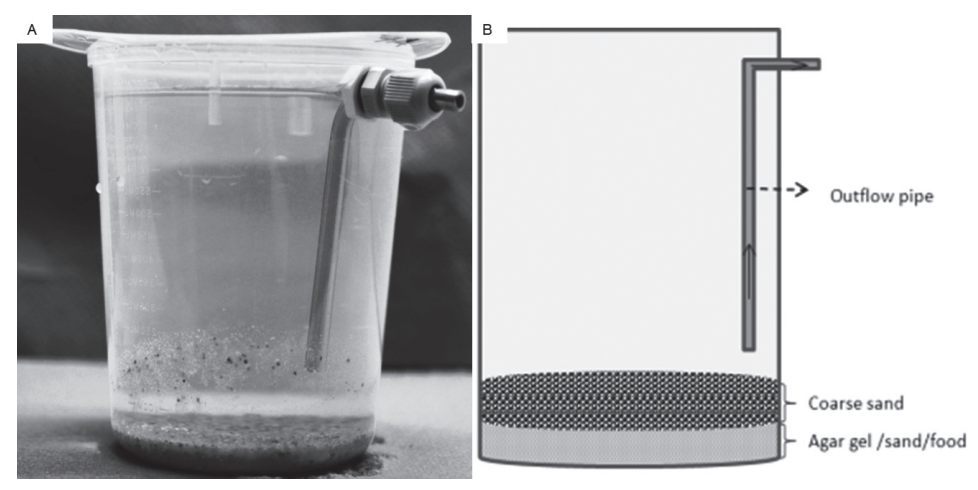

Figure $3.1(\mathrm{~A})$ Photograph and (B) schematic drawing of the test beaker set-up.

\subsubsection{Replacement of artificial sediment and worm handling}

The test beakers were withdrawn from the temperature controlled bath and approximately 70 $\%(\mathrm{v} / \mathrm{v})$ of the overlying water was removed. The beakers were gently shaken to fragment the sediment layer which incited most worms to perform their typical escape reflex (Drewes, 1999) into the overlying water. This impulse made it possible to collect the worms by pouring off the overlying water. Repeating this three times resulted in complete removal of the worms from the sediment. The collected worms were cleaned by flushing them with clean water, and all of the 
sediments were thoroughly inspected for remaining worms. The worms were placed directly into clean test beakers with new sediments and $200 \mathrm{ml}$ of water. Once per week, the total wet worm weight was measured after 3 to 4 hours of gut purging by using a pre weighted fine mesh. Worms were collected on top of the mesh, and paper towels were gently pressed against the back of the mesh for 10 seconds to absorb adherent water. The total number of worms was determined by counting the worms using a glass pipette.

\subsubsection{Estimation and comparisons of worm specific growth rates based on weight and number}

Weekly measurements of total weight and number of worms collected during substrate replacement were used to estimate the Specific Growth Rate (SGR) based on weight and Specific Reproduction Rate (SRR) based on number, both expressed in \%/day. Figure 3.2 shows an example of the growth and reproduction response of the worms. This response, consisting of three distinct phases, was observed with all the diets. During phase 1 the individual worm weight increased until a certain (average) individual worm weight was reached. During phase 2 asexual reproduction by fragmentation took place. Phase 3 gave a stable reproduction rate $(>20 \%$ of the population) and from this phase the SGR and SRR were estimated. All the datapoints in phase 3 were used for this purpose and fitted assuming exponential growth and by using a least-squares method to obtain estimates for SGR and SRR. To identify differences between diets the SGR and SRR were compared with ANOVA and Posthoc testing using Tukey HSD.
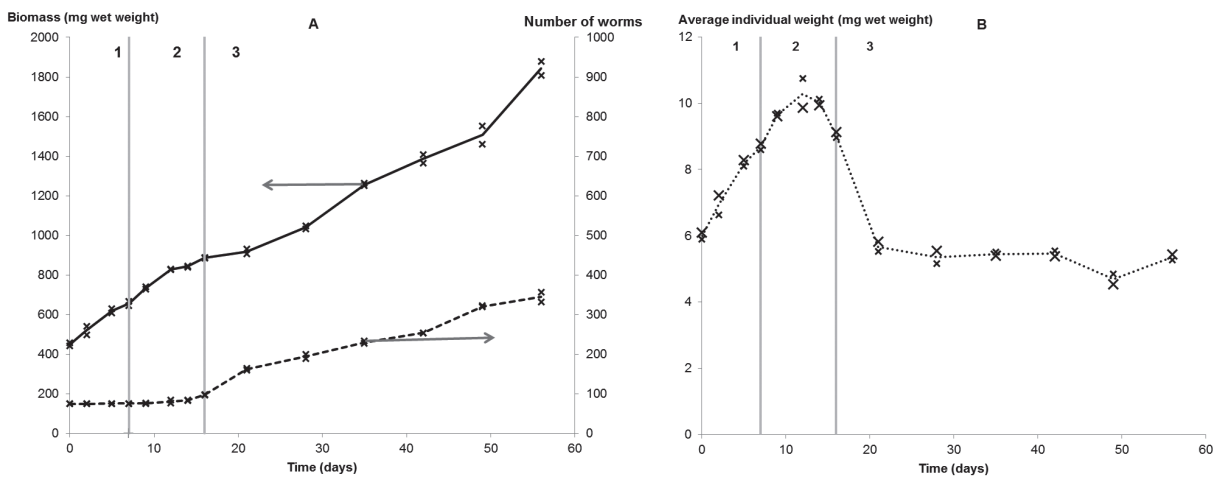

Figure 3.2 (A) Growth, reproduction and (B) the resulting average individual weight for 75 worms starting with similar individual start weights on a Tetramin ${ }^{\circledR}$ diet. Phase 1, growth without reproduction. Phase 2, growth with less than $20 \%$ of the population reproducing. Phase 3, growth with stable reproduction rate (>20 \% of the population). Specific growth rates for Phases 1 and 3 were $5.4 \% \quad\left(R^{2}=0.97\right)$ and 1.8\%/day $\left(R^{2}=0.98\right)$ Specific reproduction rates for Phases 3 was $2.8 \%\left(R^{2}=0.90\right)$, no reproduction took place during phase 1 . 


\subsubsection{Chemical analyses}

The resources, diets and previously cultured worm biomass fed with Tetramin ${ }^{\circledR}$ were analyzed according to standard national methods for COD (NEN 6633:2006; NEN, 2006), total nitrogen (NEN-EN 16169:2012;NEN_EN, 2012), total Ammonium-N (NEN-ISO 7150-1:2002; NEN-ISO, 2002), total P (CEN/TS 16188:2012; CEN/TS, 2012) combined with ICP-OES, total organic C (NEN-EN 15936:2012; NEN-EN, 2012) , and dry weigth (dw) (NEN 7432:1998; NEN, 1998). All analyses were performed by the Department of Environmental Technology at Wageningen University (Wageningen, the Netherlands).

\subsection{Results}

\subsubsection{General observations}

The different diets that were tested (Table 3.2) contained a COD of $1274 \pm 114$ and $1092 \pm 54$ $\mathrm{g} / \mathrm{kg}$ dw in experiment 1 and 2, respectively. The $\mathrm{N}$ content varied between 3.7 and $77.6 \mathrm{~g} \mathrm{~N} / \mathrm{kg}$ $\mathrm{dw}$. In the diets of experiment 1, the P content varied between 1.1 and $13.4 \mathrm{~g} \mathrm{P} / \mathrm{kg} \mathrm{dw}$, whereas in experiment 2 it was kept at a constant level of $12.4 \pm 0.9 \mathrm{~g} / \mathrm{kg} \mathrm{dw}$.

\subsubsection{Growth and reproduction of Lv with single and mixed crude wheat fractions (experiment 1)}

Lv could grow and reproduce on single as well as on mixed crude wheat fractions. Coefficients of determination for SGR and SRR estimates were all above 0.81. Only with the sugar and lipids $(S+L)$ diet very poor estimates were obtained because growth did not follow the expected exponential growth relationship. Observed differences between the diets were significant for both SGR (ANOVA, $F_{5,6}=63.9, p<0.001$ ) and SRR (ANOVA, $F_{5,6}=40.4, p<0.001$ ).

In table 3.2 the SGR and SRR are given and can be compared with $\mathrm{C} / \mathrm{N}$ and $\mathrm{C} / \mathrm{P}$ ratio of each diet. Because reproduction of Lv is size related SRR and SGR exhibit similar patterns. Within the experimental diets only a significant reduction for SGR and SRR was seen for diet 5 containing only sugar and lipids but without crude wheat gluten $(S+L$ diet). Overall, a positive trend of faster growth and reproduction was observed for diets with a lower $\mathrm{C} / \mathrm{N}$ or $\mathrm{C} / \mathrm{P}$ ratio. However, the SRR and SGR in the experimental diets still were 31-48\% lower than those obtained with the control diet.

In the experimental diets of experiment $1, \mathrm{~N}$ and $\mathrm{P}$ were mainly associated with the crude gluten and a low $\mathrm{C} / \mathrm{N}$ ratio was always accompanied by a low $\mathrm{C} / \mathrm{P}$ ratio. Whether growth was limited by 
$\mathrm{N}$ or $\mathrm{P}$ thus remains unclear. The range of the N/P ratio in the experimental diets also was rather narrow: between 15.7 and 22.5 (Table 3.2, S+L diet excluded). Therefore, a second experiment was carried out with more concentrated wheat gluten fractions enriched with phosphorus to reach nitrogen and phosphorus levels similar to those in the control diet. In the same experiment different saccharides were added to investigate if the type of sugar has an effect on growth and reproduction of LV.

\subsubsection{Growth and reproduction of $\mathrm{Lv}$ at low and high $\mathrm{C} / \mathrm{N}$ ratios at fixed $\mathrm{C} / \mathrm{P}$ ratios using concentrated wheat gluten and different saccharides (experiment 2)}

Significant differences were found for the SGR and SRR between the control diet and all other test diets (ANOVA, $F_{7,8}=20.3, p<0.001$ ). In Table 3.2 the SGR and SRR are given and can be compared with $\mathrm{C} / \mathrm{N}$ and $\mathrm{C} / \mathrm{P}$ ratio of each diet,. Wheat gluten based diets with $\mathrm{C} / \mathrm{N}$ ratios of around 7 gave a significantly higher SGR and SRR than the other diets with a $\mathrm{C} / \mathrm{N}$ ratio close to 20 (ANOVA, $F_{7,8}=10.76, p<0.002$ ), but were $29-41 \%$ lower than growth rates with the control diet. Because growth was almost absent in diets with a $\mathrm{C} / \mathrm{N}$ ratio of 20 , rate estimates for this ratio could not be established in a reliable way. For the gluten and starch diet $(\mathrm{C} / \mathrm{N} \sim 7)$ an outlier was observed with a very low SGR estimate of 0.0012 per day. This could in retrospective be explained by a lack of overlying water refreshment during this test. This value was therefore not included for further analysis or discussion.

Although the additional phosphorus gave much lower C/P ratios than in experiment 1 (Table 3.2), this did not stimulate the growth rates to achieve a level similar to those in the control diet. Apparently the growth rates were mainly controlled by the $\mathrm{C} / \mathrm{N}$ ratio. Table 3.2 also shows that the type of saccharide (starch, maltodextrin or glucose) and the gluten fraction did not exhibit an effect on the growth rates. Finally, also hydrolyzed wheat gluten did not result in a higher growth rate compared to a diet containing vital wheat gluten. This suggests that digestibility of the wheat protein matter was not an important factor for growth and reproduction at high $\mathrm{C} / \mathrm{N}$ ratios. 


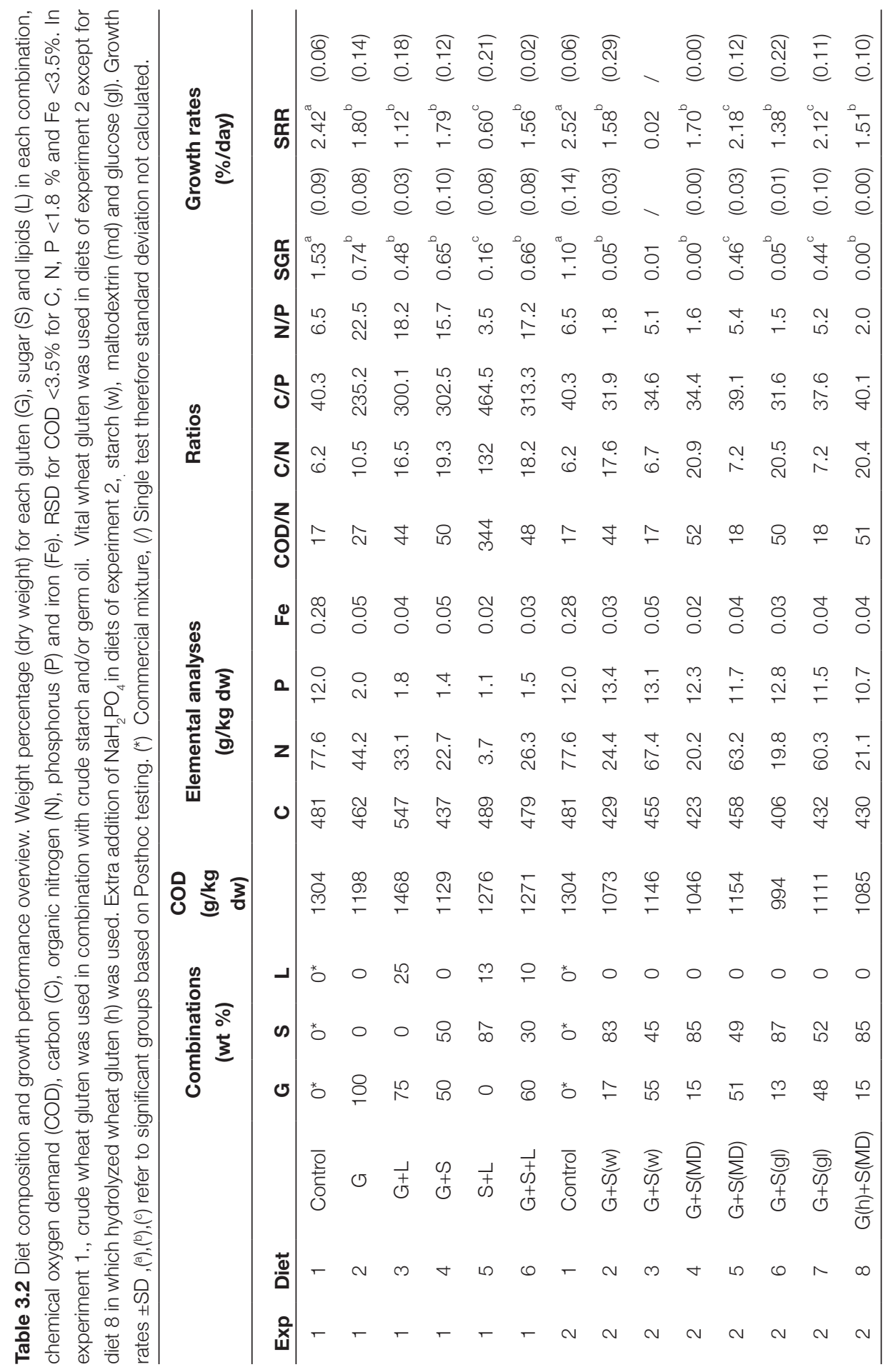




\subsection{Discussion}

A surplus of chemical energy (COD) and micro-nutrients was supplied to all diets, and therefore only the bioavailability (digestibility) and nutrient composition expressed in terms of $\mathrm{C} / \mathrm{N}$ and $\mathrm{C} / \mathrm{P}$ ratios of the food were possible factors limiting growth and reproduction. $P$ was equally dosed in all test diets of experiment 2 and therefore $P$ limitation in comparison with the control diet can be neglected. Applying hydrolyzed wheat gluten did not result in higher growth or reproduction rates compared to native wheat gluten. This implies that the digestibility of this particular wheat fraction also was not a limiting factor, and Lv or the microbial population it harbors in its gut system has a high digestible power for this proteinaceous matter.

Although worm biomass composition was not determined in this experiment, a culture of Lv fed with the same control diet (Tetramin ${ }^{\circledR}$ ) for several months was gut purged and dried overnight at $105^{\circ} \mathrm{C}$ for elemental analysis. This gave a $\mathrm{C} / \mathrm{N}$ mass ratio of 4.5 , which is a reflection of the relatively high protein content of Lv of 62-66 \% (Elissen et al., 2010). The C/P mass ratio for Lv was 32.8, which is much lower in comparison with other aquatic detritivores which have an average C/P mass ratio of approximately 95 (Frost et al., 2006).

Generally, higher nitrogen fractions in the diets (typically at a $\mathrm{C} / \mathrm{N}$ ratio around 7) gave much higher growth and reproduction rates than lower nitrogen fractions (typically at a $\mathrm{C} / \mathrm{N}$ ratio of approximately 20) Table 2. The ideal $\mathrm{C} / \mathrm{N}$ ratio for $\mathrm{Lv}$ apparently is much lower than for terrestrial worms like E.foetida, which has an ideal C/N mass ratio of 15-35 (Neuhauser et al., 1980). Because Lv and E.foetida have similar protein levels (Stafford and Tacon, 1985), it is suggested this difference in ideal food C/N ratios is related with the natural differences between terrestrial and freshwater food webs. Terrestrial food webs are often extremely nutrient-poor and autotrophic, with $\mathrm{C} / \mathrm{N}$ ratios that are much higher than in lake particulate matter (Elser et al., 2000). E.foetida can grow on relatively high $\mathrm{C} / \mathrm{N}$ ratios as a result of the high enzymatic activity related with the digestion of non-proteinaceous matter. In contrast, Lv may depend more on proteins as their source of energy and biomass. This is also supported by the observation that addition of sugars to the diets of experiment 2 did not stimulate growth and reproduction of Lv. Mass balances for $\mathrm{COD}$ and $\mathrm{N}$ performed on a Lv reactor for biological waste sludge reduction also revealed that Lv more selectively digested the protein fraction of this sludge than other fractions (Hendrickx et al.; 2009). Approximately $40 \%$ of the nitrogen and $12 \%$ of the phosphorus in the waste sludge that was digested by the worms was used for the formation of new worm biomass.

As a consequence of the above, (particulate) organic matter from food industries can be directly used by Lv, as long as it has a sufficiently low $\mathrm{C} / \mathrm{N}$ mass ratio (typically around 6 to 7 ). For organic matter with much higher $\mathrm{C} / \mathrm{N}$ ratios it probably is better to first convert it into microbial biomass to reduce the $\mathrm{C} / \mathrm{N}$ ratio, allowing subsequent efficient worm growth on this biomass. Another option is to mix by-products from different sources such that the desirable $\mathrm{C} / \mathrm{N}$ ratio is obtained. 
The growth performance of Lv in this study may not reflect the growth performance in full-scale biomass production reactors. Food hydrolysis was strongly reduced by frequent food renewals and feeding conditions which slowed down simultaneous bacterial breakdown. Most likely the contribution of microbial hydrolysis will become more important in full-scale reactors due to longer food residence times and bacterial ingrowth. This would result in lower $\mathrm{C} / \mathrm{N}$ and $\mathrm{C} / \mathrm{P}$ ratios and a shift to a more mixed food including bacterial biomass. This would imply that in practice also a $\mathrm{C} / \mathrm{N}$ ratio higher than 7 can be used without a substantial reduction of the growth rate as was observed in this study.

The control and low C/N diets of experiment 2 unexpectedly showed lower growth rates compared to experiment 1. Variance between the control diets of each experiment suggest an influence of an unknown external factor like overall condition of the worm which was not controlled within the experiment. Although this was not measured, a possible explanation for the lower growth rates for the diets in experiment 2 could be a lower lipid content in the diets of experiment 2 as a result of using more purified gluten and saccharides without residual germs. As lipids are essential for cell membrane functions, a limited availability in experiment 2 may have reduced growth in experiment 2 in comparison to the control within that same experiment. How the fatty acids composition and lipid level in the worm are related with the fatty acid composition and lipid level of the food and how this affects growth performance is valuable information for LV biomass production and its further use as fish feed. In amphipods it has been observed that the lipid content in the animal increases at a higher food availability (Perrone et al., 2003). However, whether this also is valid for Lv needs further study.

Information about mineral use and limitation on Lv growth is scarce. Particularly iron plays an important role because its function in the oxygen-binding blood protein of LV and other Annelida (Frossard, 1982). This also explains why addition of iron improved the growth of aquatic worms in wastewater treatments plants (Janssen et al., 2002). It cannot be excluded that the iron content of the control diet was higher than of the other diets, and perhaps this explains the higher growth and reproduction rates with the control diet.

\subsection{Conclusions}

The results showed that the aquatic worm Lv can grow and reproduce on different wheat sources. Growth and reproduction were mainly controlled by the $\mathrm{C} / \mathrm{N}$ ratio of the feed, with higher rates at low $\mathrm{C} / \mathrm{N}$ ratios of around 7. Although growth and reproduction rates were not as high as on a control diet containing a commercial fish feed, these results are promising with respect to the development of a worm production system, fed with by-products from the wheat processing industry. 


\section{Acknowledgements}

The authors thank Tiago Miguel Azevedo Marques and Klaudia Stanisława Straśko for their valuable contributions to the experimental work. This study was performed in the cooperation framework of Wetsus, European Centre of Excellence for Sustainable Water Technology (www.wetsus.nl). Wetsus is co-funded by the Dutch Ministry of Economic Affairs and Ministry of Infrastructure and Environment, the European Union Regional Development Fund, the Province of Fryslân, and the Northern Netherlands Provinces. The authors would like to thank the participants of the research theme "Aquatic worms" for the fruitful discussions and their financial support. 


\section{References}

Apper-Bossard, E., Feneuil, A., Wagner, A. and Respondek, F., 2013. Use of vital wheat gluten in aquaculture feeds. Aquatic Biosystems 9: 21.

CEN/TS, 2012. 16188, Slib, behandeld bioafval en bodem - Bepaling van de elementen na ontsluiting in koningswater en salpeterzuur - Atomaire-absorptiespectrometrie vlamtechniekmethode (FAAS).

Draganovic, V., van der Goot, A.J., Boom, R. and Jonkers, J., 2013. Assessment of the effects of fish meal, wheat gluten, soy protein concentrate and feed moisture on extruder system parameters and the technical quality of fish feed. Animal Feed Science and Technology 165: 238-250.

Drewes, C.D., 1999. Helical swimming and body reversal behaviors in Lumbriculus variegatus (Annelida: Clitellata: Lumbriculidae). Hydrobiologia 406: 263-269.

Ducrot, V., Péry, A.R.R., Quéau, H., Mons, R., Lafont, M. and Garric, J., 2007. Rearing and estimation of lifecycle parameters of the tubicifid worm Branchiura sowerbyi: Application to ecotoxicity testing. Science of the Total Environment 384: 252-263.

Elissen, H.J.H., Hendrickx, T.L.G., Temmink, H., Laarhoven, B. and Buisman, C.J.N., 2015. Worm-it: converting organic wastes into sustainable fish feed by using aquatic worms. Journal of Insects as Food and Feed 1: 67-74.

Elissen, H.J.H., Mulder, W.J., Hendrickx, T.L.G., Elbersen, H.W., Beelen, B., Temmink, H. and Buisman, C.J.N., 2010. Aquatic worms grown on biosolids: Biomass composition and potential applications. Bioresource Technology 101: 804-811.

Elser, J.J., Fagan, W.F., Denno, R.F., Dobberfuhl, D.R., Folarin, A., Huberty, A., Interlandi, S., Kilham, S.S., McCauley, E., Schulz, K.L., Siemann, E.H. and Sterner, R.W., 2000. Nutritional constraints in terrestrial and freshwater food webs. Nature 408: 578-580.

FAOSTAT, 2012. Food and Agriculture Organization of the United Nations.

Frossard, P., 1982. The erythrocruorin of Eisenia fetida. I. Properties and subunit structure. Biochimica et Biophysica Acta 704: 524-534.

Frost, P.C., Benstead, J.P., Cross, W.F., Hillebrand, H., Larson, J.H., Xenopoulos, M.A. and Yoshida, T., 2006. Threshold elemental ratios of carbon and phosphorus in aquatic consumers. Ecology Letters 9: 774-779.

Hendrickx, T.L.G., Temmink, H., Elissen, H.J.H. and Buisman, C.J.N., Aquatic worms eat sludge: Mass balances and processing of worm faeces. Journal of Hazardous Materials 177: 633-638.

Hendrickx, T.L.G., Temmink, H., Elissen, H.J.H. and Buisman, C.J.N., 2009. Aquatic worms eating waste sludge in a continuous system. Bioresource Technology 100: 4642-4648.

Janssen, P.M.J., Verkuijlen, J. and van der Roest, H.F., 2002. Slibpredatie door inzet van oligochaete wormen. Pilotonderzoek naar slibreductie op de rwzi Bennekom. Report 2002-17 (in Dutch with English abstract), STOWA, the Netherlands.

Laarhoven, B., Elissen, H.J.H., Temmink, H. and Buisman, C.J.N., 2016. Agar Sediment Test for Assessing the Suitability of Organic Waste Streams for Recovering Nutrients by the Aquatic Worm Lumbriculus variegatus. PLoS ONE 11: e0149165. 
McCarty, P.L., Bae, J. and Kim, J., 2011. Domestic Wastewater Treatment as a Net Energy Producer-Can This be Achieved? Environmental Science \& Technology 45: 7100-7106.

Moore, J.W., 1978. Importance of algae in the diet of the oligochaetes Lumbriculus variegatus (Müller) and Rhyacodrilus sodalis (Eisen). Oecologia 35: 357-363.

Mount, D.R., Highland, T.L., Mattson, V.R., Dawson, T.D., Lott, K.G. and Ingersoll, C.G., 2006. Use of the oligochaete, Lumbriculus variegatus, as a prey organism for toxicant exposure of fish through the diet. Environmental Toxicology and Chemistry 25: 2760-2767.

NEN-EN, 2012. 15936, Slib, behandeld biologisch afval, bodem en afval - Bepaling van de totale organische koolstof (TOC) door droge verbranding.

NEN-ISO, 2002. 7150-1, Water - Bepaling van ammonium - Deel 1: Handmatige spectrometrische methode.

NEN, 1998. 7432, Dierlijke mest en mestproducten - Bepaling van de gehalten aan droge stof en organische stof - Gravimetrische methode.

NEN, 2006. 6633, Water en (zuiverings)slib - Bepaling van het chemisch zuurstofverbruik (CZV).

NEN_EN, 2012. 16169, Slib, behandeld bioafval en bodem - Bepaling van het gehalte aan Kjeldahl-stikstof.

Neuhauser, E.F., Kaplan, D.L., Malecki, M.R. and Hartenstein, R., 1980. Materials supporting weight gain by the earthworm Eisenia foetida in waste conversion systems. AGRIC. WASTE 2: 43-60.

Perrone, F.M., Della Croce, N. and Dell'anno, A., 2003. Biochemical composition and trophic strategies of the amphipod Eurythenes gryllus at hadal depths (Atacama trench, South Pacific). Chemistry and Ecology 19: 441-449.

Stafford, E.A. and Tacon, A.G.J., 1985. The nutritional evaluation of dried earthworm meal (Eisenia foetida, Savigny, 1826) included at low levels in production diets for rainbow trout, Salmo gairdneri Richardson. Aquaculture Research 16: 213-222. 


\section{4}

\section{Aquatic worm density and production in a new reactor concept using a gravel column loaded with secondary food waste}

Submitted for publication: Laarhoven B, Stanulewicz N, Elissen H.J.H., Buisman C.J.N, Temmink H (2016). Aquatic worm density and production in a new reactor concept using a gravel column loaded with secondary food waste. Journal: Bioresource Technology 


\section{Abstract}

Lumbriculus variegatus (Oligochaeta, Lumbriculidae) (Lv) is a suitable organism to recover and valorize organic compounds, nitrogen $(N)$ and phosphorus $(P)$ from waste streams. Previous research demonstrated the feasibility of a reactor concept for this purpose in which Lv worms were immobilized in a mesh carrier, however with limited worm density, production and nutrient recovery. Therefore a new scalable reactor system was developed and tested in which LV is contained in a gravel layer, closely resembling its natural habitat. Secondary sludge originating from a potato starch processing industry was used as the substrate. This resulted in much higher worm densities (5977 compared to $1100 \mathrm{~g} / \mathrm{m}^{2}$ ), faster Lv growth rates (4.4-12 compared to $1.2 \% / d$ ), and as a result a 40 times higher areal worm production rate (560 compared to $14 \mathrm{~g} /$ $\mathrm{m}^{2} / \mathrm{d}$ ). The higher worm density was not related with different gravel size classes. The high worm density allowed for a shorter food retention time in the reactor (approximately 2.2 days compared to more than 10 days for the mesh reactor). This limited microbial mineralization of the food, allowing for relatively high nutrient recoveries by the worms (16-30\% COD, 19-22\% nitrogen and $9-11 \%$ phosphorus) and preventing release of toxic ammonium. Even shorter food retention times (e.g. higher loading rates) is not recommended as a minimum microbial activity is needed to convert the original substrate into compounds that can be taken up by the worms.

Key-words: Lumbriculus variegatus, aquatic worm, worm density, worm growth, sludge recovery 


\subsection{Introduction}

Lumbriculus variegatus (Oligochaeta, Lumbriculidae) (Lv) feeds on a complex mixture of biopolymers and bacteria (Hendrickx et al., 2009a). This makes it a suitable organism to recover organic compounds, nitrogen $(N)$ and phosphorus $(P)$ from waste streams (Elissen et al., 2015). Previous studies have demonstrated that consumption and partial digestion of sludge by LV significantly reduces the amount of wastewater solids (Elissen et al., 2010; Hendrickx et al., 2009a). Although Lv's biomass is rich in proteins, it has no safe application as animal food when produced from this type of sludge because of the risk of contamination with heavy metals, organic micro pollutants and pathogens. An application as a feed source would be feasible if other, safe feed stocks are used, for example byproducts from the food industry. In this case LV biomass can have a high value, in particular because it can replace fishmeal in aquaculture diets (Tacon and Metian, 2008).
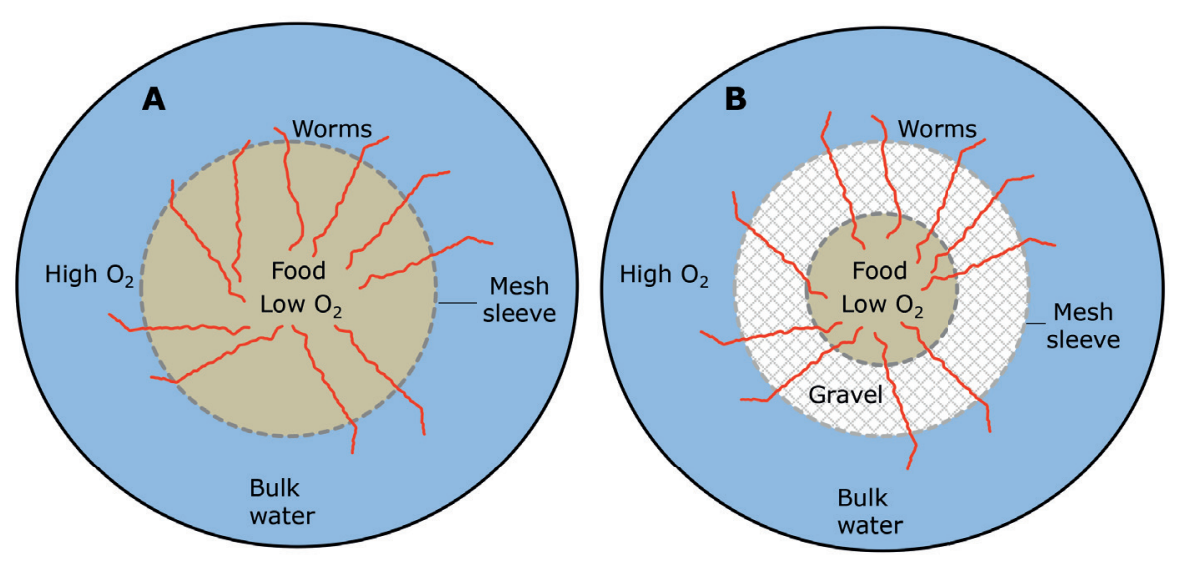

Figure 4.1 Schematic top view of a Lumbriculus variegatus production reactor with $(A)$ worms immobilized in a mesh carrier and (B) worms immobilized in a gravel layer.

(Hendrickx et al., 2010) developed and investigated a reactor concept for Lv cultivation (Fig 4.1A). A vertical, $300 \mu \mathrm{m}$ mesh polyamide carrier acted as a separation layer between the waste sludge and an oxygen rich water compartment. The worms, in the carrier material, orientated themselves horizontally with their tails protruding into the water compartment to take up oxygen, and with their mouths located in the sludge layer. This reactor concept makes it possible to separately control food addition, worm biomass and removal of worm feces. Although this concept showed a good potential for sludge reduction, the production capacity of Lv's biomass was limited with a (net) growth rate of $1.4 \% / d$ compared to $2.6 \% / d$ for worms which were not immobilized in a mesh carrier (Hendrickx et al., 2011). With secondary potato sludge non-immobilized worms even exhibited a stable growth rate as high as $3.2 \%$ /d (Laarhoven et al., 2016b). The lower net 
growth rate of immobilized worms in a mesh carrier was explained by a high worm mortality and the low worm density of $1100 \mathrm{~g}$ wet weight (ww) $\mathrm{m}^{-2}$ that was achieved compared to a theoretical density (based on 50\% open space in the mesh polyamide carrier) of $9000 \mathrm{~g}$ wet weight (ww)/ $\mathrm{m}^{2}$ Also the recoveries of organic compounds (expressed as chemical oxygen demand, COD) and nitrogen $(\mathrm{N})$ from the feed into worm biomass were relatively low: $8 \%$ and $15 \%$ respectively. This was attributed to extensive microbial mineralization prior to consumption of the sludge by the worms, taking place during the long retention time of the sludge in the feed compartment.

To improve worm production and nutrient recovery it is essential to understand that physical space is an important constraint for interstitial space dwelling organisms like Lv (Martin et al., 2012). For this reason the concept above was modified by replacing the polyamide mesh carrier by a thin vertical layer of gravel (Fig 4.1B). Such a gravel layer can be described as an interstitial labyrinth with chambers or voids, separated from each other by constrictions formed by multiple particle contact (Crisp and Williams, 1971). This mimics the natural environment of the sediment dwelling LV and was expected to result in a higher worm density than the polyamide mesh. This allows for a shorter retention time of the food in the food compartment (higher worm to food ratio), and reduces microbial mineralization and associated nutrient losses. An additional advantage is the reduced release of ammonia by microbial protein hydrolysis, which is important because above $1 \mathrm{mg} \mathrm{NH}_{3}-\mathrm{N} / \mathrm{L}$ ammonia exhibits a toxic effect on Lv (Hendrickx et al., 2009b).

To investigate the potential benefits of a gravel layer to immobilize Lv, an experimental study was carried out with semi-continuously operated laboratory scale worm production reactors. The worms were grown on secondary sludge originated from potato starch processing industry, as this previously was demonstrated to be a suitable feed stock for Lv (Laarhoven et al., 2016b). The effect of different gravel size classes (2.4-3.4, 3.6-4.5, 4.8-5.6 and 6.7-8.0 mm) was determined on worm density, specific Lv growth rate, biomass production and nutrient recovery.

\subsection{Material and methods}

\subsubsection{Worm production reactor}

Two identical systems were used (Fig 4.2), each holding a single worm reactor consisting of a rigid polypropylene mesh tube (Industrial netting type: RN1000, internal diameter 16,3 mm, outer diameter $21.5 \mathrm{~mm}, 2921 \mu \mathrm{m}$ mesh, 37\% open surface surrounded by a packed porous gravel layer (crushed clay aggregates, VDL substraatbodem ${ }^{\circledast}$ ). Gravel size classes of 2.4-3.6, 3.6-4.5, 4.8-5.6 and 6.7-8.0 $\mathrm{mm}$ were selected. These size classes provide trigonal void space diameters between 372-1240 $\mu \mathrm{m}$ and are believed to be large enough for Lv worms to enter. Size classes were prepared by using a vibrating separator machine (Retsch, VS1000). The porosity was 
between 50 and 53\%, as determined from differences in weight between empty and water filled gravel layers. No significant differences were observed between the size classes, as can be expected for well sorted gravel (Nimmo, 2004). In the reactor, the gravel was hold in place by a tubular mesh sleeve (Sefar Nitex type: 06-1140/66, outer diameter 75 mm,1140 $\mu \mathrm{m}$ mesh, 66\% open surface). The thickness of the gravel layer was $2.7 \mathrm{~cm}$, which is approximately half of the average length of Lv worms. The height of the gravel column was $290 \mathrm{~mm}$, excluding top and bottom fittings.

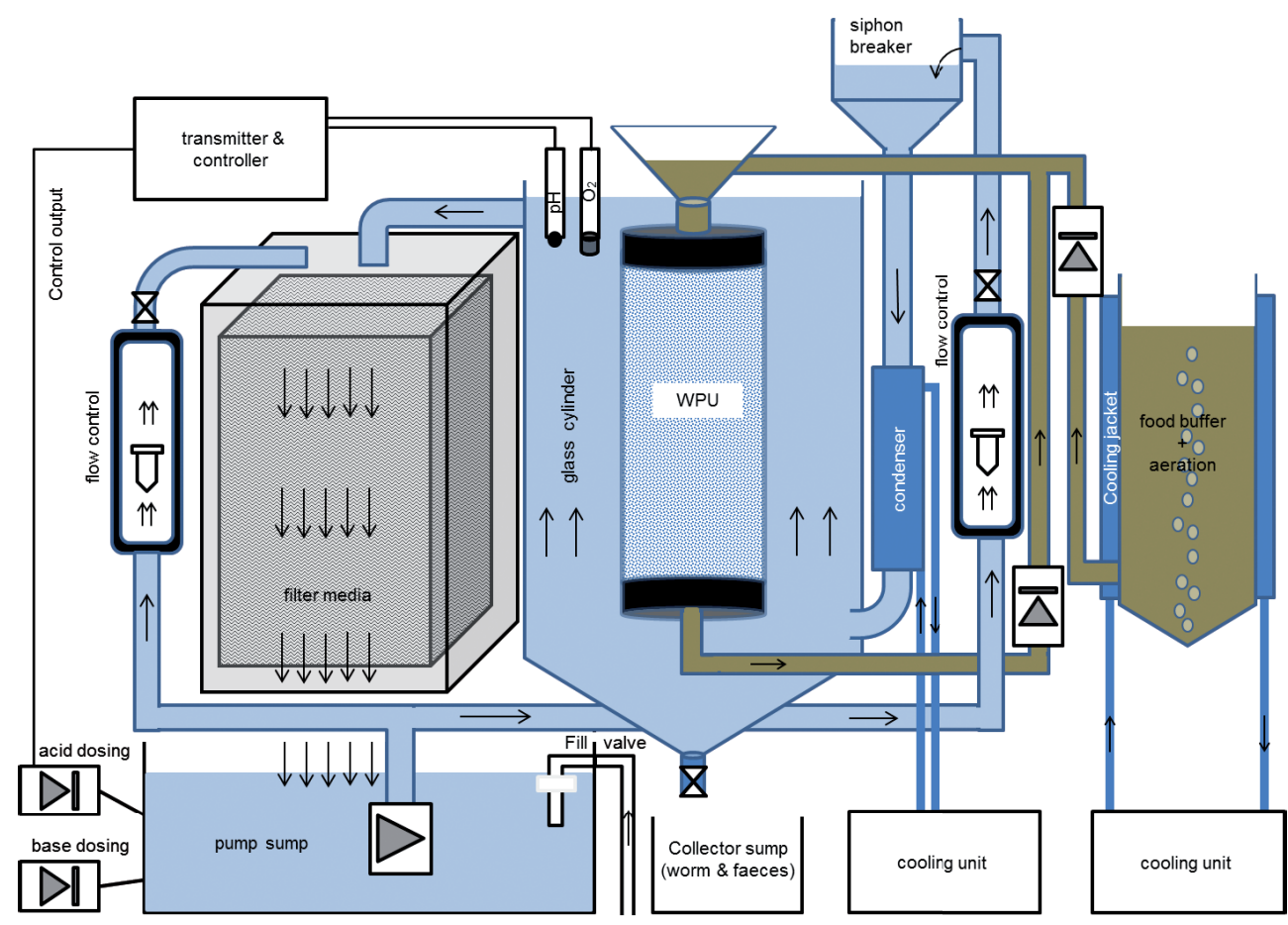

Figure 4.2 Laboratory-scale worm production system including worm production unit (WPU).

The reactors were installed in a glass cylinder (effective volume $11.3 \pm 0.1 \mathrm{~L}$ ) with a funnel shaped bottom and a terminal tap to collect faecal pellets and worms. Water entered the glass cylinder below the reactor and was recirculated over the glass cylinder at a flow rate of $50 \mathrm{~L} / \mathrm{h}$. The overflow was positioned $1 \mathrm{~cm}$ above the reactor. Effluent from the worm reactor was passed by natural gravity over a vertical flow nitrification filter (Bionet ${ }^{\circledR}, 150 \mathrm{~cm}^{2}$ and $600 \mathrm{~mm}$ height, specific surface area $200 \mathrm{~m}^{2} / \mathrm{m}^{3}$ ) to remove ammonia and aerate the water. The treated water was collected in a reservoir $(28.4 \pm 0.2 \mathrm{~L}$ ), positioned directly underneath the filter. The reservoir contained a submerged recirculation pump (EHEIM 2000, Compactplus, 35 w), universal hydraulic syphon for water level control (Wildkamp) and pH electrode (Orbisint CPS11D, Endress+Hauser). The 
pH was controlled between 7.1-7.2 by a pH controlled dispenser (Stepdos, FEM03) using 9\% ( $\mathrm{v} / \mathrm{v})$ hydrochloric acid and $25 \mathrm{~g} \mathrm{~L}^{-1}$ sodium bicarbonate. The water temperature $\left(19-23^{\circ} \mathrm{C}\right)$ was controlled by an inline condensor unit connected to a controlled temperature bath circulator (Thermo Scientific ${ }^{\circledR}$ Haake model A25) positioned at the inflow of the glass cylinder.

\subsubsection{Worms and substrate}

LV worms were collected from an in-house recirculating aquaculture system and fed with tropical fish food flakes (TetraMin)(Laarhoven et al., 2016a). Fresh secondary sludge originated from potato starch processing industry was collected weekly (Novidon, the Netherlands) containing $14-23 \mathrm{~g} \mathrm{COD} / \mathrm{L}$ and $1.25 \mathrm{~g} \mathrm{COD}$ and $0.059 \mathrm{~g} \mathrm{~N}$ per gram of solids on average. Previously it was found that this type of sludge could induce high Lv growth rates of $3.2 \% / d$ in standardized growth tests (Laarhoven et al., 2016b), and therefore was selected for the experiments.

\subsubsection{Reactor operation and experiments}

Prior to the tests all of the water in the experimental set-up was replaced by fresh tap water and left overnight for $\mathrm{pH}$ stabilization. The conductivity of the water varied between 700 and 800 $\mu \mathrm{s} / \mathrm{cm}$ and the initial $\mathrm{pH}$ between 8.2-8.4. Approximately $110 \mathrm{~g} \mathrm{ww}$ worms were used for each test. This $110 \mathrm{~g}$ was split up in 4 equal portions and using a plastic funnel these were inserted in the top of the food compartment of the worm reactor. Between each portion secondary potato sludge (300 $\mathrm{ml}$ in total) was added to stimulate the worms to enter the gravel layer. This procedure took approximately 8 hours, after which the food compartment was left overnight to allow the worms to position themselves. The remaining potato sludge was pumped out from the bottom of the food compartment. Recirculation (two minutes at $80 \mathrm{ml} \mathrm{min}^{-1}$, every $0.5 \mathrm{~h}$ ) and food supply (two minutes at $80 \mathrm{ml} \mathrm{min}^{-1}$, every $2 \mathrm{~h}$ ) were initiated $24 \mathrm{~h}$ after the first worm loading had started. For this purpose two peristaltic pumps (MASTERFLEX L/S ${ }^{\circledR}$ series, Easy-Load II Head; 6-600 rpm) were used, connected to the top and bottom of the food compartment with $6 \mathrm{~mm}$ internal diameter Teflon tubes. The food storage tank of $3 \mathrm{~L}$ was temperature controlled at $16^{\circ} \mathrm{C}$ and aerated to allow conversion of ammonium into nitrate by nitrification.

Two types of experiments were carried out. Experiment 1 focussed on the initial worm density that could be achieved. These densities were determined after $24 \mathrm{~h}$ of food recirculation for 4 different gravel size classes (Table 4.2, Tests 1-4). All of these size classes were tested in duplicate over time. Experiment 2 followed a similar procedure but focused on worm growth and nutrient recovery. For this purpose food was dosed and recirculated for a period of 14 days (Tests 1 and 2 in Table 4.3) or 22 days (Test 3 in Table 4.3). Tests 1 and 2 used the same gravel sizes as in Experiment 1 but were not carried out in duplicate. Test 3 was carried out in duplicate; a gravel size was used based on the highest worm density observed in Tests 1 and 2 of Experiment 2. 


\subsubsection{Sampling and analyses}

Worms that were lost from the reactor accumulated at the bottom of the cylinder and were collected together with the worm faeces. After these faeces were flushed out, total worm weight was determined by collecting all the worms on top of a fine mesh $(250 \mu \mathrm{m})$. Paper towels were gently pressed against the back of the mesh for 10 seconds to absorb adherent water. Worms were collected every morning and afternoon. At the end of each test, the reactors were disconnected from the feed lines and removed from the cylinder. The outer tubular mesh sleeve of the reactor was removed and the worms were washed out from the gravel in which the worms retreated after removal from the cylinder. All remaining worms were collected and cleared from gravel. The worm biomass was determined according to the procedure described above. Temperature, dissolved oxygen (Oxymax COS61, Endress+Hauser), pH (Orbisint CPS11D, Endress+Hauser) was recorded and ammonium and nitrite levels (HACH LANGE, LCK series) were tested daily. Chemical oxygen demand (COD) and total nitrogen were determined according to standard methods (APHA, 1998) using LANGE test kits.

\subsubsection{Calculations}

Worm densities were calculated from the worm biomass remaining in the gravel carrier at the end of the tests (the final stock in $\mathrm{g} w \mathrm{w}$ ) and from the surface area at the interface between the food compartment and gravel layer $\left(0.015 \mathrm{~m}^{2}\right)$. Cumulative worm losses from the carrier material in Experiment 2 exhibited near linear behavior from day 5 onwards (Fig 4.6). Assuming no significant worm accumulation took place in the gravel layer during this period (constant worm density), worm biomass production (in $\mathrm{g} \mathrm{ww/d}$ ) was calculated as the slope from this cumulative biomass loss between day 5 and the end of the experimental period. The relative growth rate of the worms $(\% / d)$ was calculated from this worm production rate divided by the worm weight of the final stock. N, P and COD (organic) recoveries in Experiment 2 were calculated as the load of these nutrient removed from the reactor with the worms (worm biomass production multiplied with their N, P and COD content) divided by the total load of these nutrient supplied to the reactor with the secondary potato sludge during the experimental period.

\subsection{Results}

The worms were evenly distributed along the entire height of the reactor, with their tails protruding into the oxygen rich water (Fig 4.3). Visual inspection showed that large food particles were immediately entrapped by the gravel layer. Entrapment of smaller particles was also quickly realized as soon as the worms had inhabited the interstitial space of the gravel layer. No pressure build-up was observed as volume of the food compartment remained constant, indicating entrapment of particles in the gravel layer was balanced by their consumption by the worms. 


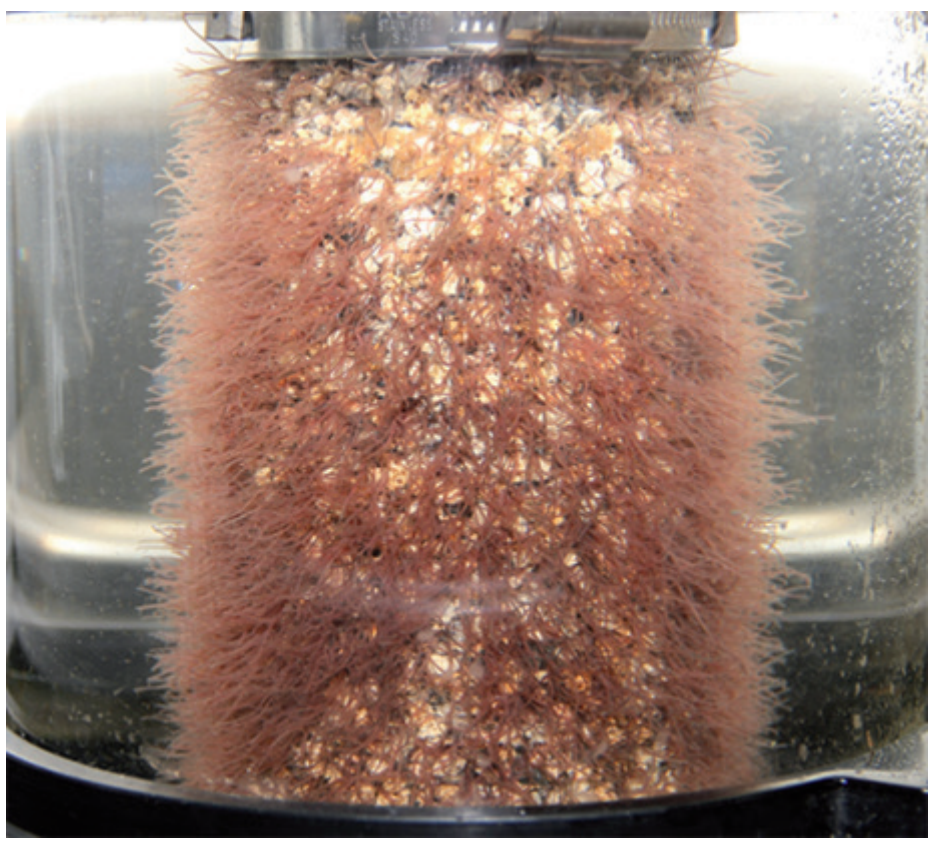

Figure 4.3 Side view of one of the worm production reactors, showing the horizontal orientation of the worms with their tails protruding into the oxygen rich water compartment.

\subsubsection{Effect of gravel size on initial worm density (experiment 1)}

Table 4.2 shows worm densities after 48 hours and Fig 4.4 relates these densities to the different gravel size class. Duplicates exhibited considerable variation (Fig 4.4), which probably can be explained by differences in the worm inocula and batches of potato sludge that were used between the different test runs. No significant effect of gravel size class was detected and the average worm density over all the tests was $4939 \pm 830 \mathrm{~g} \mathrm{ww} / \mathrm{m}^{2}$. This density relates to the interface surface area between the gravel and substrate compartment $\left(0.015 \mathrm{~m}^{2}\right)$. In Test 2 the water flow was temporarily interrupted, which had a negative effect on the density. If the values from this Test are discarded the average density would be somewhat higher: $5217 \pm 768 \mathrm{~g} \mathrm{ww} / \mathrm{m}^{2}$.

Table 4.2 Initial worm densities achieved in Experiment 1 after $48 \mathrm{~h}$ for different gravel size classes.

\begin{tabular}{lllllllll}
\hline Test & $\mathbf{1}$ & \multicolumn{2}{c}{$\mathbf{2}$} & \multicolumn{3}{c}{$\mathbf{3}$} & \multicolumn{4}{l}{} \\
\hline gravel size $(\mathrm{mm})$ & $4.8-5.6$ & $2.4-3.6$ & $3.6-4.5$ & $4.8-5.6$ & $6.7-8.0$ & $3.6-4.5$ & $2.4-3.6$ & $6.7-8.0$ \\
worm input $(\mathrm{g} \mathrm{ww})$ & 112.3 & 110.7 & 109.9 & 112.5 & 110.0 & 109.6 & 111.3 & 109.3 \\
final stock $(\mathrm{g} \mathrm{ww})$ & 80.5 & 73.0 & 58.2 & 58.5 & 86.9 & 89.4 & 60.4 & 70.1 \\
density $\left(\mathrm{g} \mathrm{ww} / \mathrm{m}^{2}\right)$ & 5500 & 5100 & 4100 & 4100 & 6000 & 6000 & 4100 & 4600 \\
\hline
\end{tabular}




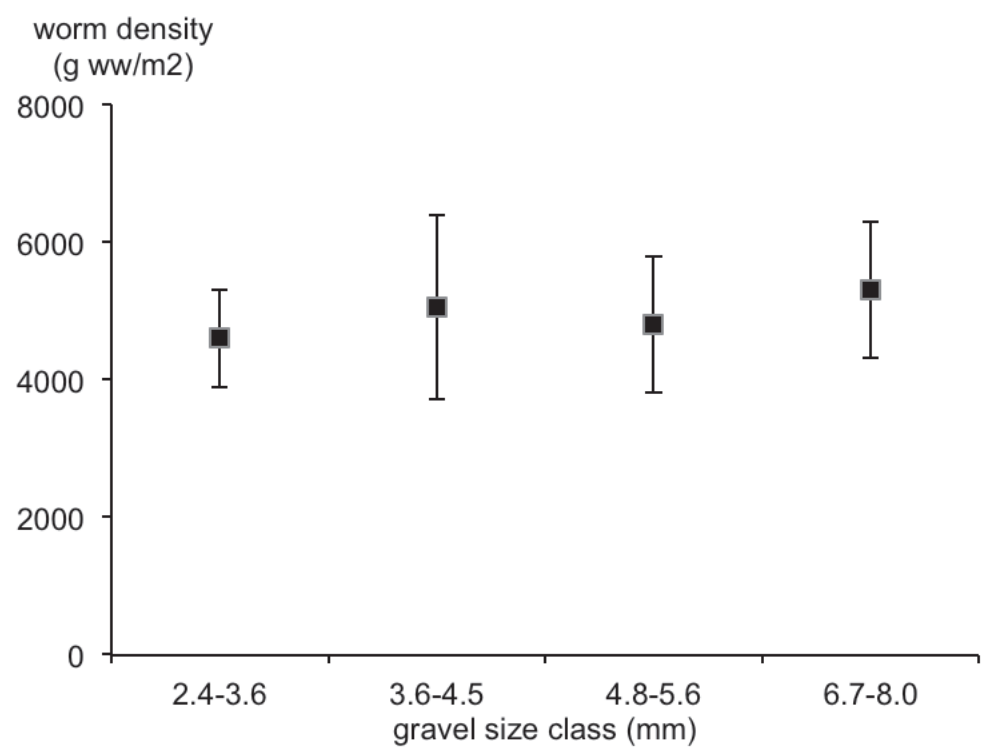

Figure 4.4 Initial worm densities as a function of gravel size class. Error bars; average of two biological replicates \pm standard deviation.

Fig 4.5 shows cumulative worm losses during tests 1, 3 and 4, i.e. the worm mass collected from the bottom of the water compartment. The worm loss pattern was similar in all the Tests, with high losses during the first $24 \mathrm{~h}$ in the absence of feed supply and recirculation, followed by a much smaller loss during the following $24 \mathrm{~h}$ during which food was added and recirculated. The initial losses during the first $24 \mathrm{~h}$ contributed 66 to $93 \%$ to the total losses. The differences in environmental conditions ( $\mathrm{pH}$, temperature, dissolved oxygen and ammonia and nitrate levels) between these two periods were very small and could not explain why the worm losses during the first $24 \mathrm{~h}$ were so much higher.

\subsubsection{Effect of gravel size on worm production and nutrient recovery (experiment 2)}

Table 4.3 shows worm densities, worm productivities, relative growth rates of the worms and nutrient recoveries achieved in Experiment 2. Similar to Experiment 1, no significant effect of gravel size on worm density could be detected. The average worm density at the end of the operational period was $5977 \pm 869 \mathrm{~g} \mathrm{ww} / \mathrm{m}^{2}$, which is higher than the average density of Experiment 1 of $4939 \pm 830 \mathrm{~g} \mathrm{ww} / \mathrm{m}^{2}$. Most likely this can be explained by more accumulation of new worm biomass in the gravel layer because of the 12 and 20 days longer operational period that was applied. 
Fig 4.6 shows cumulative worm losses (cumulative worm production) in time. Biomass productivity, calculated from the slope from the cumulative worm losses after day 5, varied between 4.6 and $8.3 \mathrm{~g} \mathrm{ww} / \mathrm{d}$. Similar productivities were achieved in Tests 1 and 3, while the productivities in Test 2 were significantly higher. A similar trend was observed for the relative growth rates, which varied between 4.4 and $12.0 \% / \mathrm{d}$.

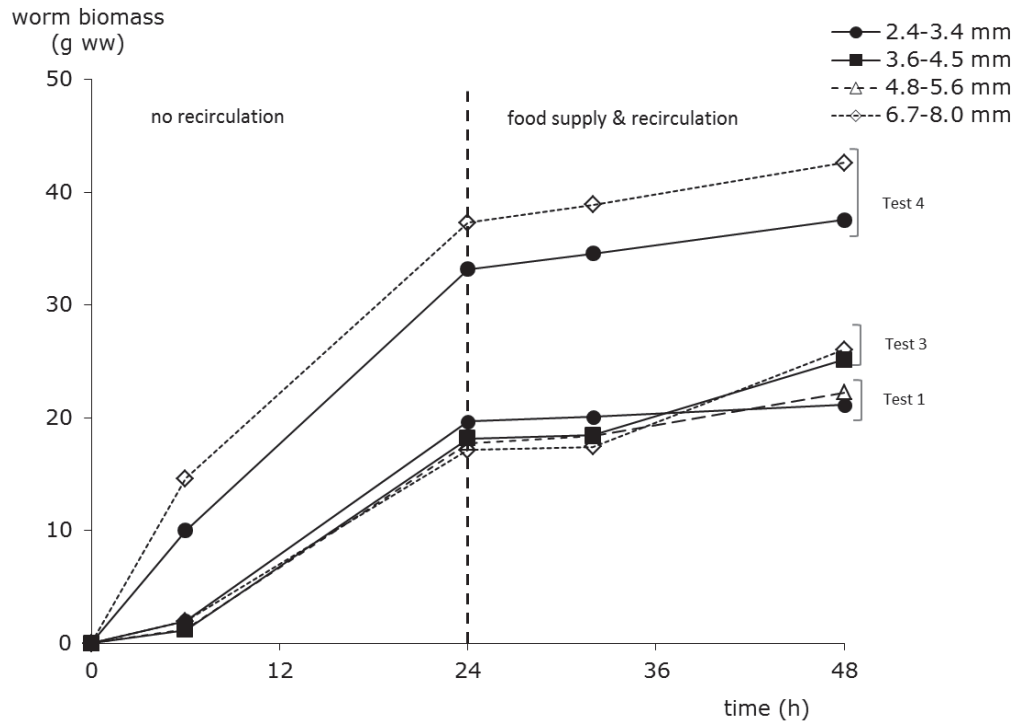

Figure 4.5 Worm losses during Tests 1, 3 and 4 in Experiment 1.

Table 4.3 Worm densities, worm productivities, relative growth rates of the worms and nutrient recoveries as achieved in Experiment 2. Average nutrient ratios for the sludge were: COD/N = 18 and COD/P $=82$. Average nutrient ratios for worm biomass were: $\mathrm{COD} / \mathrm{N}=14.3$ and $\mathrm{COD} / \mathrm{P}=133$

\begin{tabular}{lllllll}
\hline Test & $\mathbf{1}$ & & $\mathbf{2}$ & & $\mathbf{3}$ & \\
\hline gravel size (mm) & $4.8-5.6$ & $3.6-4.5$ & $6.7-8.0$ & $2.4-3.6$ & $4.8-5.6$ & $4.8-5.6$ \\
worm input (g ww) & 108.9 & 108.7 & 109.2 & 108.7 & 109.7 & 109.8 \\
duration (d) & 14 & 14 & 14 & 14 & 22 & 22 \\
food dosing (g COD/d) & 4.8 & 4.8 & 5.1 & 5.1 & 4.8 & 4.8 \\
final stock (g ww) & 104.5 & 91.5 & 65.0 & 92.0 & 90.2 & 89.4 \\
density $\left(\mathrm{g} \mathrm{ww} / \mathrm{m}^{2}\right)$ & 7037 & 6161 & 4377 & 6195 & 6074 & 6020 \\
production $(\mathrm{g} \mathrm{ww/d)}$ & 4.6 & 4.7 & 7.8 & 8.3 & 4.7 & 5.5 \\
relative growth rate (\%/d) & 4.4 & 5.2 & 12.0 & 9.0 & 5.2 & 6.2 \\
food dosing (g COD/g ww/d) & 0.046 & 0.052 & 0.078 & 0.055 & 0.053 & 0.054 \\
COD recovery (\%) & 25 & 19 & 30 & 28 & 15 & 17 \\
$\mathrm{~N}$ recovery (\%) & n.a & n.a & n.a & n.a & 19 & 22 \\
P recovery (\%) & n.a & n.a & n.a & n.a & 9 & 11 \\
\hline
\end{tabular}




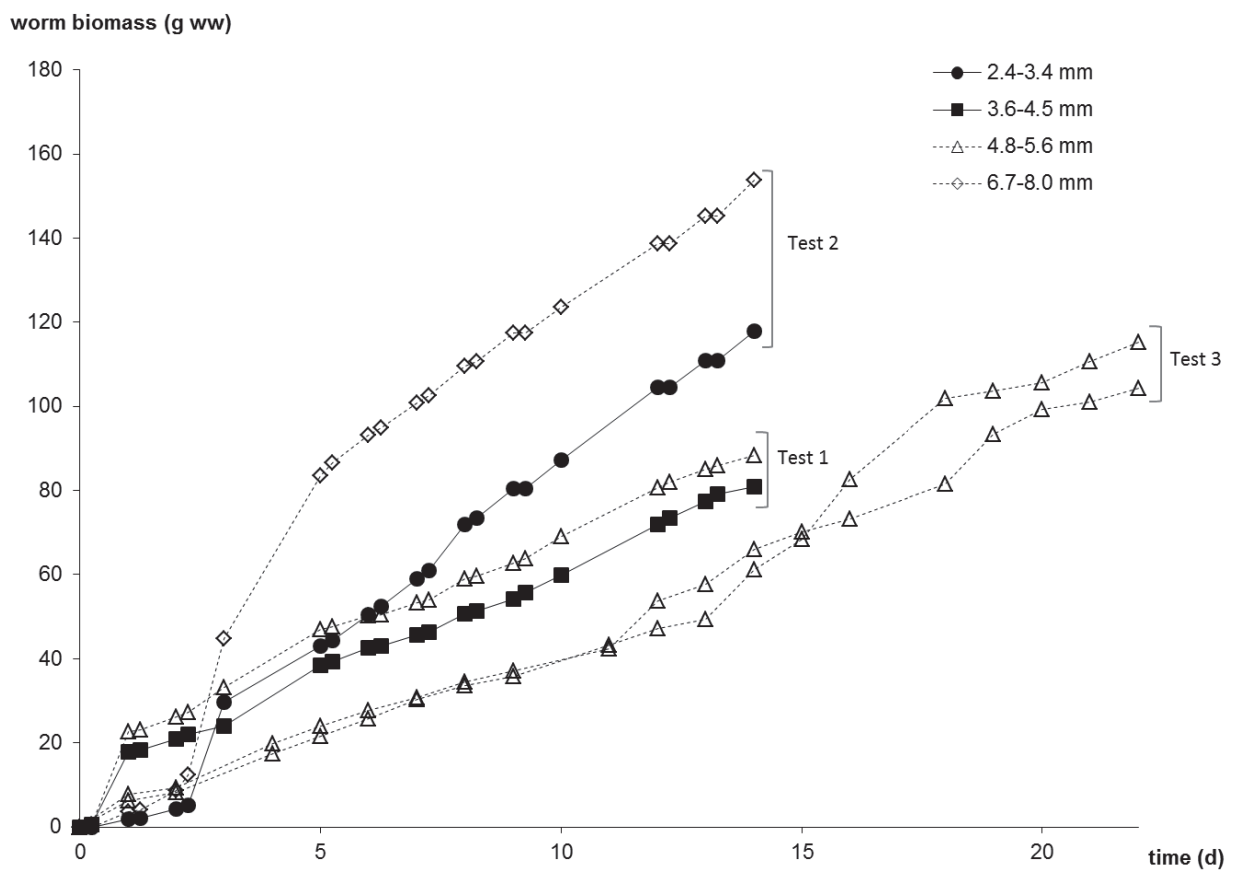

Figure 4.6 - Worm losses during Tests 1-3 in Experiment 2. Test 3 was a duplicate experiment using the same gravel size.

COD recoveries varied between 15 and 30\%. Due to the higher biomass production rate in Test 2 also the $\mathrm{N}$ and $\mathrm{P}$ recovery in this Test was higher than in the other Tests. $\mathrm{N}$ and $\mathrm{P}$ recoveries were only determined for the duplicates in Test 3 and were $20.5 \pm 2.1$ and $10.0 \pm 1.4 \%$, respectively.

\subsection{Discussion}

Table 4.4 summarizes the main results as obtained with the reactor employing a gravel layer as carrier material for Lv worms. These results are compared to those obtained in a similar reactor concept with a mesh layer instead of a gravel layer (Fig 4.1). The food source was different (secondary potato sludge and excess municipal sludge, respectively), but both are of bacterial origin and induced high growth rates. 


\subsubsection{Worm density}

The average worm density in the gravel reactor was $5977 \pm 869 \mathrm{~g} \mathrm{ww} / \mathrm{m}^{2}$, this is lower than a maximum (theoretical) density of $10000 \mathrm{~g} \mathrm{ww} / \mathrm{m}^{2}$, calculated from the assumption that the average diameter of a Lv worm is $1060 \mu \mathrm{m}$. However, the worm density was more than 5 times higher than in the previous reactor concept without such a gravel layer $\left(1100 \mathrm{~g} \mathrm{ww} / \mathrm{m}^{2}\right)$, which confirms our expectations that Lv worms need a support layer resembling their natural habitat. Worm density was not determined by gravel size (between 2.4 and $8.0 \mathrm{~mm}$ ) (Fig. 4), but mainly by a fast worm loss upon inoculation of the gravel layer with (fresh) worms (Fig 4.5). The extent of this loss varied between the different Tests, and was probably determined by differences in initial worm activity, oxygen gradient in the gravel layer and food composition. Based on our results this could not be further substantiated but this phenomenon deserves more attention as it is important for the start-up of large-scale worm reactors. After starting recirculation of the food, the worm density stabilized.

Table 4.4 Comparison between two worm production reactors (Fig. 1) Data for the mesh reactor were collected from (Hendrickx et al., 2011).

\begin{tabular}{lll}
\hline Performance & Mesh layer & Gravel layer \\
\hline worm density $\left(\mathrm{g} \mathrm{ww} / \mathrm{m}^{2}\right)$ & 1100 & $5977 \pm 869$ \\
specific growth rate $(\% / \mathrm{d})$ & 1.4 & $4.4-12.0$ \\
worm production $\left(\mathrm{g} \mathrm{ww} / \mathrm{m}^{2} / \mathrm{d}\right)$ & 14 & $311-560$ \\
COD recovery (\%) & 8 & $17-30$ \\
$\mathrm{~N}$ recovery (\%) & 15 & $19-22$ \\
P recovery $(\%)$ & n.a & $9-11$ \\
\hline
\end{tabular}

\subsubsection{Growth rate of the worms}

The relative growth rate of $L v$ in the gravel based reactor $(4.4-12.0 \% / d)$ was 3 to 9 times faster than in the reactor without gravel layer $(1.4 \% / d)$, and also much higher than the net growth rate of non-immobilized worms growing on municipal activated sludge $(2.6 \% / d)$ or on secondary potato sludge substrate $(3.2 \% / d)$. This faster growth rate is most likely caused by the use of gravel which improved the overall conditions for food uptake and growth. The immobilization of worms using coarse gravel with large interstitial spaces causes less constriction of the worm's body than with the use of a mesh carrier, allowing worms to move more freely in the carrier. The higher worm density allowed for a higher worm to food ratio and shorter food retention times (2.2 days compared to more than 10 days, also see below). This probably reduced microbial mineralization and related ammonia release, preventing ammonia inhibition. 
Interestingly, the higher worm densities resulted in a lower (net) growth rate of the worms (Fig 4.7). Probably this can be explained by a lower food to worm ratio at higher densities, resulting in substrate limitation for the worms (also see below).

\subsubsection{Worm Production rate}

Areal worm production is determined by worm density and growth rate. In the reactor with a gravel layer both these parameters were considerably higher than in the mesh reactor without gravel layer, which explains why also the areal production rate in the gravel reactor was much higher: 311-560 compared to $14 \mathrm{~g} \mathrm{ww} / \mathrm{m}^{2} / \mathrm{d}$ (Hendrickx et al., 2011). The results showed that a relatively low density such as observed in Test 2 of Experiment 2 (Table 4.3) not necessarily results in a low biomass production. On the contrary, the lower density was compensated by a much higher growth rate compared to the other Tests in Experiment 2, even resulting in a higher biomass production. Fig 4.8 shows the effect of food loading on worm productivity. This indicates that with secondary potato sludge as the feed source the loading rate should exceed $0.055 \mathrm{~g}$ COD g ww/d to avoid substrate limitation. Obviously for other feed stocks this minimum loading rate may be different.



Figure 4.7 Effect of worm density on (net) worm growth rate, based on the results of experiment 2. 


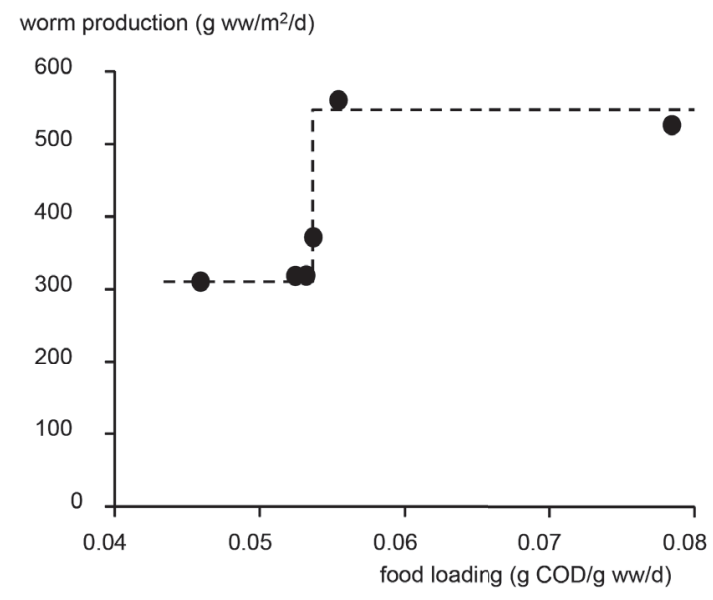

Figure 4.8 Effect of food loading on worm productivity, based on the results of experiment 2.

\subsubsection{Nutrient recovery}

In all the Tests the recovery of organic matter (expressed as COD) and of $\mathrm{N}$ were higher than what was achieved in the reactor with the mesh carrier. It cannot be excluded that this is caused by differences in the digestibility of the two substrate type, i.e. secondary potato sludge versus municipal excess activated sludge. However, a more likely reason is the shorter retention time of the substrate in the food compartment of the gravel reactor (2.2 d) compared to reactor with the mesh carrier $(>10 \mathrm{~d}$ ), made possible by the higher worm density in the gravel reactor. $\mathrm{A}$ shorter retention time results in less microbial mineralization in the food compartment and in this manner more of the nutrients become available for uptake by the worms. However, applying even shorter retention times may not be recommended as, depending on the type of substrate, (limited) microbial activity can help to improve the digestibility of the substrate for the worms.

The recovery of COD, $\mathrm{N}$ and $\mathrm{P}$ shows that the uptake by worms is mainly caused by the digestion of bacterial cells which contain most of the $\mathrm{N}$ (proteins) and P. Lv was assumed to depend more on proteins as their source of energy and biomass(Laarhoven et al., 2016a), which is supported by the relatively low COD and high N uptake from the food in this study and former study on LV (Hendrickx et al., 2009a) and other aquatic worms (de Valk et al., 2017). Also the low COD/N of 14.3 (high protein percentages) of worm biomass itself favors a high uptake of nitrogen assuming a strict homeostasis (Cross et al., 2003). 


\subsection{Conclusions}

- Worm density in a gravel column did not depend on the gravel size (between 2.4 and $8.0 \mathrm{~mm})$.

- The average worm density in the gravel reactor of $5977 \pm 869 \mathrm{~g} \mathrm{ww} / \mathrm{m}^{2}$ was more than 5 times higher than in a previous reactor concept without a gravel layer (1100 $\left.\mathrm{g} w \mathrm{w} / \mathrm{m}^{2}\right)$.

- The Areal worm production was 22 times higher than in the previous reactor concept, caused by a combination of a higher worm density and a faster specific worm growth.

- Specific recoveries of COD, N and P up to 30, 22 and $11 \%$ were established for LV feeding on secondary waste from a starch processing industry.

- To avoid substrate limitation the loading rate of the worms with secondary potato sludge should exceed $0.055 \mathrm{~g}$ COD/g ww/d.

\section{Acknowledgements}

The authors thank Ede László Bobák for his valuable contributions to the experimental work. This study was performed in the cooperation framework of Wetsus, European Centre of Excellence for Sustainable Water Technology (www.wetsus.nl). Wetsus is co-funded by the Dutch Ministry of Economic Affairs and Ministry of Infrastructure and Environment, the European Union Regional Development Fund, the Province of Fryslân, and the Northern Netherlands Provinces. The authors would like to thank the participants of the research theme "Aquatic worms" for the fruitful discussions and their financial support. 


\section{References}

Crisp, D.J. and Williams, R., 1971. Direct measurement of pore-size distribution on artificial and natural deposits and prediction of pore space accessible to interstitial organisms. Marine Biology 10: 214-226.

Cross, W.F., Benstead, J.P., Rosemond, A.D. and Bruce Wallace, J., 2003. Consumer-resource stoichiometry in detritus-based streams. Ecology Letters 6: 721-732.

de Valk, S., Khadem, A.F., van Lier, J.B. and de Kreuk, M.K., 2017. Unravelling the protein preference of aquatic worms during waste activated sludge degradation. Environmental Technology: 1-8.

Elissen, H.J.H., Hendrickx, T.L.G., Temmink, H., Laarhoven, B. and Buisman, C.J.N., 2015. Worm-it: converting organic wastes into sustainable fish feed by using aquatic worms. Journal of Insects as Food and Feed 1: 67-74.

Elissen, H.J.H., Mulder, W.J., Hendrickx, T.L.G., Elbersen, H.W., Beelen, B., Temmink, H. and Buisman, C.J.N., 2010. Aquatic worms grown on biosolids: Biomass composition and potential applications. Bioresource Technology 101: 804-811.

Hendrickx, T.L.G., Elissen, H.H.J., Temmink, H. and Buisman, C.J.N., 2011. Operation of an aquatic worm reactor suitable for sludge reduction at large scale. Water Research 45: 4923-4929.

Hendrickx, T.L.G., Temmink, H., Elissen, H.J.H. and Buisman, C.J.N., 2009a. Aquatic worms eating waste sludge in a continuous system. Bioresource Technology 100: 4642-4648.

Hendrickx, T.L.G., Temmink, H., Elissen, H.J.H. and Buisman, C.J.N., 2009b. The effect of operating conditions on aquatic worms eating waste sludge. Water Research 43: 943-950.

Hendrickx, T.L.G., Temmink, H., Elissen, H.J.H. and Buisman, C.J.N., 2010. Design parameters for sludge reduction in an aquatic worm reactor. Water Research 44: 1017-1023.

Laarhoven, B., Elissen, H.J.H., Buisman, C.J.N. and Temmink, H., 2016a. The carbon to nitrogen ratio in isoenergetic wheat based diets controls the growth rate of the aquatic worm Lumbriculus variegatus. Journal of Insects as Food and Feed 2: 225-231.

Laarhoven, B., Elissen, H.J.H., Temmink, H. and Buisman, C.J.N., 2016b. Agar Sediment Test for Assessing the Suitability of Organic Waste Streams for Recovering Nutrients by the Aquatic Worm Lumbriculus variegatus. PLoS ONE 11: e0149165.

Martin, S.D., Harris, B.A., Collums, J.R. and Bonett, R.M., 2012. Life between predators and a small space: substrate selection of an interstitial space-dwelling stream salamander. Journal of Zoology 287: 205-214.

Nimmo, J., 2004. Porosity and pore size distribution. Encyclopedia of Soils in the Environment 3: 295-303.

Tacon, A.G.J. and Metian, M., 2008. Global overview on the use of fish meal and fish oil in industrially compounded aquafeeds: Trends and future prospects. Aquaculture 285: 146-158. 


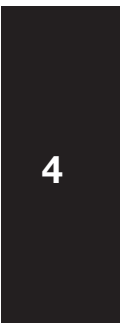




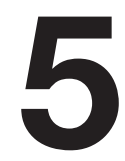

Growth and fatty acid profile of aquatic worms cultured on various waste streams

In preparation for publication: B. Laarhoven, E.T.H.M. Peeters, B.G. van Zuidam, H.J.H. Elissen, C.J.N. Buisman, H. Temmink 


\section{Abstract}

Aquatic worms have great potential to be used as a sustainable fish feed when mass produced economically using clean (no pollutants or pathogens) and low value waste streams from e.g. food industries. In this study freshwater worms (Lumbriculus variegatus) were fed with various waste streams and by-products from different bacterial, animal and plant origins. A standardized test setup was used to compare the influence of 26 different diets at high food levels on worm growth, reproduction and fatty acid content and profile of $L$. variegatus. Diets that consisted of single cell biomass from bacterial or plant origin with high protein (carbon to nitrogen $(C / N)$ ratio $<8.8$ ), high phosphorus (C/P < 50) and low total ammonia nitrogen (TAN) $(<20 \mathrm{~g} \mathrm{~N} / \mathrm{kg}$ ) resulted in the highest growth rates and produced vital worms without any signs of mortality. Besides the experimental $\mathrm{C} / \mathrm{P}$ ratio of the diet worm conditions related with the difference between test and pre-culture conditions and the worm start weight, all seem to be of influence on total fatty acids (FA) content of the final worm biomass but this needs further investigation. The growth potential of a diet rich in protein and $P$ depends on how much TAN is associated with the diet. This factor can potentially be more controlled in the future by blending different food sources. Worms seem to have a distinct and very stable FA composition irrespective of the diet's FA composition. Worms are rich in polyunsaturated fatty acids (PUFAs) including several $\omega 3$ and $\omega 6$ FAs and relative high levels of $\mathrm{C} 18$ and C20 PUFAs which makes them suitable as fish feed for especially freshwater fish. 


\subsection{Introduction}

\subsubsection{The future need for proteins}

World food production is facing the challenge of feeding over 9 billion people by the year 2050 (Godfray et al., 2010). This results in a high pressure on natural food resources, risking severe overexploitation of natural ecosystems. Combined with a major shift in human diets towards consumption of more animal products (Makkar et al., 2014), this will create a rising demand for livestock feeds. Already over $75 \%$ of the natural fish stocks worldwide are fully exploited or overexploited (Miller et al., 2008). The demand for resources is most obvious in the aquaculture sector, which heavily depends on fish oil/meal (FO/FM) from wild fish (Tacon and Metian, 2008). With an annual growth of more than $6 \%$ during the 2000 s aquaculture is one of the fastest growing food production sectors worldwide (Msangi et al., 2013).

\subsubsection{Aquatic worms as sustainable fish feed}

Prices for FO/FM are rapidly rising and aquaculture feed producers already are addressing the need for more sustainable feed solutions. Although partial replacement of FO/FM by plant based ingredients and algae can lower environmental impacts, it is not always clear whether plant based proteins and oils are more sustainable than FM/FO because of the resources that are consumed and the waste emissions generated during the production and transport of these ingredients (Draganovic et al., 2013). Also the presence of anti-nutritional factors such as protease inhibitors, potential inflammation of the fish digestive tract and decreased palatability of most plant meals prevent full use in most aquaculture diets (Henry et al., 2015).

Alternatives for FM/FO could be insects, which can be harvested as a plague animal or can be reared on low quality organic waste (Van Huis et al., 2013). Insects are a natural diet for most freshwater and marine fish and are rich in proteins, lipids, vitamins and minerals. They often have a small ecological footprint because they feed on low value organic residuals like detritus and leaf litter (Henry et al., 2015). Similarly, freshwater worms of the species Lumbriculus variegatus (Oligochaeta, Lumbriculidae, common name blackworms, abbreviated as LV) cultivated on low quality but safe organic waste streams have been suggested as a suitable replacement of FM (Elissen et al., 2015). In comparison with terrestrial insects they seem richer in polyunsaturated fatty acids (PUFAs) (Elissen et al., 2015) and can easily be cultured on suspended solids in waste streams. 


\subsubsection{Lumbriculus variegatus}

Based on its fatty acid (FA) and amino acid (AA) profiles it has been concluded LV is an excellent fish feed. It performs as good as, or even better than, regular fish feeds in terms of fish growth and health (Mount et al., 2006). The average composition of Lv when fed with bio solids or commercial fish feeds on a dry weight (DW) basis is 62-66 \% protein, 11-25\% lipid and 7-12 \% FAs (Elissen et al., 2010; Hansen et al., 2004).

The FA profile of $L v$ is comparable to that of other live freshwater feeds like Tubifex tubifex and chironomid larvae. Their profiles all contain high levels of polyunsaturated fatty acids (PUFAs) and an $\omega 3: \omega 6$ ratio below 1 (Elissen et al., 2015). In general $w 3: \omega 6$ ratios are higher in FM than in most freshwater invertebrates due to $w 3$ rich plankton consumption by marine fish (Kainz et al., 2004). Also, higher percentages of PUFAs (as percentage of total FAs) have been observed in Lv than in their feeds, indicating bioaccumulation of PUFAs (Elissen et al., 2015). A high PUFA content may be beneficial for growth, development and the prevention of pathologies in salmon parr (Bell et al., 1994). In line with other freshwater worms, odd and branched-chain FAs (OBCFA), typical for bacteria, appeared in Lv, indicating ingestion of bacteria by Lv and by freshwater worms in general (Torres-Ruiz et al., 2007).

Lv potentially can be cultured on a variety of natural and food industrial organic waste streams (Elissen et al., 2015). For example, they can be applied for processing of municipal waste sludge, which results in a significant reduction and compaction of the sludge (Elissen, 2007; Emamjomeh et al. , 2017; Hendrickx, 2009). However, in order to replace FM by $L v$, it is necessary to produce them on safe waste streams such as by-products from food industries and aquaculture (fish faeces) to prevent potential transfer of unwanted compounds such as organic micropollutants, pathogens and heavy metals. To produce worm biomass on a large scale it is important to evaluate growth performance and biomass quality of the worms on different by-products.

Worm growth, reproduction and quality (e.g. FA profiles) of worms fed with different waste streams from food industries were therefore studied using an agar based worm food test as proposed by Laarhoven et al. (2016b). Terrestrial matter differs greatly in chemical composition from aquatic matter, with a larger fraction of refractory compounds and a higher $\mathrm{C} / \mathrm{N}$ ratio, resulting in it being a lower-quality food source for invertebrates (Allan, 1995). However, fungal and bacterial breakdown and conversion can reduce the $\mathrm{C} / \mathrm{N}$ ratio of the diet, improving its nutritional quality (Suberkropp, 2001) and improving accessibility of the nutrients to aquatic worms. In this publication we describe worm growth performance, FA content and macro composition on diets of different origin. Food by-products vary widely in chemical composition due to their origin (agriculture, dairy, meat sector, aquaculture), processing (grinding, boiling), fractionation (sieving, decanting), secondary treatment (fermentation, bacterial conversion), storage (frozen, cooled, 
dried) and preservation (salt, acidified, preservatives). It will be investigated how FA composition of the by-products influences the worm's FA composition. The results will be used to define criteria for selection of waste streams for mass production of LV.

\subsection{Materials and methods}

\subsubsection{Experimental design}

Three experiments (Exp. 1, 2, 3), similar in design and procedure, were performed to test the worm diets of Table 5.1. To detect differences between the three experiments a standard diet (Tetramin ${ }^{\mathrm{TM}}$ ) was used as an internal control. A standardized test setup was used that was described in detail by Laarhoven et al. (2016b).

\subsubsection{Standardization of test diets}

Several diets (Table 1) of vegetable, animal, bacterial or mixed origin were collected from local producers and retailers and, with the exception of Chlorella vulgaris powder, were all standardized by freeze drying (Modulyo freeze dryer, Edwards High Vacuum International) and ground to pass through a 200 micron screen. The sieved fraction $(<200 \mu \mathrm{m})$ is suitable for worm ingestion (Laarhoven et al., 2016b). The powders were stored dry at room temperature in closed vials until use in the tests and for macro chemical analyses (dry weight (dw), ash, Chemical Oxygen Demand (COD), N, Total Ammonia Nitrogen (TAN), C, P and Fe) and FA analysis) (Laarhoven et al., 2016a). Diets of bacterial origin were bacterial cultures growing on wastewaters from different industries (sludges), further referred to as bio solids. Bio solids from sewage treatment were collected from two small scale membrane bioreactors with a sludge retention time (SRT) of 12 hours or 28 days.

Protocols for determination of worm biomass and number, food dosing to the test beaker, system configuration, replacement of artificial sediment, worm handling, initial worm selection and chemical analyses of diets and worm biomass were described in detail by Laarhoven et al. (2016a). Instead of 56 days mentioned in the standard protocol, the diets were tested in duplicate for a period of 28 days and no additional compounds such as nutrients or $\mathrm{pH}$ buffers were added. At the start of the protocol 50 fully developed worms were selected for each test beaker. Relative growth rate (RGR in \%/d) was defined as the average daily change in (wet) worm weight relative to the initial weight. Relative reproduction rate (RRR in \%/d) was defined as the average daily change in worm number relative to the initial number. Growth and reproduction were both calculated using only untransformed initial and final values for the first day $(\mathrm{t}=0)$ and the final day $(\mathrm{t}=28)$. 


\subsubsection{Release of total ammonium nitrogen (TAN)}

As high levels of ammonium influence worm growth in a negative way (Laarhoven et al., 2016b), release of TAN by all diets was measured by suspending $100 \mathrm{mg}$ dw into $200 \mathrm{ml}$ demi water while stirring until the entire sample was fully hydrated and suspended. It was left for 24 hours at room temperature, after which an aliquot was taken while stirring, and subsequently centrifuged. The supernatant was used for colorimetric determination of TAN using a salicylate colour agent. Further detection was by standard method for ammonium determination (NEN-ISO, 2002).

\subsubsection{Method used for fatty acid analysis of test diets and worm samples}

Initial and final worm populations for each diet were gut purged for four hours, freeze dried and stored at room temperature in closed vials until further analysis by CCL Nutricontrol B.V., Veghel, The Netherlands. FA profiles of duplicate samples were measured according to standard methods (ISO, 2002) by Soxhlet extraction, saponification, esterification and finally extraction of fatty acid methyl esters (FAMEs) in hexane. FAMEs were quantified by a capillary GC, equipped with a flame-ionization detector (FID) and peak areas were quantified and expressed as $\mathrm{g} / \mathrm{kg} \mathrm{dw}$.

\subsubsection{Analysis of effect of diet origin}

Analysis of variance (ANOVA) was used to test whether worm growth and total fatty acids (TFA) differed between the diets. Separate ANOVAs were performed to test for differences in RGR, RRR or TFA of the worms. The diet origin was used as an explanatory factor in these analyses. Prior to the ANOVAs, the assumptions on homogeneity of variance and normality were checked using Levene's test and Shapiro-Wilk's test respectively and this confirmed that ANOVA could be applied to the data. Tukey's honest significant differences test was used as a post-hoc test to determine which diets differed from each other. In the analysis of worm TFA content, duplicated measurements of the TFA content of worms from the same beaker were used as independent replicas. The bio solids (animal) diet was excluded from the analysis of the effect of diet composition on worm TFA content, because only a single measurement of worm TFA content was available for this diet.

\subsubsection{Analysis of effect of diet composition}

Linear regression was used to analyse the effect of diet composition on worm growth (both RGR and RRR) and TFA content. In these regression models, RGR, RRR or total fatty acids of the worms were used as response variables. Separate models were fitted, each containing one of the diet composition variables as the only explanatory variable. The diet composition variables that were analysed included $\mathrm{C} / \mathrm{N}, \mathrm{C} / \mathrm{P}$ and N/P ratios, TFA content, sum of all monounsaturated 
fatty acids (MUFAs), sum of all PUFAs and sum of trans FAs. The $R^{2}$, F-value and p-value were obtained from the regression models to quantify the correlation between the three response variables and each of the diet composition variables. Multiple regression models, containing more than one diet composition variable were also tested, but no relevant relations were found with additional explanatory variables.

Preliminary analyses showed that growth (both RGR and RRR) in experiment 1 was slower than in experiments 2 and 3 . This difference between the experiments could therefore not be explained by the composition of the diet but was probably due to a difference in worm start weight or differences in worm condition. For this reason, experiment 1 was excluded from the analysis of the effect of diet origin and diet composition on worm growth and TFA content. R version 3.1.3 (Team, 2015) was used for the ANOVA and regression analyses.

\subsubsection{Multivariate analysis using FA composition of diets and worms}

Multivariate analyses were performed with absolute and relative FA concentrations of diets and worms (start and final values). Preliminary Detrended Correspondence Analyses with data transformed using $\log (x+1)$ for absolute FA content showed that the lengths of gradient were relatively short $(<2.3)$ and therefore the linear response model was regarded as appropriate (Braak and Šmilauer, 2012). Therefore, Principal Component Analyses (PCA) were executed on the absolute FA concentrations of diets and worms (start and final values) with $\log (x+1)$ transformation and on the relative FA concentrations using the program CANOCO version 5.0 (Braak and Šmilauer, 2012) and invoking the option 'centering by species'.

\subsection{Results \& Discussion}

The total start wet weight of the worms in Exp. 1 (667 $\pm 4 \mathrm{mg}$ ) was much higher than in Exp. 2 and $3(513 \pm 20$ and $430 \pm 16 \mathrm{mg}$, respectively). Comparing the control diets (Tetramin) between the three experiments showed that Exp. 1 resulted in much lower RGR and RRR values than Exp. 2 and 3 while for the latter two experiments the results were comparable. To study the effect of diet composition on RGR and RRR, therefore only the results from Exp. 2 and 3 were used. For investigating the effect of food composition on worm FA content and composition the data from all three experiments could be used. 


\subsubsection{Effect of diet origin on growth}

Significant differences in RGR were observed between the 19 diets of Exp. 2 and 3 (Anova $F(17,19)=120.54, p<0.0001$ ) (Fig 5.1). Diets that consisted of single cell biomass of bacterial origin gave more than $3 \%$ growth, and were performing as good as or even better than the control diet (approximately $3.5 \%$ growth). With $3.2 \%$, growth is similar to the performance on secondary sludge from the potato starch processing industry (Laarhoven et al., 2016b). The only two exceptions were the bio solid diets from the animal and potato industries, with significantly lower growths of 1.54 and $0.49 \%$, respectively. Relatively high levels of toxic ammonium of 28.7 $\mathrm{g} / \mathrm{kg}$ were measured for the animal bio solids (as defined by the custom method in this study), which probably explains these low growth rates. Also abnormal high levels of $141 \mathrm{~g} \mathrm{Fe} / \mathrm{kg}$ in the potato bio solids (Table 1), resulting from the addition of iron salts to these solids to enhance flocculation, had this effect. The other diets resulting in less growth than the control diet were all based on multicellular biomass of vegetable or animal origin, with the exception of the poultry blood diet.

Another exception was observed for the C. vulgaris diet. Even though we cannot directly compare the growth rates of Exp. 1 with those of Exp. 2 and 3, it is remarkable that the C. vulgaris diet of Exp. 1 resulted in a much higher growth rate $(1.42 \%)$ than the control diet $(0.81 \%)$. In contrast to the observation that only diets with single cell biomass of bacterial origin induce high growth rates, this indicates that these are not necessary to induce a high growth rate.

Gray starch, potato pulp, pig gut slime and root tips gave negative growth. Gray starch, potato pulp and root tips had very low protein levels, which suggets thisis caused by protein deficiency. The lack of growth on pig gut slime could not be explained based on the (known) composition alone.

Table 5.1 Composition of the diets and worm growth performance on these diets. Ash, Chemical oxygen demand (COD), Nitrogen (N), Total ammonium nitrogen (TAN), Carbon (C), Phosphorus (P), Iron (Fe) and Total fatty acids (TFA) are all expressed as $\mathrm{g} / \mathrm{kg} \mathrm{dw}$. Relative standard deviation for $\mathrm{COD}$ and $\mathrm{Fe}<3.5 \%$, for $\mathrm{dw}$, ash, $\mathrm{C}, \mathrm{N}$ and $\mathrm{P}<1.8 \%$, for TFA $<5 \%$. Growth (RGR) and reproduction (RRR) rates \pm standard deviation (between brackets), expressed in \%/day. Origin; (V)egetable, (A)nimal, (B)acterial, (M)ixture, (*) contains yeast. 


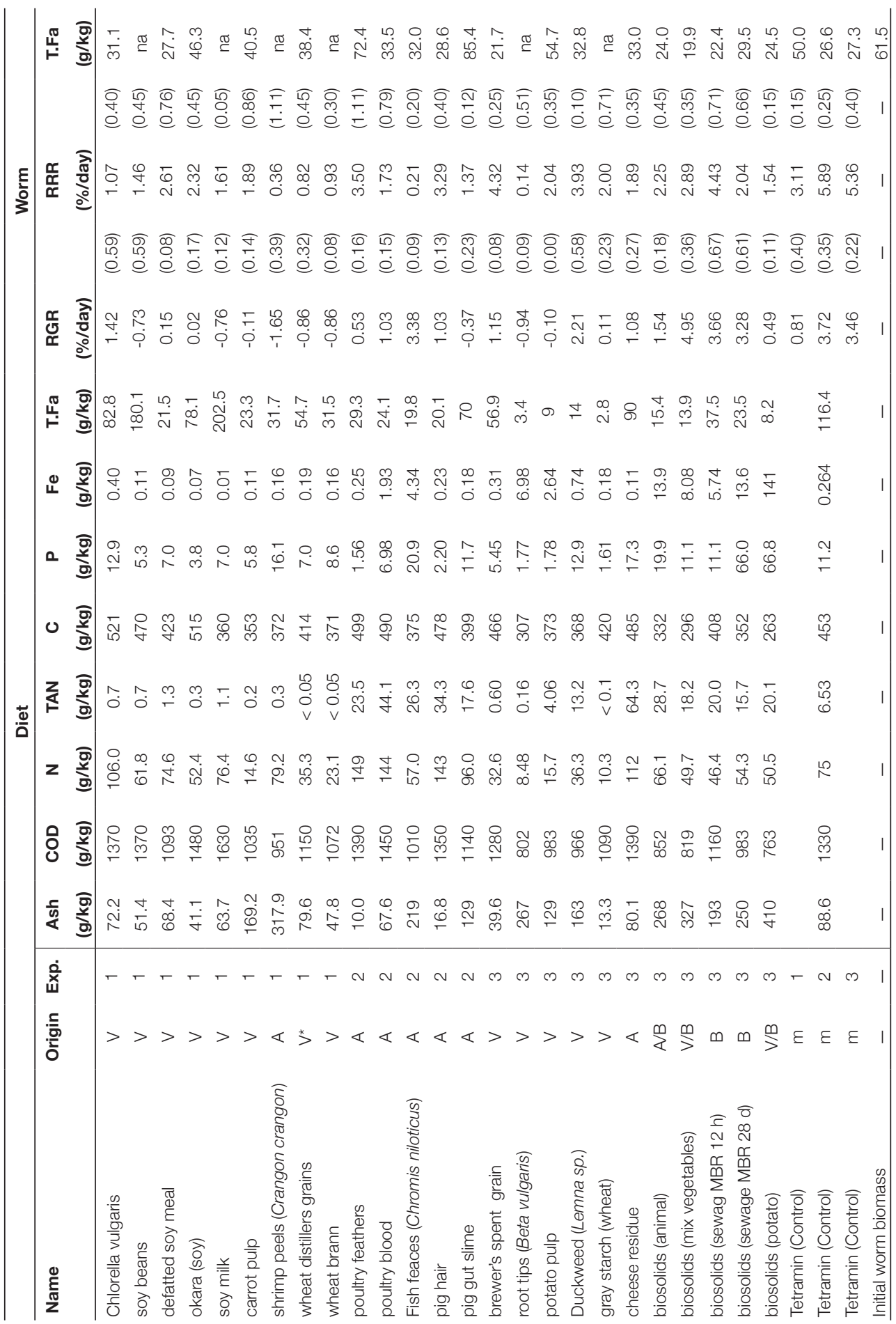




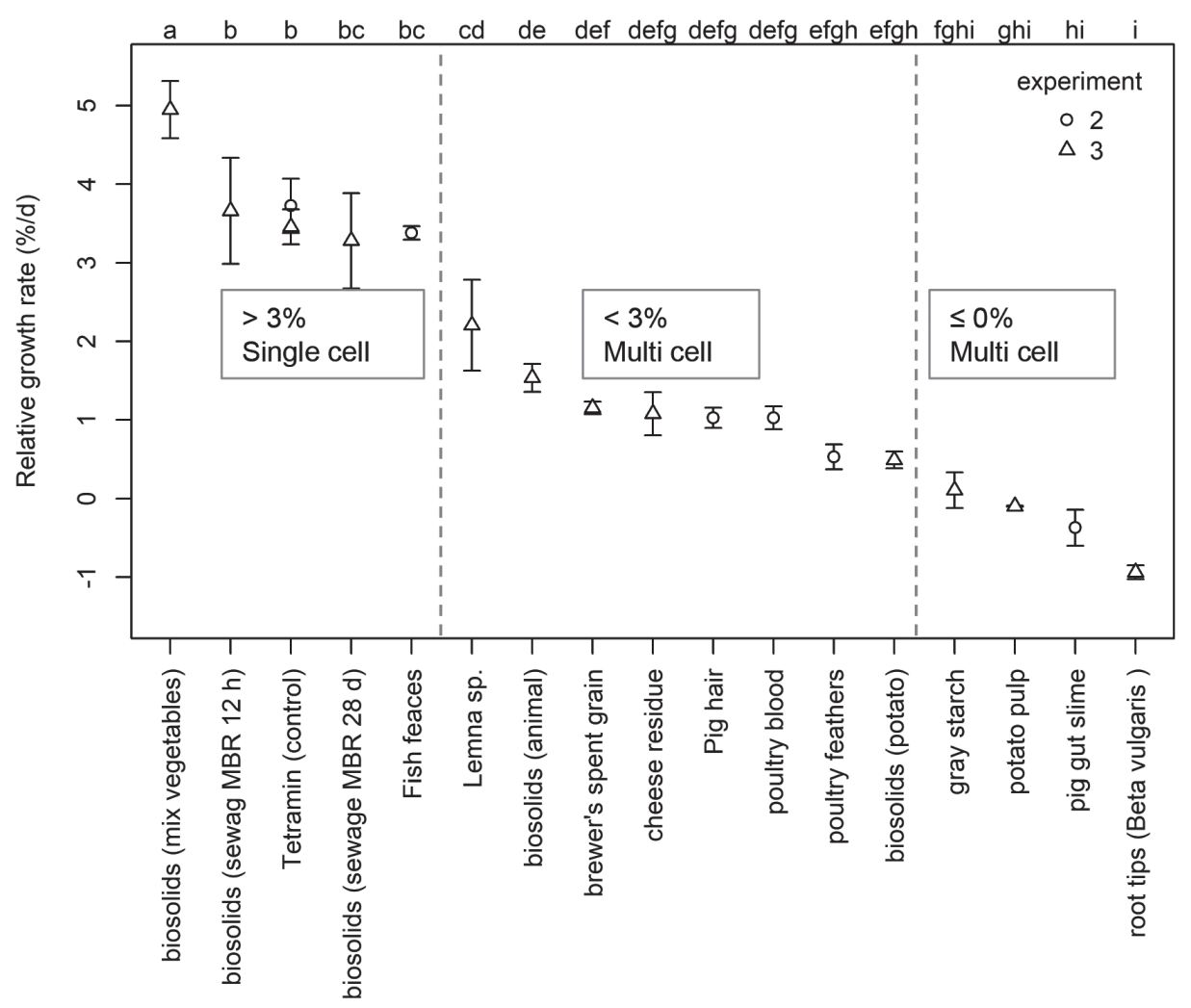

Figure 5.1 Relative worm growth rates (RGR) per diet in Exp. 2 and 3. Diets are sorted according to descending RGR's. Homogeneous subsets from the Tuckey's HSD posthoc test are indicated with letters at the top. For each diet the average \pm SD is shown. Groups on the basis of RGR and single either multi cellular diet composition is indicated.

\subsubsection{Effect of diet origin on reproduction}

Fig 5.2 shows the RRR of the diets. To allow a comparison with the RGR, similar to Fig 5.1 the diets in this figure were sorted according to descending RGR's. The variation in reproduction within and between diets (between 0 and $6 \% / d$ ) (Anova, $F(17,19)=79.62, p<0.0001$ ) was much larger than the variation in growth rates (Fig 5.2). It seems that reproduction was not directly related with growth and the diets induced different rates of reproduction.

Fast growth combined with slow reproduction as well as combinations of slow growth combined with fast reproduction were observed. This resulted in worm populations with variable average individual worm weights. 
Only diets that induce growth in combination with reproduction are suitable for continuous production of worm biomass. Therefore gray starch, potato pulp, pig gut slime and root tips cannot be used. Also C. vulgaris and fish faeces exhibited very low reproduction rates, while their RGR was high. This was believed to be a temporary effect caused by a shift towards a larger specific individual worm weight. It is known that the individual worm weight is substrate specific. In general worms cultured on waste sludge are larger than those grown on fish food and other substrates (Conrad et al., 2002; Gnaiger and Staudigl, 1987a). It is expected that reproduction will increase once the maximum worm size is achieved, necessary to induce architomy. Which specific nutritional factors control worm size remains unknown.
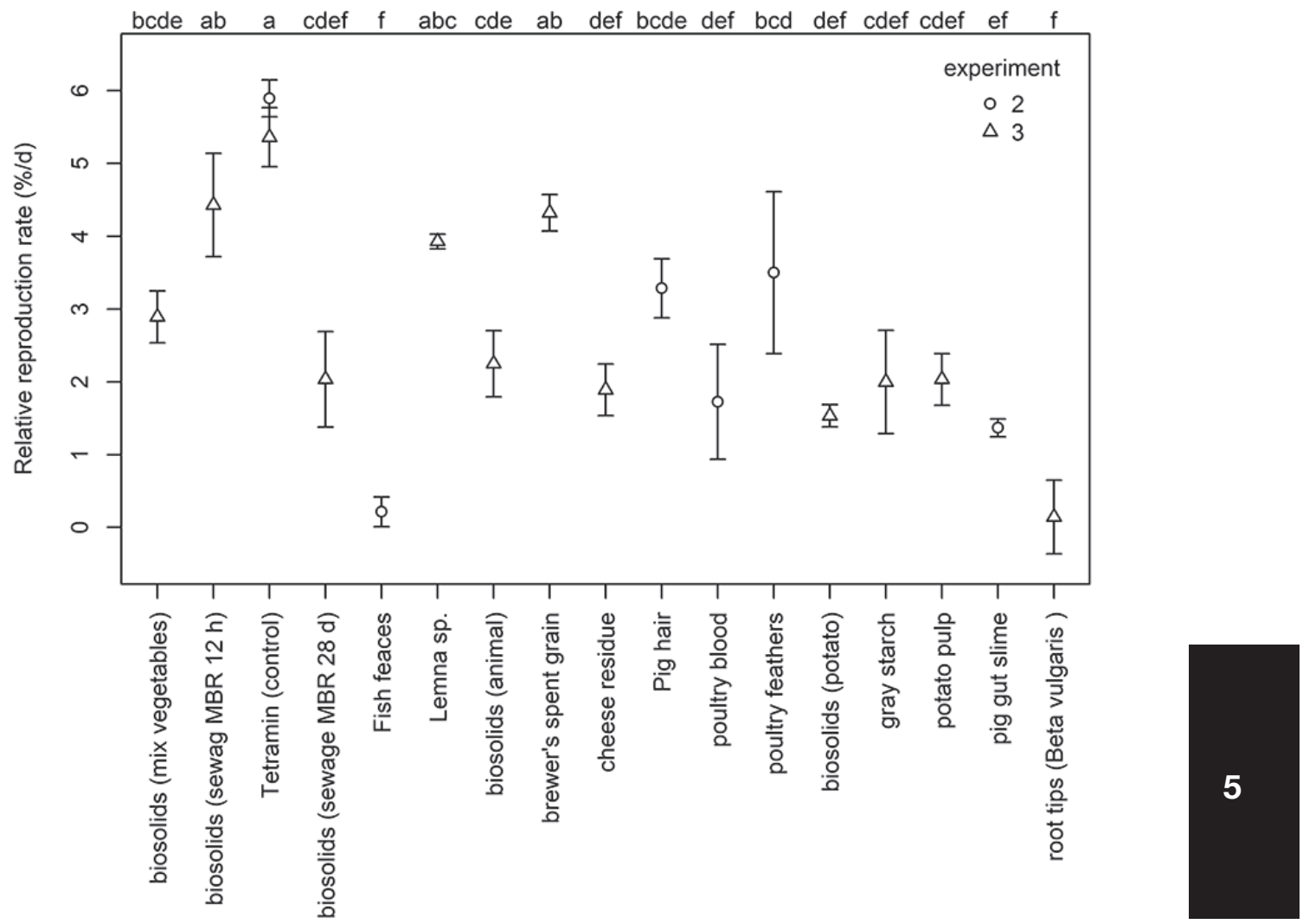

Figure 5.2 Relative worm reproduction rate (RRR) per diet for Exp. 2 and 3. Similar to Fig 5.1 the diets are sorted according to descending RGR's. Homogeneous subsets from the Tuckey's HSD posthoc test are indicated with letters at the top. For each diet the average $\pm S D$ is shown. 


\subsubsection{Effect of diet composition on growth}

A few studies (Lawson et al., 1984; Vos et al., 2000) indicated that growth of benthic invertebrates is stimulated at high food levels with high N, P and lipid contents of the diet and low C/N and C/P ratios. This supports the finding of the present study. Multiple linear regressions showed that growth was mainly explained by the $\mathrm{N}$ and $\mathrm{P}$ content and to a lesser extent by the FA content of the diet (S 5.1). Together, the C/N and C/P ratios could explain $49 \%$ of the growth of LV.

Also for other benthic consumers a low C/P ratio in the diet enhances their growth and reproduction (Frost et al., 2002). As most test diets contained relatively high (and thus probably sufficient) levels of protein $(\mathrm{N})$, it is probably the $\mathrm{P}$ content that ultimately determines the potential growth rate on a diet. This was supported by the C/P ratio being the most informative of all variables and ratios, explaining $29 \%$ of the total variation observed in growth among all diets of Exp. 2 and $3(F(1,34)=14.13, p=0.0006)$. Growth rates above $2 \% / d$ only occurred below C/P ratios of 50, whereas poor growth generally took place over a wider range up to ratios of 320 . This indicates that $\mathrm{P}$ limits worm growth at $\mathrm{C} / \mathrm{P}$ ratios higher than 50 (Fig 5.3).

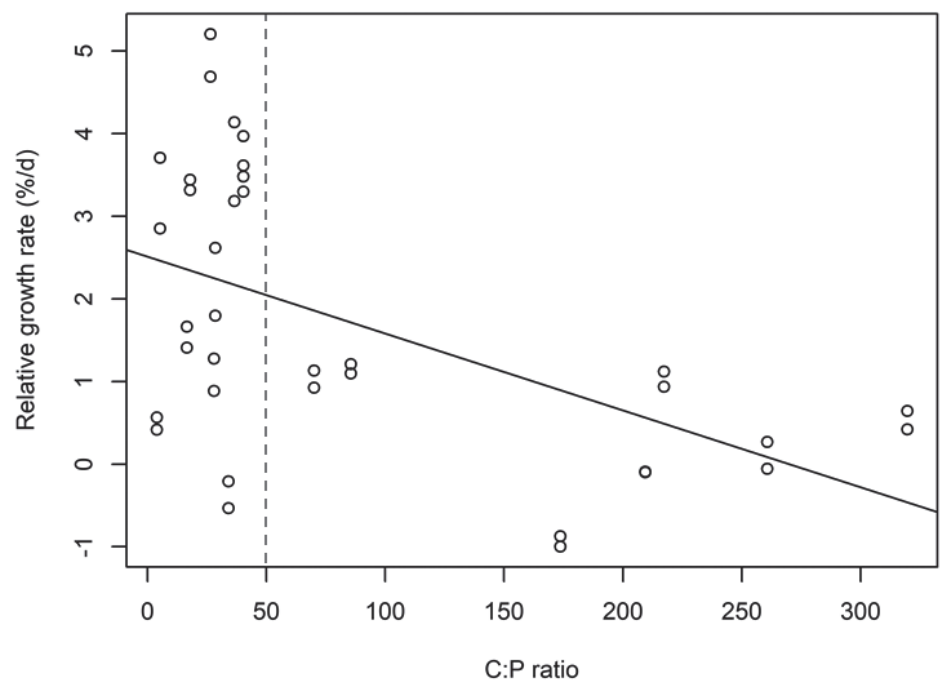

Figure 5.3 Relative worm growth rate (RGR), plotted against C/P ratio of the diet. The solid line shows the effect of $\mathrm{C} / \mathrm{P}$ ratio estimated by the regression model. The vertical dotted line divides the plot in area's with a RGR $>2 \% / d$ and an area with much lower RGR values.

A C/N ratio between 6.0 and 8.8 induced high growth rates (>2\%/d) and this supports previous findings on the effect of the $\mathrm{C} / \mathrm{N}$ ratio on Lv growth (Laarhoven et al., 2016a). A C/N ratio below 4 or above 15 resulted in much lower growth rates. As Lv is believed to rely mainly on proteins 
for energy and growth (Laarhoven et al., 2016a), diets with a C/N ratio higher than 15 probably were protein deficient. Poor growth on a $\mathrm{C} / \mathrm{N}$ ratio below 4 probably can be related to elevated TAN levels in such diets, which were all of animal origin (Table 5.1). This is in agreement with the observation that TAN has a strong negative (toxic) effect on Lv growth (Hendrickx et al., 2009).

\subsubsection{Effect of diet composition on reproduction}

A positive effect on reproduction was best explained by the total FA content of the diet (Fig 5.4) $(F(1,34)=16.60, p=0.0003)$. Overall, higher reproduction rates were observed with a higher dietary FA content, which explained $33 \%$ of the variation in reproduction. Multiple linear regressions (Supplement 5.2) indicated that total PUFAs as an explaining variable resulted in a stronger correlation. However, this had to be rejected because it was too much dependent on only two of the diets with an extremely high level of PUFAs, i.e. Tetramin (control, Exp. 2 and 3) and brewer's spent grain (Exp. 3).

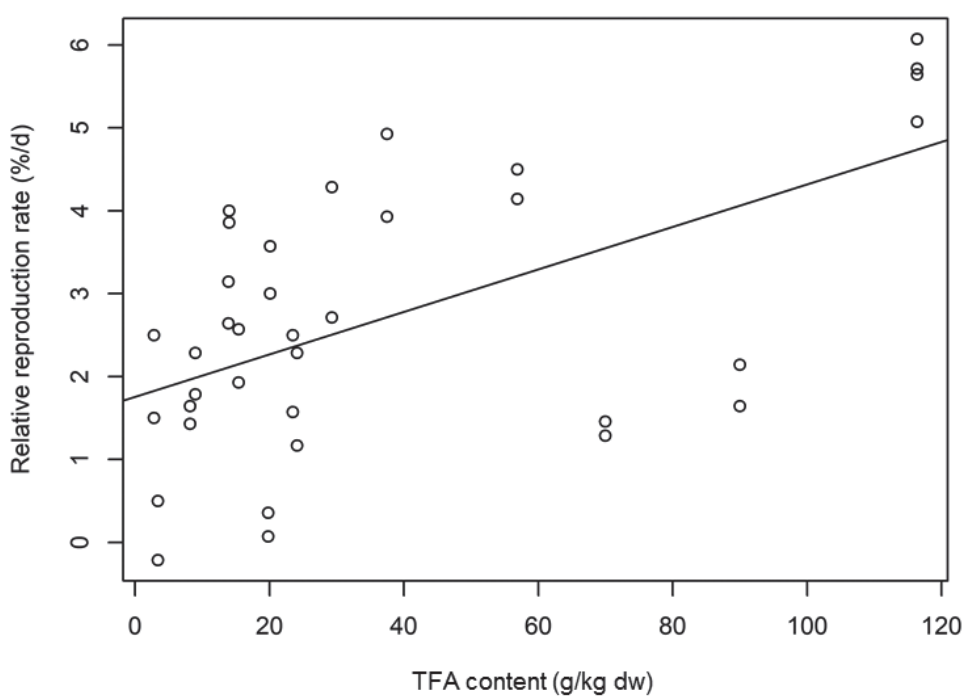

Figure 5.4 Relative worm reproduction rate (RRR) plotted against TFA content. The line shows the effect of TFA estimated with the regression model.

\subsubsection{Effect of diet FA content on worm growth and worm's FA}

There were large and significant differences in worm TFA content in Exp. 2 and 3 (Anova, $F(14,16)=436.6, p<0.0001)$. The TFA content of the worms seemed to be affected by the C/P ratio of the diet, the test and culture conditions (e.g. feed dosing, recirculating water, and worm 
supporting material) and start weight of the worms. The best (positive) correlation was found between the TFA content of the worms and the C/P ratio of the diet (Supplement 5.3), explaining $23 \%$ of the variation $(F(1.29)=8.45, p=0.0069)$.

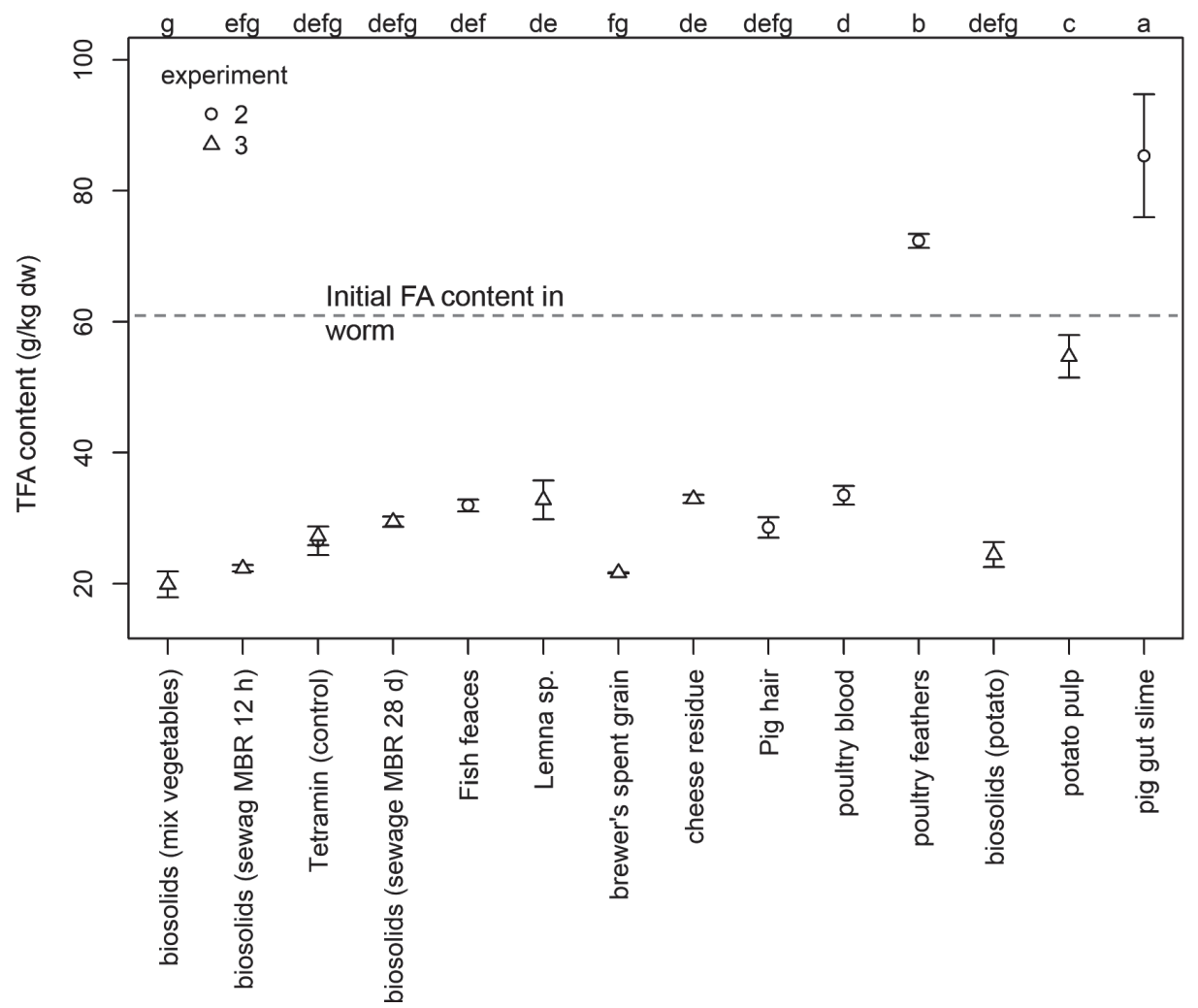

Figure 5.5 Total worm FAs (g/kg dw worm) per diet. Similar to Fig 5.1, the data are sorted according to descending RGR. Homogeneous subsets from the Tuckey's HSD posthoc test are indicated with letters at the top. For each diet average $\pm S D$ is shown. The horizontal dotted line represents the initial worm biomass FA content of $61.5 \mathrm{~g} / \mathrm{kg} \mathrm{dw}$. Bio solids (animal) was excluded due to lack of duplicate analysis.

Worm FA levels below $33 \mathrm{~g} / \mathrm{kg}$ dw were more common with diets giving high and moderate growth rates (Fig 5.5). Pig gut slime, poultry feathers and potato pulp resulted in a worm TFA content similar or higher than in the initial worms $(61.5 \mathrm{~g} / \mathrm{kg} \mathrm{dw})$, but also gave a negative or very low RGR (Fig 5.1). Whether the increased TFA content obtained for these diets also reflects an increase in the absolute amount of FA in the worms is questionable. Worms with a high FA content were losing weight over time and the increase in FA content may have been caused by a weight loss of other body components such as proteins and carbohydrates. 
Undefined differences between culture and test conditions were of influence on the final FA content of the worms. This can be deduced from tests with the control diet, which all resulted in a reduction of the FA content compared to initial FA content. The control diet in Exp. 1 resulted in a higher worm TFA than measured in Exp. 2 and 3 (Table 5.1). To further investigate the effect of culture and test conditions on TFA content more controlled experiments (on these variables) are required as well as additional worm biomass analyses for components such as lipids, proteins and carbohydrates.

\subsubsection{Does the diet change worm FA composition?}

FA composition and content vary strongly in all diets and worm biomass as shown by Pearson correlation test of $0.925(p<0.000, n=43$ ) (Supplements 5.4 and 5.5). Ordination using both content and composition shows a clear distinction between worms and diets and only a weak distinction between diets of different origin (Fig 5.6A and 5.6B). A second ordination with percentage FA data showed a much clearer separation between diet origins (vegetable, animal and bacterial) and worm biomass (Fig 5.7A and 5.7B). An obvious correlation between individual diet FA and the worm's FA composition was not detected, except for the bacterial marker iso-C15:0. Apparently, the FA profile of the worms was not determined by the FA profile of the diet.

The differences in FA between diets and worms could be attributed to certain specific FAs. The highest FA levels in the diets were observed for C16:0, unsaturated C18 FAs and C4:0 (Supplement 5.4), the highest levels of worm FAs for C20:2n6, C20:1n11, C18:0 and C18:1n9 (supplement 5.5). The sum of these four FAs contributes 33-45\% to the worm TFA content, which is considerably more than in the corresponding diets (with the exception of okara and pig gut slime). As was mentioned before, the increased level of these FAs does not necessarily imply a specific uptake from the diets because during the tests the worms lost weight.

The horizontal distribution of feed and worms in Fig 5.6A seems to be mainly based on FA chain length and the level of FA saturation since worm biomass and diets positioned towards the left are more abundant in medium odd-chain and branched saturated fatty acids (Fig 5.6B). This matches with the composition of bacterial diets (Kharlamenko et al., 1995). If they are more positioned towards the right they contain more PUFAs. Especially the bacterial marker iso-C15:0 is shared by bacterial diets and worms growing on these diets, suggesting an enhanced uptake of this specific FA.

Deviation from the average worm FA composition, observed for the diets Chlorella, carrot peels, wheat distiller's grains, okara and tetramin (Exp.1), can be attributed to differences between the experimental start conditions of Exp. 1 and the other two experiments. This indicates that initial worm size or other start conditions may have had an effect on the FA composition of the worms. 
Deviations from the average FA worm composition for the diets potato pulp, poultry feathers and pig gut slime, were all accompanied by negative growth. This resulted in a FA profile similar to the initial FA composition of worms.

The ordination based on the percentage of each individual FA relative to the TFA content (Fig 5.7A and 5.7B) shows that diets origins and worms can be better distinguished then when absolute FA content expressed in $\mathrm{g} / \mathrm{kg}$ is used. It shows how different the worm biomass is in comparison to the diets. Several short and long chain saturated FAs (C4:0, C5:0, C10:0, C16:0, C22:0, C24:0) are pointing towards the right, and thus were strongly associated with diets of animal origin. Bacterial diets were more associated with several saturated C14 and C15 FAs and diets with a plant origin with PUFAs and highly unsaturated fatty acids (HUFAs) with a chain length between $\mathrm{C} 18$ and C24. Worm biomass is mostly associated with MUFAs and PUFAs with a chain length of C20 and C22, which includes the essential FAs for fish and other vertebrates, eicosapentaenoic acid (EPA)(C20:5n3), docosahexaenoic acid (DHA)(C22:6n3) and arachidonic acid (AA)(20:4n6) (Sargent et al., 1999).

In nature aquatic oligochaetes consume a mix of organic matter from both terrestrial and aquatic origin (e.g. algae, bacteria and fungi) and this is reflected in their FA profile (Torres-Ruiz et al., 2007). The present results contradict the observations of Torres Ruiz et al (2017) since they clearly show a stable worm FA profile and only a minor impact of diet on this profile. Perhaps this can be explained from the relatively short test duration. The low FA content of only 2 to 3 $\%$ in the diets that induced high growth rates, combined with the suspicion that worms mainly use proteins for energy and growth purposes (Laarhoven et al., 2016a), suggests that Lv is not strongly influenced by the FA content of the diet. Little is known about the FA requirements of macroinvertebrates in general, but like most animals they have certain lipid requirements that must be fulfilled. Although the essential FAs for Lv are unknown, a minimal amount of 20:3n$6,20: 4 n-6$ and $20: 5 n-3$ probably is required for biosynthesis of the eicosanoids that play an important role in cell signalling, regulation of reproduction, immune response and ion transport in vertebrates as well as in invertebrates (Heckmann et al., 2008). 


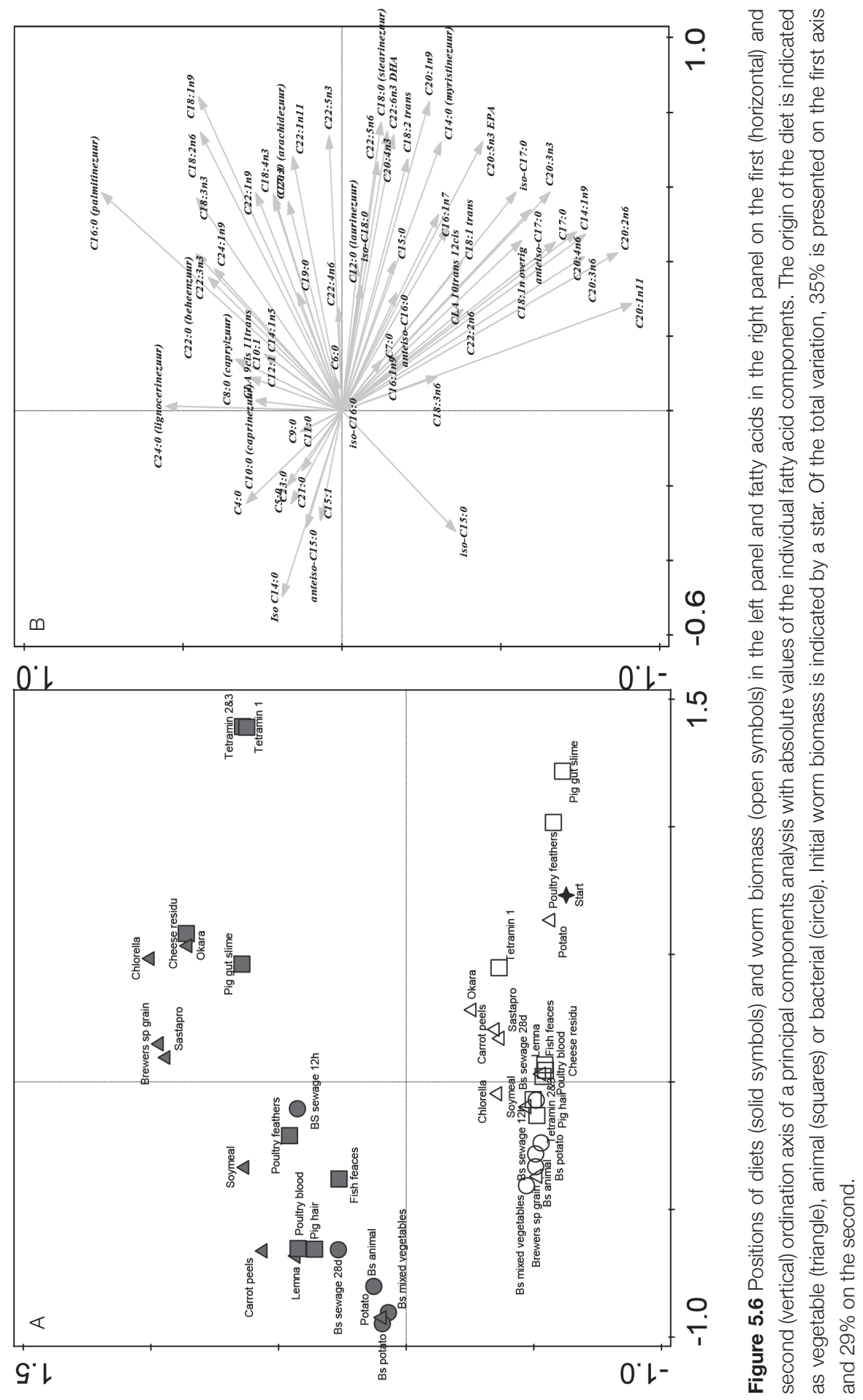






\subsubsection{Suitability of different waste streams for worm production}

The results of this study confirmed that Lv worms can grow on diets of different origin. The highest growth rates were observed for diets containing bio solids originating from vegetable waste or sewage processing. In general, animal, bacterial and plant based diets with more than $40 \mathrm{~g} \mathrm{~N} / \mathrm{kg}(\mathrm{C} / \mathrm{N}$ ratio < 8.8) have a high growth rate potential, providing that TAN levels are not higher than approximately $20 \mathrm{~g}$ TAN/kg dw, and P levels are higher than $12 \mathrm{~g} / \mathrm{kg} \mathrm{dw}(\mathrm{C} / \mathrm{P}<50)$. As not all diets meet these requirements it may be effective to mix different food sources. This also may prevent micro-nutritional limitations or growth impeding factors related with the use of a single food source.

The use of certain animal based sources should be further investigated. Although it is known that protein in animal-based foodstuff is well available for aquatic organisms such as fish (e.g. O. niloticus (Hanley, 1987), this does not necessarily result in a higher growth rate for Lv. Plotting the TAN level in the diet against their total $N$ content (Fig 5.8) shows that diets of different origin (bio solids, vegetable and animal) also have a different TAN level in comparison with their $\mathrm{N}$ content. Only protein rich diets with low ammonium levels $(\leq 20 \mathrm{~g} / \mathrm{kg}$ ) seemed to induce high growth rates, which implies that the application of animal based food sources in worm diets is restricted.

The impact of diet related TAN on growth needs to be further investigated to understand which specific concentration of TAN inhibits worm growth and how it can be counteracted, by e.g. adjusting food origin, food dosing, pre-treatment and worm cultivation conditions (like flow rate and $\mathrm{pH}$ ). For example, food dosing on the basis of protein content and TAN level can prevent conditions in which TAN will inhibit growth. Multiple factors play a role in how much TAN is directly available or released from a diet over time, including bioavailability (digestibility), source, type of processing, initial protein hydrolysis activity and storage (decay). The use of protein and TAN level based selection of food sources can provide a better strategy than the use of COD level based food dosing as was applied in this study and previous studies (Laarhoven et al., 2016a; Laarhoven et al., 2016b). This is further supported by the observation that worms seem to be dominantly reliant on protein for growth and energy use, irrespective of other organic components in their diet. 




Figure 5.8 Total $N$ and TAN level for worm diets (Exp. 1, 2 and 3) categorized by their origin. Feed cheese, and wheat distiller's grains diets were excluded from this figure as they do not belong to any of the plotted sources.

\subsubsection{Suitability of Lv for aquaculture feed applications}

Healthy worms were produced on a wide range of diets, resulting in worms with a very stable FA composition and a high percentage of TFA consisting of PUFAs, including several $\omega 3$ and $\omega 6$ FAs and relative high levels of C18 and C20 PUFA. It can be concluded that worm biomass is an excellent fish feed, in particular for freshwater fish (Bell et al., 1994).

Although worm FAs were rich in PUFAs they contained relatively low absolute FAs level (2-3 \%). Therefore, worms should mainly be considered as a source of protein. Worm biomass cultured on clean and safe waste streams seems to be a very acceptable aquaculture feed and may fully replace fishmeal, especially in freshwater fish feeds. This is based on their PUFA rich FA profile (this study) and AA profile, showing similar levels of lysine, methionine and threonine to fishmeal (Elissen et al., 2010). 


\subsection{Conclusions}

- Diets that consist of single cell biomass from bacterial or plant origin, high in protein $(\mathrm{C} / \mathrm{N}$ ratio $<8.8)$ high in $\mathrm{P}(\mathrm{C} / \mathrm{P}<50)$ and low in TAN $(<20 \mathrm{~g} \mathrm{~N} / \mathrm{kg})$ resulted in the highest growth rate of LV.

- Reproduction was high at a higher TFA content of the diet

- Reproduction varied independent of growth rate

- C/P ratio of the diet, the difference between test and culture conditions and the start weight of the worms all affected the TFA content of the final worm biomass.

- A clear link between the presence of specific individual FAs in the diet and the worm's FA profile could not be detected except for the bacterial marker iso-C15:O.

- Worms have a distinct and stable FA composition in comparison to their diets.

- Diets that are rich in proteins have a large worm growth potential but the amount TAN in the diet can have a strong negative impact on growth.

\section{Acknowledgements}

The authors thank Ernest Mejías Cumplido and Tian Li for their valuable contributions to the experimental work. This study was performed in the cooperation framework of Wetsus, European Centre of Excellence for Sustainable Water Technology (www.wetsus.nl). Wetsus is cofunded by the Dutch Ministry of Economic Affairs and Ministry of Infrastructure and Environment, the European Union Regional Development Fund, the Province of Fryslân, and the Northern Netherlands Provinces. The authors would like to thank the participants of the research theme "Aquatic worms" for the fruitful discussions and their financial support. 


\section{References}

Allan, J.D., 1995. Stream ecology: structure and function of running waters. Springer, Londen, UK.

Bell, J.G., Ghioni, C. and Sargent, J.R., 1994. Fatty acid compositions of 10 freshwater invertebrates which are natural food organisms of Atlantic salmon parr (Salmo salar): a comparison with commercial diets. Aquaculture 128: 301-313.

Braak, C.J.F. and Šmilauer, P., 2012. CANOCO reference manual and user's guide: software for ordination (version 5.0). Biometris Ithaca.

Conrad, A.U., Comber, S.D. and Simkiss, K., 2002. Pyrene bioavailability; effect of sediment-chemical contact time on routes of uptake in an oligochaete worm. Chemosphere 49: 447-454.

Draganovic, V., Jørgensen, S.E., Boom, R., Jonkers, J., Riesen, G. and van der Goot, A.J., 2013. Sustainability assessment of salmonid feed using energy, classical exergy and eco-exergy analysis. Ecological Indicators 34: 277-289.

Elissen, H.J.H., 2007. Sludge reduction by aquatic worms in wastewater treatment with emphasis on the potential application of Lumbriculus variegatus. PhD thesis Thesis, Wageningen University, the Netherlands, Wageningen, $192 \mathrm{pp}$.

Elissen, H.J.H., Hendrickx, T.L.G., Temmink, H., Laarhoven, B. and Buisman, C.J.N., 2015. Worm-it: converting organic wastes into sustainable fish feed by using aquatic worms. Journal of Insects as Food and Feed 1: 67-74.

Elissen, H.J.H., Mulder, W.J., Hendrickx, T.L.G., Elbersen, H.W., Beelen, B., Temmink, H. and Buisman, C.J.N., 2010. Aquatic worms grown on biosolids: Biomass composition and potential applications. Bioresource Technology 101: 804-811.

Emamjomeh, M.M., Tahergorabi, M., Farzadkia, M. and Bazrafshan, E., 2017. A Review of the Use of Earthworms and Aquatic Worms for Reducing Sludge Produced: An Innovative Ecotechnology. Waste and Biomass Valorization: 1-15.

Frost, P.C., Stelzer, R.S., Lamberti, G.A. and Elser, J.J., 2002. Ecological stoichiometry of trophic interactions in the benthos: Understanding the role of C:N:P ratios in lentic and lotic habitats. Journal of the North American Benthological Society 21: 515-528.

Gnaiger, E. and Staudigl, I., 1987a. Aerobic metabolism and physiological responses of aquatic oligochaetes to environmental anoxia: heat dissipation, oxygen consumption, feeding and defecation. Physiological Zoology 60: 659-677.

Godfray, H.C.J., Beddington, J.R., Crute, I.R., Haddad, L., Lawrence, D., Muir, J.F., Pretty, J., Robinson, S., Thomas, S.M. and Toulmin, C., 2010. Food Security: The Challenge of Feeding 9 Billion People. Science 327: 812-818.

Hanley, F., 1987. The digestibility of foodstuffs and the effects of feeding selectivity on digestibility determinations in tilapia, Oreochromis niloticus (L). Aquaculture 66: 163-179.

Hansen, J.A., Lipton, J., Welsh, P.G., Cacela, D. and MacConnell, B., 2004. Reduced growth of rainbow trout (Oncorhynchus mykiss) fed a live invertebrate diet pre-exposed to metal-contaminated sediments. Environmental Toxicology and Chemistry 23: 1902-1911. 
Heckmann, L.H., Sibly, R.M., Timmermans, M.J. and Callaghan, A., 2008. Outlining eicosanoid biosynthesis in the crustacean Daphnia. Frontiers in Zoology 5.

Hendrickx, T.L.G., 2009. Aquatic worm reactor for improved sludge processing and resource recovery. PhD thesis Thesis, Wageningen University, the Netherlands, Wageningen.

Hendrickx, T.L.G., Temmink, H., Elissen, H.J.H. and Buisman, C.J.N., 2009. The effect of operating conditions on aquatic worms eating waste sludge. Water Research 43: 943-950.

Henry, M., Gasco, L., Piccolo, G. and Fountoulaki, E., 2015. Review on the use of insects in the diet of farmed fish: Past and future. Animal Feed Science and Technology 203: 1-22.

ISO, 2002. Animal Feeding Stuffs - Determination of the content of FAtty Acids- Part 2: Gas Chromatographic Method. ISO/TS 17764-2.

Kainz, M., Arts, M.T. and Mazumder, A., 2004. Essential fatty acids in the planktonic food web and their ecological role for higher trophic levels. Limnology and Oceanography 49: 1784-1793.

Laarhoven, B., Elissen, H.J.H., Buisman, C.J.N. and Temmink, H., 2016a. The carbon to nitrogen ratio in isoenergetic wheat based diets controls the growth rate of the aquatic worm Lumbriculus variegatus. Journal of Insects as Food and Feed 2: 225-231.

Laarhoven, B., Elissen, H.J.H., Temmink, H. and Buisman, C.J.N., 2016b. Agar Sediment Test for Assessing the Suitability of Organic Waste Streams for Recovering Nutrients by the Aquatic Worm Lumbriculus variegatus. PLoS ONE 11: e0149165.

Lawson, D.L., Klug, M.J. and Merritt, R.W., 1984. The influence of the physical, chemical, and microbiological characteristics of decomposing leaves on the growth of the detritivore Tipula abdominalis ( Diptera: Tipulidae). Canadian Journal of Zoology 62: 2339-2343.

Makkar, H.P.S., Tran, G., Heuzé, V. and Ankers, P., 2014. State-of-the-art on use of insects as animal feed. Animal Feed Science and Technology 197: 1-33.

Miller, M.R., Nichols, P.D. and Carter, C.G., 2008. n-3 Oil sources for use in aquaculture--alternatives to the unsustainable harvest of wild fish. Nutrition research reviews 21: 85-96.

Mount, D.R., Highland, T.L., Mattson, V.R., Dawson, T.D., Lott, K.G. and Ingersoll, C.G., 2006. Use of the oligochaete, Lumbriculus variegatus, as a prey organism for toxicant exposure of fish through the diet. Environmental Toxicology and Chemistry 25: 2760-2767.

Msangi, S., Kobayashi, M., Batka, M., Vannuccini, S., Dey, M. and Anderson, J., 2013. Fish to 2030: prospects for fisheries and aquaculture. World Bank Report: 102.

NEN-ISO, 2002. 7150-1,Water - Bepaling van ammonium - Deel 1: Handmatige spectrometrische methode.

Sargent, J., Bell, G., McEvoy, L., Tocher, D. and Estevez, A., 1999. Recent developments in the essential fatty acid nutrition of fish. Aquaculture 177: 191-199.

Suberkropp, K., 2001. Fungal Growth, Production, and Sporulation during Leaf Decomposition in Two Streams. Applied and Environmental Microbiology 67: 5063-5068.

Tacon, A.G.J. and Metian, M., 2008. Global overview on the use of fish meal and fish oil in industrially compounded aquafeeds: Trends and future prospects. Aquaculture 285: 146-158.

Team, R.C., 2015. R: A language and environment for statistical computing. R Foundation for Statistical Computing, Vienna, Austria. URL http://www. R-project. org. Accessed (June 25, 2015). 
Torres-Ruiz, M., Wehr, J.D. and Perrone, A.A., 2007. Trophic relations in a stream food web: Importance of fatty acids for macroinvertebrate consumers. Journal of the North American Benthological Society 26: 509-522.

Van Huis, A., Van Itterbeeck, J., Klunder, H., Mertens, E., Halloran, A., Muir, G. and Vantomme, P., 2013. Edible insects: future prospects for food and feed security, 171. BioOne.

Vos, J.H., Ooijevaar, M.A.G., Postma, J.F. and Admiraal, W., 2000. Interaction between food availability and food quality during growth of early instar chironomid larvae. Journal of the North American Benthological Society 19: 158-168. 


\section{Supporting Information}

S 5.1 Effect of diet composition variables on the relative growth rate (RGR)

\begin{tabular}{|c|c|c|c|}
\hline Variable & $\mathbf{R}^{2}$ & F value & $P$ value \\
\hline $\mathrm{C} / \mathrm{P}$ & 0.29 & 14.13 & 0.0006 \\
\hline $\mathrm{C} / \mathrm{N}$ & 0.20 & 8.76 & 0.0056 \\
\hline MUFA absolute & 0.13 & 5.05 & 0.0312 \\
\hline PUFA absolute & 0.09 & 3.33 & 0.0768 \\
\hline Total FA & 0.09 & 3.16 & 0.0845 \\
\hline $\mathrm{N} / \mathrm{P}$ & 0.06 & 2.05 & 0.1618 \\
\hline FA saturated relative & 0.06 & 2.03 & 0.1635 \\
\hline MUFA relative & 0.06 & 2.03 & 0.1636 \\
\hline Ash & 0.05 & 1.89 & 0.1779 \\
\hline Total P & 0.04 & 1.39 & 0.2459 \\
\hline FA trans absolute & 0.04 & 1.29 & 0.2647 \\
\hline FA saturated absolute & 0.02 & 0.78 & 0.3828 \\
\hline Total Fe & 0.02 & 0.61 & 0.4384 \\
\hline FA trans relative & 0.01 & 0.20 & 0.6591 \\
\hline Dry Matter & 0.00 & 0.16 & 0.6953 \\
\hline Total C & 0.00 & 0.13 & 0.7176 \\
\hline TAN & 0.00 & 0.02 & 0.8804 \\
\hline Total N & 0.00 & 0.02 & 0.8968 \\
\hline PUFA relative & 0.00 & 0.01 & 0.9336 \\
\hline COD & 0.00 & 0.00 & 0.9758 \\
\hline
\end{tabular}


S 5.2 Effect of diet composition variables on the relative reproduction rate (RRR)

\begin{tabular}{|c|c|c|c|}
\hline Variable & $\mathbf{R}^{2}$ & $F$ value & $P$ value \\
\hline PUFA absolute & 0.46 & 29.16 & 0.0000 \\
\hline Total FA & 0.33 & 16.60 & 0.0003 \\
\hline MUFA absolute & 0.30 & 14.59 & 0.0005 \\
\hline COD & 0.21 & 8.79 & 0.0055 \\
\hline Total C & 0.18 & 7.49 & 0.0098 \\
\hline FA saturated relative & 0.17 & 7.12 & 0.0116 \\
\hline PUFA relative & 0.17 & 6.96 & 0.0125 \\
\hline Ash & 0.14 & 5.45 & 0.0256 \\
\hline FA saturated absolute & 0.11 & 4.27 & 0.0464 \\
\hline FA trans absolute & 0.09 & 3.25 & 0.0803 \\
\hline $\mathrm{C} / \mathrm{N}$ & 0.08 & 2.87 & 0.0994 \\
\hline TAN & 0.05 & 1.80 & 0.1890 \\
\hline Total Fe & 0.05 & 1.67 & 0.2044 \\
\hline Total P & 0.04 & 1.56 & 0.2202 \\
\hline$N / P$ & 0.02 & 0.75 & 0.3930 \\
\hline Dry Matter & 0.02 & 0.67 & 0.4178 \\
\hline Total N & 0.01 & 0.50 & 0.4864 \\
\hline MUFA relative & 0.01 & 0.43 & 0.5170 \\
\hline FA trans relative & 0.01 & 0.25 & 0.6168 \\
\hline $\mathrm{C} / \mathrm{P}$ & 0.00 & 0.06 & 0.8051 \\
\hline
\end{tabular}


S 5.3 Effect of diet composition variables on the total fatty acid content of worms

\begin{tabular}{|c|c|c|c|}
\hline Variable & $\mathbf{R}^{2}$ & F value & $P$ value \\
\hline $\mathrm{C} / \mathrm{P}$ & 0.23 & 8.45 & 0.0069 \\
\hline $\mathrm{N} / \mathrm{P}$ & 0.18 & 6.23 & 0.0185 \\
\hline Total N & 0.11 & 3.53 & 0.0704 \\
\hline Ash & 0.11 & 3.52 & 0.0709 \\
\hline FA saturated relative & 0.09 & 3.04 & 0.0919 \\
\hline Dry Matter & 0.08 & 2.66 & 0.1136 \\
\hline Total P & 0.07 & 2.03 & 0.1654 \\
\hline FA saturated absolute & 0.05 & 1.45 & 0.2379 \\
\hline Total C & 0.04 & 1.28 & 0.2665 \\
\hline PUFA relative & 0.04 & 1.28 & 0.2680 \\
\hline Total Fe & 0.04 & 1.20 & 0.2830 \\
\hline PUFA absolute & 0.04 & 1.08 & 0.3079 \\
\hline COD & 0.03 & 0.87 & 0.3593 \\
\hline FA trans relative & 0.03 & 0.85 & 0.3631 \\
\hline FA trans absolute & 0.00 & 0.10 & 0.7560 \\
\hline MUFA relative & 0.00 & 0.06 & 0.8103 \\
\hline Total FA & 0.00 & 0.01 & 0.9328 \\
\hline TAN & 0.00 & 0.01 & 0.9404 \\
\hline $\mathrm{C} / \mathrm{N}$ & 0.00 & 0.00 & 0.9472 \\
\hline MUFA absolute & 0.00 & 0.00 & 0.9579 \\
\hline
\end{tabular}



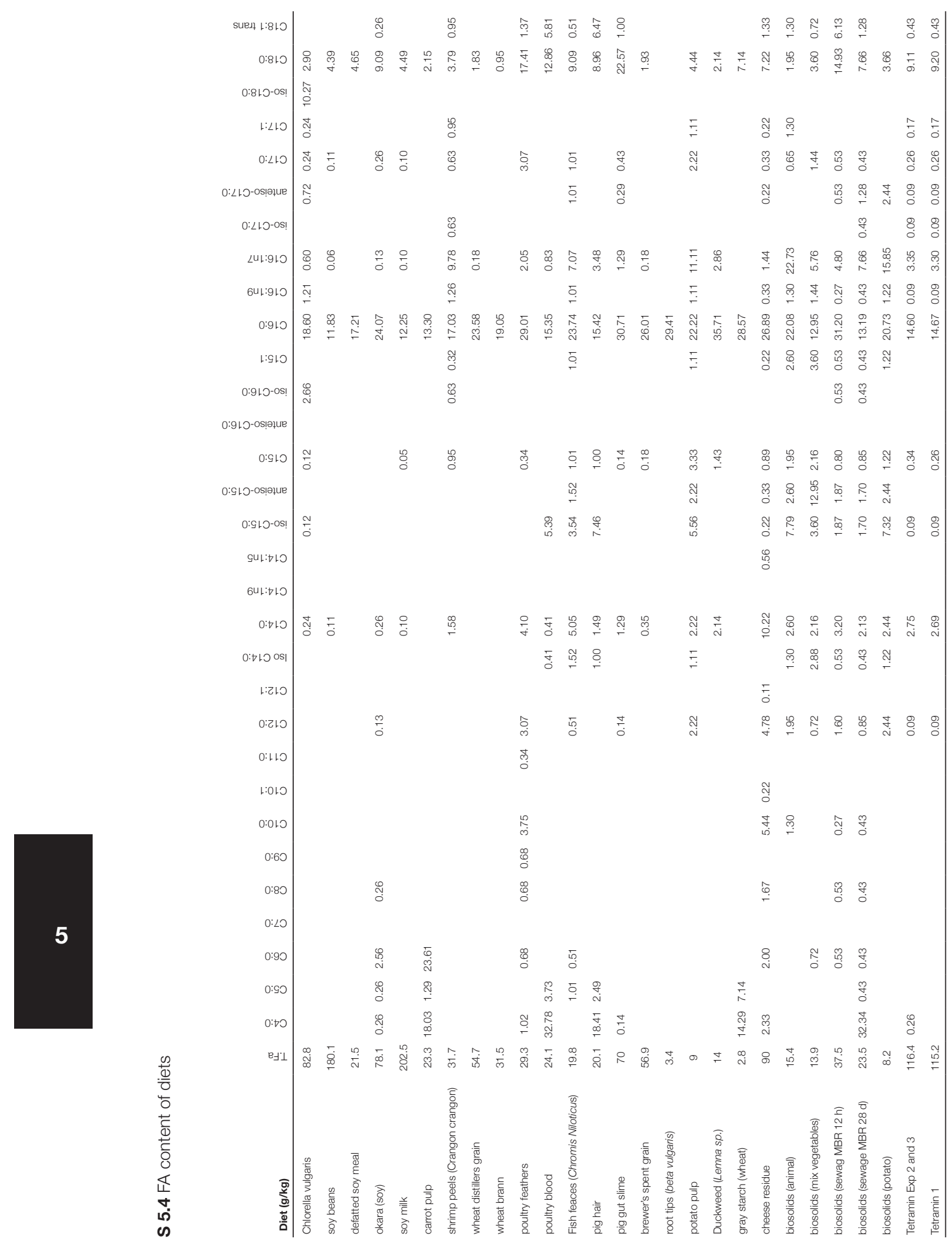

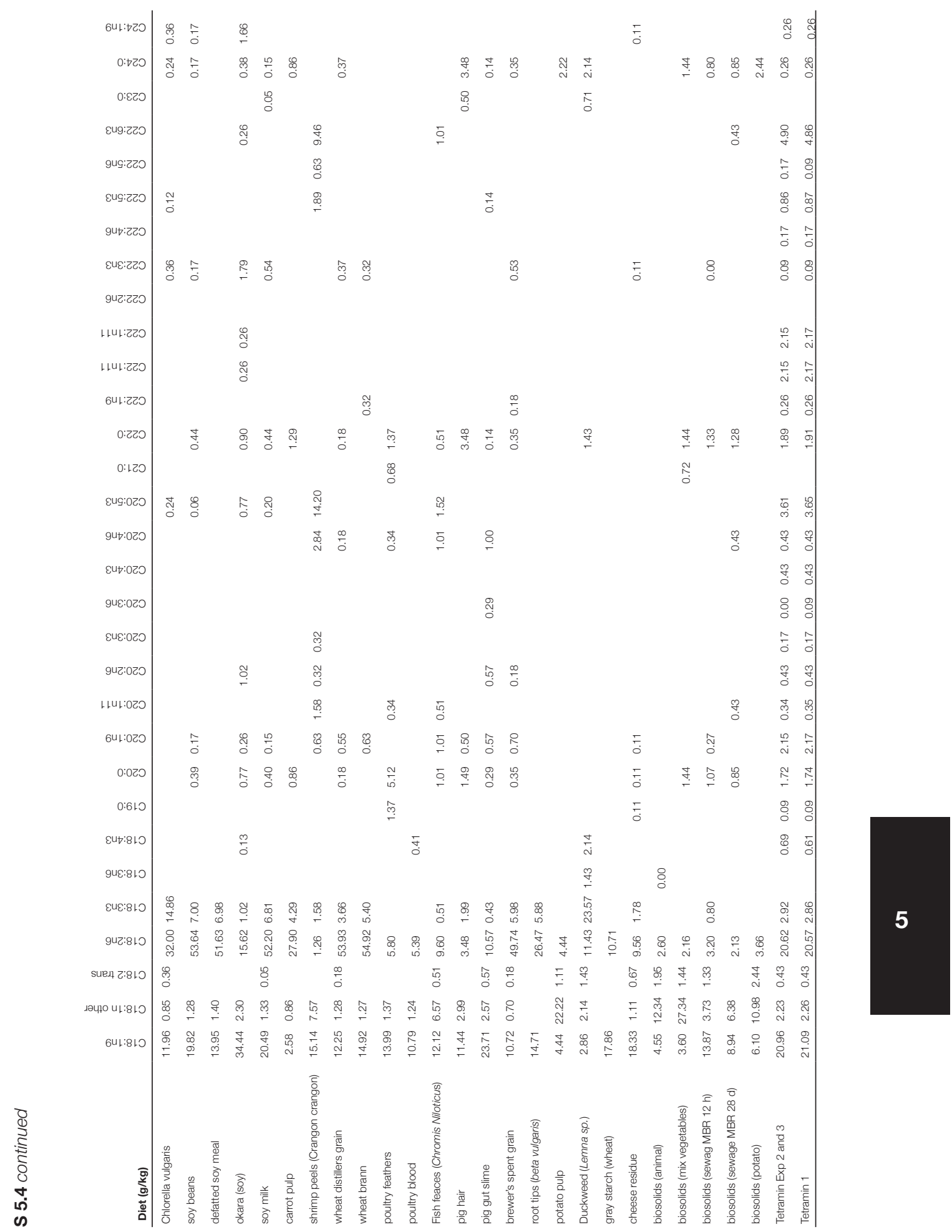

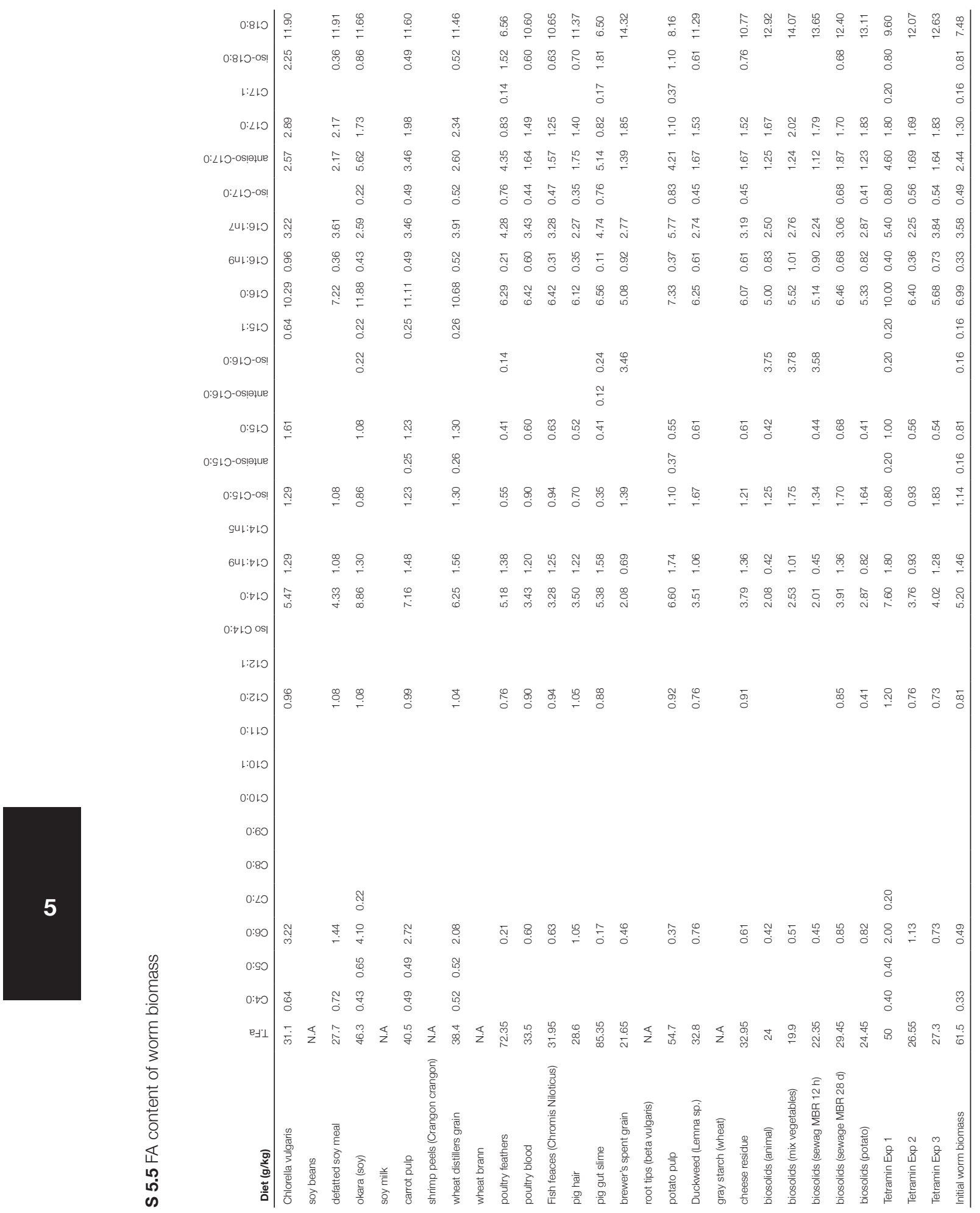


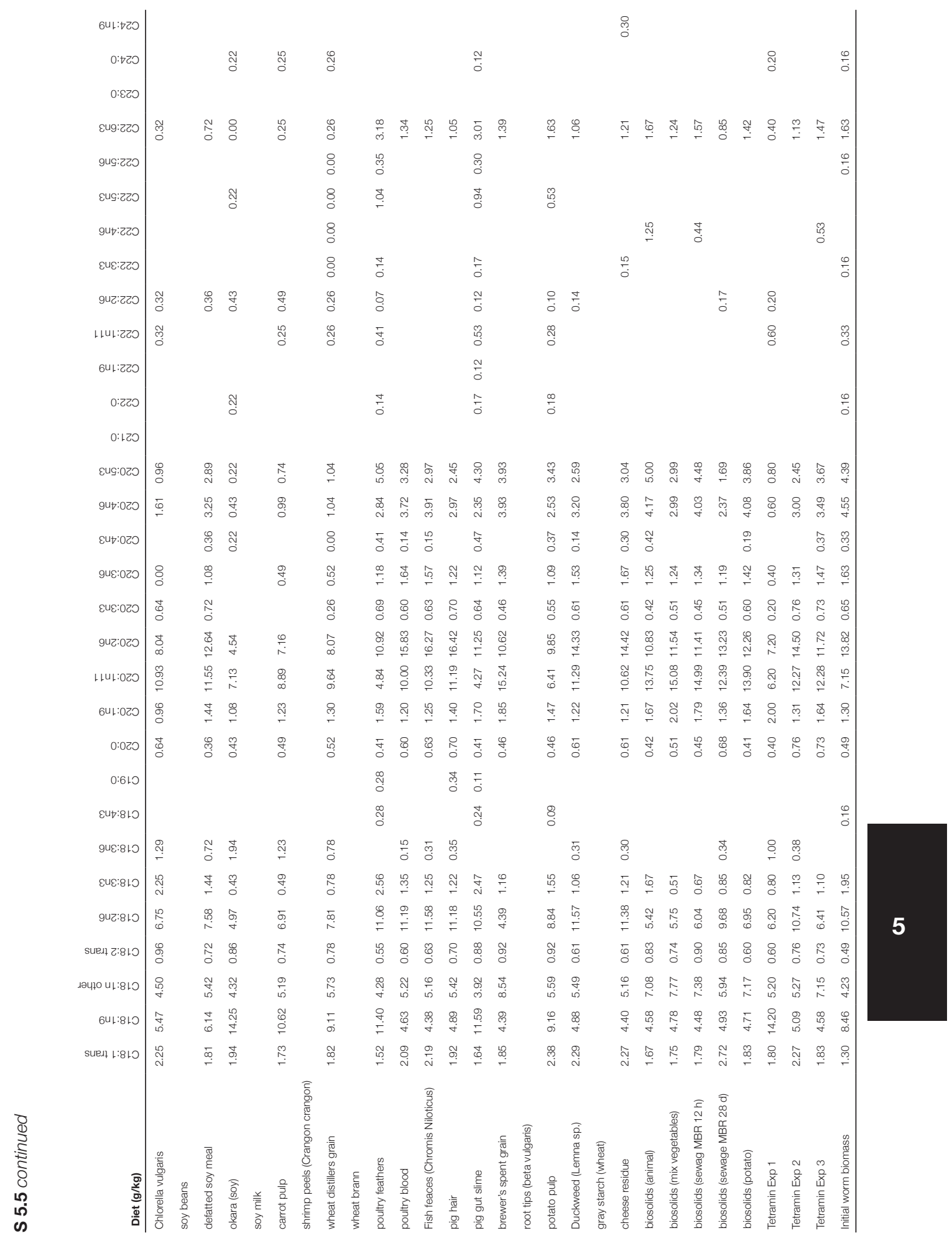




\section{6}

General discussion and outlook 


\subsection{Introduction}

In order to serve aquaculture feed markets with an attractive alternative to fish meal, such as aquatic worm biomass, a continuous and secure bulk production needs to be realized. This thesis has demonstrated the technical feasibility of a bench-scale reactor to produce the aquatic worm Lumbriculus variegatus (Lv) with secondary sludge from the potato processing industry as its substrate (chapter 4). It was demonstrated that also other waste streams can be applied as suitable substrates for Lv (chapter 3 and 5). The key element of the reactor is a gravel layer that mimics the natural habitat of the sediment dwelling Lv. In this manner a much higher worm density and worm growth rate could be accomplished than with a previous reactor design (Hendrickx, 2009), and this resulted in a 20 to 40 times higher areal worm production rate (chapter 4). The new reactor concept combines waste stream reduction (in solids and volume) with the production of protein-rich worm biomass. This biomass not only can be used as fish feed (Chapter 4), but probably also as a source for non-feed (technical) products. For example, the proteins may be used for the production of adhesives and the fatty acids for olea-chemicals in detergents (chapter 1).

In this chapter the performance parameters of the bench-scale reactor (worm growth rate, density, biomass production rate and nutrient recovery) will be used as the input for an assessment of the economic feasibility of large scale worm biomass production on secondary sludge from the potato industries. However, as was already mentioned above, also other waste streams may provide suitable substrates for worm production as fish feed, as long as they do not contain pathogens, heavy metals, organic (micro) pollutants and high levels of ammonium. The economic feasibility assessment will be followed by a discussion on the application of the worm biomass for food and non-food related destinations. Finally, topics for further research on laboratory and pilot-scale, required to realize large-scale worm production will be discussed.

\subsection{Worm production from secondary sludge generated by the potato industry}

Figure 6.1 summarizes volume and mass fluxes of a worm production system treating the surplus secondary sludge from a Dutch (hypothetical) potato processing factory. These fluxes were calculated using the results of this thesis and with data from previous studies (Table 6.1) (Elissen, 2007; Hendrickx, 2009).

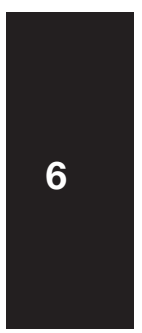


Table 6.1 Design parameters worm production system. ${ }^{\text {A }}$ data from (Elissen, 2007), ${ }^{\text {B }}$ recalculated value based on $79 \mathrm{~g} \mathrm{COD} / \mathrm{kg} \mathrm{ww} / \mathrm{d}$ and $1.25 \mathrm{~g} \mathrm{COD} / \mathrm{g}$ dw bio solids (chapter 4), ${ }^{\circ}$ data from (Hendrickx, 2009), TSS (Total suspended solids), COD (chemical oxygen demand), ww (wet weight), dw (dry weight.

\begin{tabular}{lll}
\hline TSS reduction by worms & $50^{\mathrm{A}}$ & $\%$ \\
Worm biomass density & 1.6 & $\mathrm{~kg} \mathrm{ww} / \mathrm{m}^{2}$ (outer surface) \\
TSS consumption rate by worms & $63^{\mathrm{B}}$ & $\mathrm{g} \mathrm{TSS} / \mathrm{kg} \mathrm{ww} / \mathrm{d}$ \\
Dry weight/wet weight worms & 0.14 & - \\
Worm biomass yield & 0.3 & $\mathrm{~kg} \mathrm{dw} / \mathrm{kg}$ TSS dosed \\
Carrier surface per reactor volume & $22.5^{\mathrm{C}}$ & $\mathrm{m}^{2}$ (interface gravel-water compartment) $/ \mathrm{m}^{3}$ \\
Height of worm reactor & 3 & $\mathrm{~m}$ \\
\hline
\end{tabular}

The worm production system can achieve a waste sludge reduction of $50 \%$ in solids and of $62 \%$ in volume. It produces $1585 \mathrm{~kg}$ fresh (222 kg dry) worm biomass on a daily basis from $1479 \mathrm{~kg}$ TSS surplus sludge. The reactor has a footprint of only $217 \mathrm{~m}^{2}$. Compared to the former reactor design (Hendrickx, 2009) this footprint is at least two times smaller, mainly caused by a higher worm density of 1.6 instead of $1.0 \mathrm{~kg} \mathrm{ww} / \mathrm{m}^{2}$. It should be recognized that this density of $1.6 \mathrm{~kg} \mathrm{ww} / \mathrm{m}^{2}$ is a very conservative estimate as densities as high as $6 \mathrm{~kg} /$ $\mathrm{m}^{2}$ were observed (chapter 4). The worm faeces need to be thickened and have a potential application as a combined organic, nitrogen and phosphorus fertilizer. Remark that only 12.4 $\mathrm{m}^{3} / \mathrm{d}$ of worm faeces are produced, which is a $75 \%$ reduction in volume compared to the volume that would be produced by conventional sludge processing $\left(49 \mathrm{~m}^{3} / \mathrm{d}\right)$. This can be explained by the excellent dewatering properties of the worm faeces (Hendrickx, 2009). The worm biomass should be quickly transported and further processed to retain its nutritional quality and value. As an alternative, the worm biomass can be preserved by e.g. freezing.

\subsection{Economic perspectives}

The yearly costs, savings and potential income for a large scale worm production are given in Table 6.2 and were estimated from design data (Table 6.1) and a number of economic assumptions (Table 6.3). A purchase of $10 \%$ of the total biomass was assumed to be sufficient for start-up. Assuming a growth of $6.8 \%$ per day (chapter 4) this 10\% initial would only take 36 days to grow to a sufficient amount of biomass to fully occupy the carrier material in the reactor. 


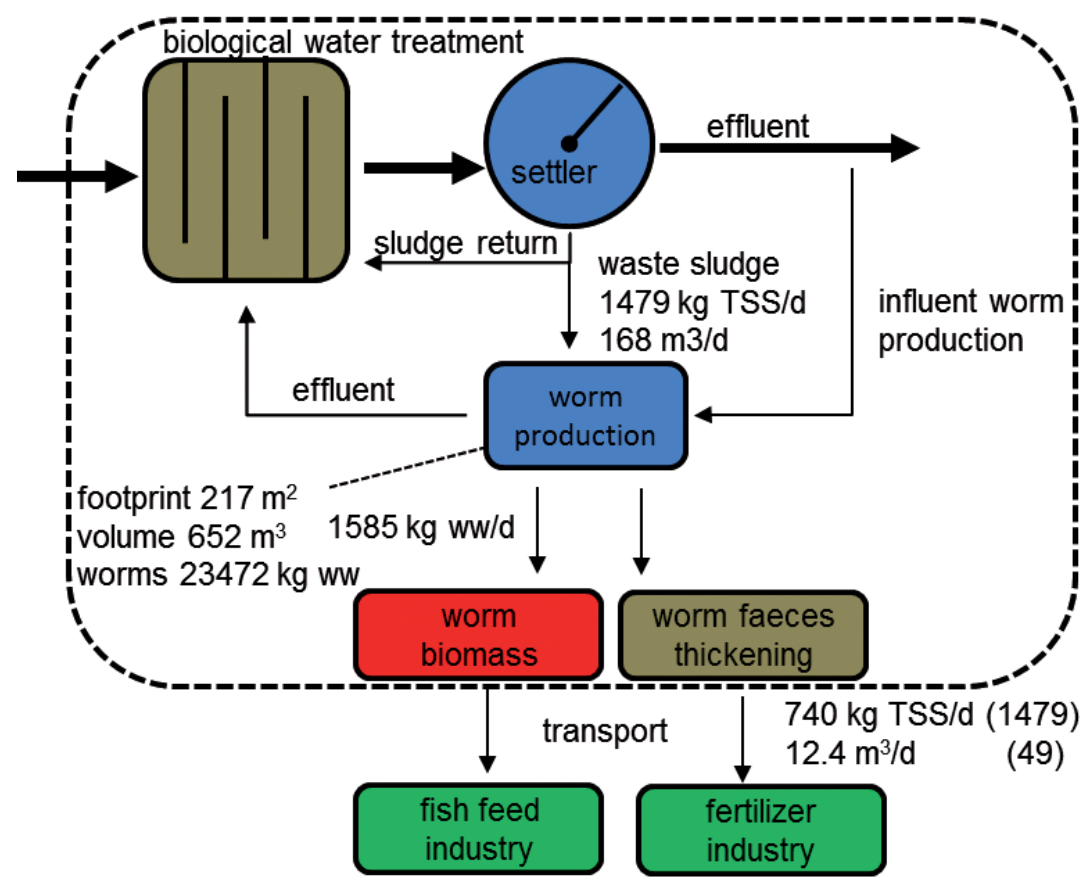

Figure 6.1 Overview of a decentralized worm production unit on secondary waste sludge from a potato processing industry. Numbers in brackets show the volume and solid fluxes that would be produced on site without applying a worm reactor.

The value of worm biomass was set at a very conservative value of $1.4 € / \mathrm{kg}$, i.e. the current price of fishmeal, to see if worm biomass production can compete with the fishmeal market. The investments are relatively high, but the yearly benefits from sludge disposal savings and income from worm biomass make that the annual return rate can be as short as 3 years. If no income from worm biomass is realized, i.e. the only objective is to save on sludge disposal (transport and incineration), the annual return rate would be around 16 years.

The market price of worm biomass has a huge impact on the outcome of the economic evaluation. Once worm biomass is for example valued as 2.8 instead of $1.4 € / \mathrm{kg} \mathrm{dw}$, income will double and payback time reduce from 3.0 to 1.6 years. Once worm biomass values are as high as 3 - $4 € / \mathrm{kg} \mathrm{dw}$, the concept also would be feasible without taking the savings on incineration and sludge transport into account. In this case even by-products from food industry with a positive market price can be considered for the production of worm biomass. In practice the value of worm biomass will depend on several factors including its specific use, performance, supply and market demand. 
Table 6.2 Estimated costs, savings and potential income for a large scale worm production

\begin{tabular}{lll}
\hline$\times 1000 €$ & & \\
\hline Investments & 391.4 & $€$ \\
Worm reactor construction & 23.5 & $€$ \\
Initial worm biomass (10\%) & $\mathbf{4 1 4 . 9}$ & $€$ \\
Total & & \\
\hline Yearly costs & 41.5 & $€ /$ year \\
Capital & 24.9 & $€ /$ year \\
Operational & $\mathbf{6 6 . 4}$ & $€ /$ year \\
subtotal costs & & \\
\hline Yearly benefits & 113.4 & $€ /$ year \\
Income from worm biomass & 67.5 & $€ /$ year \\
Savings on incineration & 24.0 & $€ /$ year \\
Savings on transport & $\mathbf{2 0 4 . 9}$ & $€ /$ year \\
subtotal benefits & & years \\
\hline Result (benefits-costs) & $\mathbf{1 3 8 . 6}$ & \\
Annual rate of return & 3.0 & \\
\hline
\end{tabular}

Table 6.3 Economic assumptions. ${ }^{A}\left(\right.$ Hendrickx, 2009), ${ }^{B}$ assumed bulk price based on current commercial price $17 € / \mathrm{kg} w w$ for small amounts (supplier Eastern Aquatics), ${ }^{\circ}$ Estimated fishmeal price (Rabobank, Netherlands), Dbased on expected lifespan of materials used for the reactor.

\begin{tabular}{lll}
\hline Sludge incineration & $250^{\mathrm{A}}$ & $€ / \mathrm{ton} \mathrm{dw}$ \\
Transport thickened sludge & $1.8^{\mathrm{A}}$ & $€ / \mathrm{m} 3$ \\
Construction costs & 600 & $€ / \mathrm{m} 3$ \\
Operational costs (year) & $6^{\mathrm{A}}$ & $\%$ of total investment \\
Investment cost worm biomass & $10^{\mathrm{B}}$ & $€ / \mathrm{kg} \mathrm{ww}$ \\
Value worm biomass & $1.4^{\mathrm{C}}$ & $€ / \mathrm{kg} \mathrm{dw}$ \\
Depreciation period & $10^{\mathrm{D}}$ & year \\
\hline
\end{tabular}

Finally, the investments were estimated based on $600 € / \mathrm{m}^{3}$ for reactor construction and $10 € / \mathrm{kg}$ ww for the $10 \%$ starting culture of worms, resulting in a total investment of $€ 414,900$. Higher or lower construction costs will have a considerable impact on the payback time and financial risks. Construction costs are depending mostly on the material costs related with construction of the gravel columns itself. Therefore altering and minimizing the use of materials in the current design can be of great use to lower the overall costs. Also the operational costs of a worm production system have an important impact. These are mainly determined by the personal costs. Thus, 
automatization of the worm production system can be expected to have a large effect. More accurate cost estimates associated with construction, initial stocking and operation are needed, and should be based on a more detailed design and on practical experience with operating a pilot-scale reactor.

\subsection{Valorisation of worm biomass}

Depending on the waste stream that is used to cultivate the worms, and in particular the risks associated with the presence of pathogens and (organic) micro pollutants, two application classes of this biomass can be identified: food grade and non-food (technical) grade (Fig. 1.2 and Table 6.4). Blackworms currently are sold as live, freeze dried and frozen food for ornamental fish by a few large US and Australian producers (>10.000 kg per year per producer). Smaller market volumes are dedicated for scientific purposes, i.e. as test organisms in toxicology and bioaccumulation tests.

To open up bulk markets further refinery of crude worm biomass may be required into a lipid (worm oil) and protein fraction (protein isolate). Thus, two general product types, whole biomass and refined products can be distinguished and applied in two application areas (feed and technical), depending on the quality of the organic (waste) sludge that the worms have been grown on (Table 6.4). This can result in several new and unique business models in the aquaculture, feed, chemical and agriculture sectors. Obviously, an assessment of economical and legislative boundary conditions needs to be part of such business models.

Revenues will be generated from product sales as well as from a reduction of waste processing costs (remediation or gate keeper fee). Technical product applications most likely will yield lower revenues than food grade applications, but the remediation fees of sewage sludge used for technical products applications are in turn higher than those of agrofood sludge. This implies that technical applications should not be excluded beforehand since they still can contribute to a feasible business case. 
Table 6.4 Different types of potential bulk products from aquatic worm biomass (Lumbriculus variegatus) (Elissen, 2007; Hendrickx, 2009)

\begin{tabular}{llll}
\hline Product type & Basic products & Feed applications & $\begin{array}{l}\text { Technical (non-food) } \\
\text { applications }\end{array}$ \\
\hline Whole biomass & Worm meal & $\begin{array}{l}\text { 1. Feed product } \\
\text { (Fish meal alternative) }\end{array}$ & 2. Organic fertilizer \\
Refined products & Worm lipid fraction & $\begin{array}{l}\text { 3. Poly unsaturated fatty } \\
\text { acids (fish oil alternative) }\end{array}$ & $\begin{array}{l}\text { 4. Oleochemicals (glycerine, } \\
\text { fatty acids, methyl esters) } \\
\text { for e.g. anticorrosive paint or } \\
\text { lubricants }\end{array}$ \\
& Worm protein isolate & $\begin{array}{l}\text { 5. Functional ingredients } \\
\text { (emulgators, foam } \\
\text { stabilisers, gelling agents) }\end{array}$ & $\begin{array}{l}\text { 6. Adhesives, technical } \\
\text { foams, paints } \\
\text { (e.g. glue or paint binder). }\end{array}$ \\
& &
\end{tabular}

Downstream processing of worm biomass was not investigated in this thesis and evaluation and testing of methods for worm biomass isolation, extraction and purification are still required. Based on the soft structure of worm tissue and because, unlike insects, worms are free of bones and ligaments, it is expected that bio-refinery and downstream processing can be relatively simple and cheap.

\subsection{Worm biomass compared to other fishmeal replacers}

Only a few resources are considered as fishmeal replacer by aqua feed compounders: (1) singe cell protein (Bacteria, Yeast, Micro algae), (2) plant oil seeds and legumes, (3) terrestrial animal by-product meals and (4) miscellaneous plant protein sources (Tacon, 1995). Among these, only singe cell protein can be produced from residual sources and is therefore considered as the only resource efficient option currently available.

Waste based insect production for animal feed currently is scaled up by several pioneers, backed up by legislative changes. Production of black soldier fly (BSF) larvae (Hermetia illucens), house flies and mealworms are the most common with BSF generally regarded the most promising organism (Barragan-Fonseca et al., 2017). Aquatic worm production using clean, secondary bio-solids thus far has not been considered, mostly because a controlled and stable worm production technique was missing (chapter 1). However, a comparison between Lv and fishmeal regarding crude composition (Table 1.1), essential amino acids (Fig. 6.2) and fatty acids (Table 6.5) learns that $L v$ is a highly suitable source for fish feed. 




Figure 6.2 Essential amino acid pattern of protein from bacteria (Pseudomonas/Methylophilus spp.), yeast (Candida spp.), microalgae (Spirulina maxima), high quality fishmeal (Engraulis ringens), blackworms (Lumbriculus variegatus) and black soldier fly prepupae (Hermetia illucens). Between brackets \% crude protein on dw basis. Source (Elissen et al., 2010; St-Hilaire et al., 2007; Tacon, 1995)

A comparison of the amino acid pattern of fishmeal protein (FM) with those of protein alternatives (bacteria, yeast, algae, blackworms and BSF) (Fig 6.2) shows that most of these alternatives can provide the essential amino acids at sufficiently high levels. Only BSF and microalgae have significantly lower levels of Methionine and Cystine. Strikingly, Lv is the only species that provides enough Lysine (compared to fishmeal).

The alternatives vary in their protein content with yeast and BSF having the lowest amount (Fig. 6.2). With $64 \%$ protein and only $8 \%$ crude fat or even lower as was found in this study (chapter 5), Lv can best be considered a protein source. Still, it is recognized that they are relatively rich in poly unsaturated fatty acids, and perhaps can yield a high value product for feed applications (chapter 5). The fatty acid composition (Table 6.4) of Algae, fishmeal, Lv and BSF shows that LV is more similiar to fishmeal than Algae and BSF. Algae provide a good source of C16:0 and C18:2n6 and BSF a good source of C12:0 and C18:1n9. However, the longer chain fatty acids ( $\geq$ C20) present in fishmeal are not provided by algae or BSF but only by LV. 
Table 6.5 Selected fatty acid composition of Fishmeal (FM, Engraulis ringens),Algae (Spirulina maxima), Blackworms (Lv, Lumbriculus variegatus) and Black soldier fly prepupae (BSF, Hermetia illucens). Between brackets \% crude fat on a dw basis. Source (Ötleş and Pire, 2001; Plante et al., 2017; St-Hilaire et al., 2007) and chapter 5 . Bacteria and yeast are not included in the table.

\begin{tabular}{lllll}
\hline \% of fatty acids & FM (9.6) & Algae (9.6) & Lv (8) & BSF (33.1) \\
\hline C12:0 & n.a & 0.5 & 0.0 & 49.3 \\
C14:0 & 5.9 & 0.0 & 2.5 & 6.8 \\
C16:0 & 17.4 & 35.8 & 5.5 & 10.5 \\
C16:1n7 & 8.5 & 0.9 & 2.8 & 3.5 \\
C18:0 & 2.0 & 1.5 & 14.1 & 2.8 \\
C18:1n9 & 5.6 & 5.0 & 4.8 & 11.8 \\
C18:2n6 & 0.5 & 16.3 & 5.8 & 3.7 \\
C18:3n3 (ALA) & 0.0 & 0.0 & 0.5 & 0.1 \\
C18:4n3 & 0.5 & n.a & 0.0 & 0.0 \\
C20:4n6 (AA) & 0.0 & n.a & 3.0 & 0.0 \\
C20:5n3 (EPA) & 4.6 & 0.0 & 3.0 & 0.0 \\
C22:4n6 & N.A & n.a & 0.0 & 0.0 \\
C22:5n3 & 0.6 & 0.0 & 0.0 & 0.0 \\
C22:6n3 (DHA) & 3.9 & 0.0 & 1.2 & 0.0 \\
\hline
\end{tabular}

Production efficiencies can be compared in terms of feed conversion ratio's (FCR) and yield (Table 6.6). Because the production efficiency depends on several factors such as the quality of the substrate, growth conditions and physiology, a direct comparison is difficult. The growth efficiency of Lv on the basis of FCR and yield seems to be lower than of bacteria but higher compared to BSF. A lower growth efficiency of Lv than of bacteria is mainly caused by its larger body size and longer life span, which increase the energetic costs for somatic maintenance (Kooijman, 2010). Insects like BSF have a lower growth efficiency than Lv, most likely because they need to invest heavily in the complex polymeric structures of their exoskeleton.

Table 6.6 Feed Conversion Ratio (FCR) and yield for different organisms for biomass production. FCR defined as; weight of ingested food/ fresh weight gained. Yield defined as product ( $d w)$ per amount of substrate ( $d w)$. Source (Diener et al., 2009; Matassa et al., 2015; Oesterholt et al., 2015) and chapter 4

\begin{tabular}{lll}
\hline Organisme & FCR & Yield \\
\hline Bacteria & 0.5 & 0.4 \\
Blackworms & $0.68-0.81$ & $0.25-0.3$ \\
Black soldier fly & $1.5-3.0$ & $0.10-0.16$ \\
\hline
\end{tabular}


Not only production efficiency but also biomass production rate is of importance as it determines the footprint of the production unit and herewith significantly contributes to the investment costs. The production rate is determined by both the growth rate and the biomass density. Bacteria have a high productivity derived from their fast growth rate (doubling in the order of hours), which however only can be maintained at low densities: typically less than $50 \mathrm{~g} / \mathrm{l}$ (Nasseri et al., 2011). This neccesitates extensive downstreaming including dewatering, which significantly contributes to the production costs. BSF is produced at high (albeit final) biomass densities of $5 \mathrm{~kg} / \mathrm{m}^{2}$, with doubling times in the order of 1 to 2 weeks (Caruso et al., 2014). Lv (standing stock) densities around $5 \mathrm{~g} / \mathrm{l}$ reactor volume or $1.6-6 \mathrm{~kg} \mathrm{ww} / \mathrm{m}^{2}$ (chapter 4) are lower or similar compared to bacterial or BSF production systems while biomass doubling times of 7-17 days are in between those of BSF and bacteria.

Compared to BSF and bacterial production systems, Lv biomass can be more easily harvested because they (passively) fall out of the carrier material, settle and can be collected at high concentration from the bottom of the reactor. In addition, Lv has very simple life stages compared to BSF and does not need additional hatchery systems for the production of larvea and frequent restocking of the production units. Although BSF probably can be produced in low-tech/low-cost systems, its biomass needs more downstream processing because of the much higher ash and chitin content of the crude product. . In contrast, dried and grounded bacterial and Lv biomass can be directly applied as fishfeed. Lv can also be sold as live feed and has the benefit compared to the other two alternatives that it contains more poly unsaturated fatty acids.

Additional advantages of LV worm biomass to replace fishmeal are: (1) LV acts as a strong natural fish attractant as was observed in tests with juvenile eels (Elissen, 2016), (2) The growth efficiency of fish on worms is high in comparison to regular feeds (Mount et al., 2006), (3) Worms are a natural feed source for freshwater fish and (4) Worms allow secure and stable feed production that is independent of natural resources.

\subsection{Regulations and product requirements for worm biomass as feedstuff}

Currently worm biomass from the species Lumbriculus variegatus cannot be brought to the market as animal feed. Legal requirements for the introduction of novel feeds on the market require obligatory testing which must be performed prior to final consideration of worm biomass as feedstuff, including allergens, nutritional value and digestibility. Admission of new products as animal feed need to be done conform art. 24 part 6 of regulation 767/2009/EG. As Lumbriculus variegatus is not yet listed in the Feed Materials Register an application as a new feedstuff material needs to be performed. The application will then be first judged by the European food 
safety authority (EFSA), which is responsible for the evaluation of the provided data and advises the commission for authorisation of novel feedstuff. After a positive review the EFSA will setup a regulatory concept for the admission of Lv worm biomass in the European Union. This concept will be used for a procedure in which all state members of the standing committee on plants, animals, food and feed can judge the admission.

Another route often seen in practice is that acceptance of new ingredients in animal feeds is realised by certifying the new product in accordance with GMP Plus standards. GMP Plus standards combine Good Manufacturing Practices with the certification on the basis of the HACCP (Hazard Analysis and Critical Control Points) system.

As similar to the regulation of e.g. bacterial biomass, the following steps can be foreseen to achieve legal approval of worm production and worm biomass as feedstuff (Matassa, 2016).

1. Confirmation of the competing legal authority

2. Introduce GMP in the production process (production facilities, personnel, procedures and documentation)

3. Acquire the GMP certification

4. Quality control and quality assurance

\subsection{Recommendations for further research}

The current reactor design should be scaled up to pilot- or even full-scale to verify the excellent performance parameters that were achieved on bench-scale, and to further improve the technology. For the technological up-scaling of the current production system the gravel columns should be elongated and multiplied to validate the design parameters that were obtained at smaller scale (Table 6.1). To extrapolate from bench and pilot-scale to full-scale, modular reactor units could be developed. Sludge dosing and distribution should be optimized to secure resource sufficiency and reliable feeding conditions. For this purpose laboratory based research can be carried out to better understand the effect of food availability (sludge dosing) on worm consumption and digestion rate.

The worm bioconversion technology can be interesting for several industries. At least three types of demonstration reactors are believed to be valuable: (1) processing of sewage sludge while exploring non-feed applications of worm biomass, (2) processing of clean sludge from the food industry, mainly to produce fish feed and (3) processing of fish faeces from a worm-fish integrated recirculation system with direct re-use of fresh worm biomass as aquaculture feed. 
Strong indications are that secondary (biological) sludge from treatment plants operated at short solids retention times (SRT) provide a better growth substrate for Lv than sludge from treatment plants operated at longer SRTs (chapter 5). Thus, preferably worm production systems should be connected to high-loaded biological wastewater treatment systems. In this manner also more organic substrate in the wastewater will be diverted to worm production rather than being mineralized. This not only increase worm production but also saves considerable treatment reactor volumes and operational costs (for aeration of the treatment reactor).

The gravel layer used in this study mimics the natural habitat of $L v$ and resulted in a surprisingly large improvement of its growth rate and density. However, a mechanistic explanation of this phenomenon is not available. Also the factors that cause the worms to fall out of the carrier material are largely unknown. Therefore the effect of carrier characteristics (e.g. shape, size, material use) on growth conditions, growth, worm density and worm loss should be investigated in more detail. This can be done by varying size and shape of the carrier while monitoring the water quality (in and outside the carrier) and position of worms inside the carrier (e.g. animal motion video analysis) and quantify resulting growth and fall out of the worms. Both short- and long-term effects should be investigated in order to evaluate if production is sustainable under the given conditions.

This thesis does not provide information regarding the composition of the worm faeces and their potential valorization as an (organic) fertilizer. Extensive composition analysis and field test with commonly used crops therefore would be of great interest.

How worm length and asexual fragmentation are controlled is unknown, but probably this is related with food composition and external conditions such as the availability of carrier material (Laarhoven et al., 2016). A better understanding of this could lead to a better control of the production process. Controlled growth experiments in which the composition of the diet is systematically altered on the basis of e.g. protein, phosphorus and fat level perhaps can give more inside how worm length and reproduction are related with food composition.

The relation between food composition and food accessibility on worm growth, and in particular the role of microbial conversion process in this relation is not fully understood. How bacterial content of their food interacts with the microbial community imbedded in the worms digestive system is unknown. More fundamental understanding why certain food substrates can or cannot be exploited by LV and how this depends on microbial interactions is needed. This complex research should be supported by state of the art and novel techniques used in other worm feed studies using isotope labelled bacterial food and study of the gut microbiome using e.g. next generation sequencing (de Valk et al., 2017). 
The test system for controlled worm growth as developed in chapter 2 has the potential to be used for toxicological studies. However, first more validation and comparison with established standard methods is needed. As the test system supports high growth rates it could be very suitable for studies that investigate the effect of toxic components which are dominantly taken up through food particles. 


\section{References}

Barragan-Fonseca, K., Dicke, M. and van Loon, J., 2017. Nutritional value of the black soldier fly (Hermetia illucens L.) and its suitability as animal feed-a review. Journal of Insects as Food and Feed: 1-16.

Caruso, D., Devic, E., Subamia, I., Talamond, P. and Baras, E., 2014. Technical handbook of domestication and production of Diptera Black Soldier Fly (BSF), Hermetia illucens, Stratiomyidae.

de Valk, S., Khadem, A.F., van Lier, J.B. and de Kreuk, M.K., 2017. Unravelling the protein preference of aquatic worms during waste activated sludge degradation. Environmental Technology: 1-8.

Diener, S., Zurbr $\tilde{A} 1 / 4$ gg, C. and Tockner, K., 2009. Conversion of organic material by black soldier fly larvae: Establishing optimal feeding rates. Waste Management and Research 27: 603-610.

Elissen, H.J.H., 2007. Sludge reduction by aquatic worms in wastewater treatment with emphasis on the potential application of Lumbriculus variegatus. PhD thesis Thesis, Wageningen University, the Netherlands, Wageningen, $192 \mathrm{pp}$.

Elissen, H.J.H., 2016. Personal communication, Wetsus, Centre for Sustainable Water Technology, the Netherlands.

Elissen, H.J.H., Mulder, W.J., Hendrickx, T.L.G., Elbersen, H.W., Beelen, B., Temmink, H. and Buisman, C.J.N., 2010. Aquatic worms grown on biosolids: Biomass composition and potential applications. Bioresource Technology 101: 804-811.

Hendrickx, T.L.G., 2009. Aquatic worm reactor for improved sludge processing and resource recovery. PhD thesis Thesis, Wageningen University, the Netherlands, Wageningen.

Kooijman, S.A.L.M., 2010. Dynamic energy budget theory for metabolic organisation. Cambridge university press.

Laarhoven, B., Elissen, H.J.H., Temmink, H. and Buisman, C.J.N., 2016. Agar Sediment Test for Assessing the Suitability of Organic Waste Streams for Recovering Nutrients by the Aquatic Worm Lumbriculus variegatus. PLoS ONE 11: e0149165.

Matassa, S., 2016. Exploring protein production by hydrogen-oxidizing microbiomes, Ghent University.

Matassa, S., Batstone, D.J., Hülsen, T., Schnoor, J. and Verstraete, W., 2015. Can Direct Conversion of Used Nitrogen to New Feed and Protein Help Feed the World? Environmental Science \& Technology 49: 5247-5254.

Mount, D.R., Highland, T.L., Mattson, V.R., Dawson, T.D., Lott, K.G. and Ingersoll, C.G., 2006. Use of the oligochaete, Lumbriculus variegatus, as a prey organism for toxicant exposure of fish through the diet. Environmental Toxicology and Chemistry 25: 2760-2767.

Nasseri, A., Rasoul-Amini, S., Morowvat, M. and Ghasemi, Y., 2011. Single cell protein: production and process. American Journal of food technology 6: 103-116.

Oesterholt, F., Versteeg, E., Verstraete, W. and Boere, J., 2015. Toepassing van het "Power-to-Protein" concept in de stedelijke watercyclus van Amsterdam KWR 2015.049

Ötleş, S. and Pire, R., 2001. Fatty acid composition of Chlorella and Spirulina microalgae species. Journal of AOAC international 84: 1708-1714. 
Plante, S., Béland, F., Tchoukanova, N. and Gagnon, J., 2017. Novel Meals from Eastern Canada's Marine Fishery By-products as Alternatives to Fishmeal. Journal of Aquatic Food Product Technology: 1-9.

St-Hilaire, S., Sheppard, C., Tomberlin, J.K., Irving, S., Newton, L., McGuire, M.A., Mosley, E.E., Hardy, R.W. and Sealey, W., 2007. Fly prepupae as a feedstuff for rainbow trout, Oncorhynchus mykiss. Journal of the World Aquaculture Society 38: 59-67.

Tacon, A.G., 1995. Feed ingredients for carnivorous fish species: alternatives to fishmeal and other fishery resources. Sustainable fish farming: 89-114. 


\section{Summary}

There is a global demand for more feed resources to keep up with the increasing production of livestock. The hunger for resources is most urgent in the aquaculture sector, which to a large degree depends on the non-sustainable use of fish oil/ meal from wild fish. Aquatic macro invertebrates such as the freshwater worm Lumbriculus variegatus (Oligochaeta, Lumbriculidae, common name blackworms, further abbreviated as LV) are rich in proteins, lipids, vitamins and minerals. When cultivated on safe and low-grade organic wastes they can provide a sustainable fishmeal alternative for most freshwater and marine fish.

Chapter 1 introduces the concept of aquatic worm production on waste streams. Worm biomass composition and relevant research lines are explained. Organic waste sludges from food industries are a rich source of bio-molecules and can be upgraded to (fish) feed when fed to aquatic worms. For valorisation of waste streams by aquatic worms, as proposed in this thesis, these streams preferably are free from contaminants such as organic micro pollutants, heavy metals and pathogens. For example, this would not be the case when sewage (municipal) sludge is used as a substrate for the worms. However, such contaminated sludges may still be applied for non-food applications. Thus, the quality of the waste stream that is used as a substrate for the worms determines the application potential of the worm biomass as well as the options for downstream processing and refinery.

Previous research showed that Lv can be used for reduction and compaction of sewage sludge. The consumption of (suspended) sludge particles results in a dry matter reduction of 25 - $50 \%$ and in worm faeces that are $60 \%$ more compact than the original waste sludge. This contributes to a significant reduction in sludge processing costs. Sludge reduction by aquatic worms is mainly studied by research groups in The Netherlands and in China. Unfortunately, it is generally accepted free swimming worms in full-scale wastewater treatment plants is extremely difficult, mainly because of large (seasonal) population fluctuations. A controlled reactor concept applying the sessile (crawling, sediment dwelling) species Lv already was developed in earlier research. The key characteristic of this reactor is a carrier material for the worms, which also functions as a separation layer between the waste stream (worm food) and a water phase used for aeration, worm harvesting and worm faeces collection. This concept also was the starting point for the development of the improved reactor concept that is described in this thesis.

The two main objectives of this thesis were: (1) to assess the potential of organic waste streams and by-products for Lv production for fish feed and (2) to develop a (cost and resource) effective bioreactor for this purpose. 
In Chapter 2 a new, standardized method is described and tested that can be used for a quantitative and qualitative assessment of the effect of different substrates on worm growth. This method not only can be used to select waste streams suitable for worm production, but also is proposed as a tool is ecotoxicology studies.

The test method consists of beaker experiments with a combination of agar and sand to optimize food uptake by and growth of the worms. The effects of agar gel, sand, and food quantity were studied and evaluated for different food sources. Agar gel addition ameliorated growth conditions by reducing microbial food hydrolysis and by improving the sediment structure. This guaranteed that substrate ingestion and worm growth in the first place were the result of the food quality and the effect of other (environmental) factors was reduced. A final test with secondary potato starch sludge demonstrated the test method is appropriate for the evaluation of solid and suspended organic feedstuffs/waste streams.

In Chapter 3 the standardized method of chapter 2 was used for worm growth studies, focussing on the effect of carbon to nitrogen $(\mathrm{C} / \mathrm{N})$ ratios of diets on worm growth and reproduction. Growth and reproduction of LV on different combinations of wheat based derivatives like gluten and gray starch was studied at fixed isoenergetic levels (expressed as chemical oxygen demand (COD) of the food), but at different $\mathrm{C} / \mathrm{N}$ ratios. Growth and reproduction rates were compared to those on Tetramin, a substrate known to result in excellent worm growth. Growth was mainly controlled by the $\mathrm{C} / \mathrm{N}$ ratio of the single and mixed wheat fraction diets. Lower $\mathrm{C} / \mathrm{N}$ ratios of around 6-7 gave a much better performance than high $\mathrm{C} / \mathrm{N}$ ratios of around 20 . This probably was caused by Lv relying on the presence of proteins as carbon and energy source. Although growth and reproduction rates were not as high as on the control diet, the results were promising for development of a worm biomass production reactor, operating on by-products from wheat processing industries.

In Chapter $\mathbf{4}$ a new reactor concept for LV cultivation on waste streams was developed and tested. In a vertical tubular reactor a centralized food compartment was surrounded by a gravel layer that mimicked the natural habitat of Lv. Secondary (biological) sludge from a potato starch processing industry was used as a clean and low value food source. The results with respect to worm growth rate, density and production and nutrient recovery were compared to the previous reactor design. Much higher worm densities were achieved $\left(6.0\right.$ compared to $1.1 \mathrm{~kg} \mathrm{ww} / \mathrm{m}^{2}$ carrier material) as well as much faster Lv growth rates (4.4 - 12 compared to $1.2 \% / \mathrm{d}$ ). As a result the areal worm production rate was no less than 40 times higher (560 compared to $14 \mathrm{~g}$ $\mathrm{ww} / \mathrm{m}^{2} / \mathrm{d}$ ). The higher worm density, which was found to be independent of gravel size in a range of 2.4 to $8.0 \mathrm{~mm}$, allowed for a significantly shorter food retention time in the reactor $(\sim 2.2$ days compared to $>10$ days for the previous reactor design). This restricted microbial mineralization of the food, making high nutrient recoveries from waste to worm biomass possible: $16-30 \%$ 
COD, $19-22 \% \mathrm{~N}$ and $9-11 \% \mathrm{P}$. The high biomass density also limited the release of ammonium, which at large concentrations is toxic for the worms. However, even shorter food retention times (e.g. higher loading rates) are not recommended as a minimum microbial activity is needed for conversion of the original substrate into compounds that can be taken up by the worms.

In Chapter 5 worm growth, reproduction and biomass quality were evaluated on several waste streams and by-products of bacterial, animal and plant origin. The effect of 26 different diets, all applied at high food levels, on Lv growth, reproduction and fatty acid (FA) content and profile were investigated. For this purpose the standardized test method of Chapter 2 was used. In addition, it was discussed which diet composition and food sources would be most suitable for large scale production of Lv.

Diets consisting of single cell biomass from bacterial or plant origin with a high protein content ( $\mathrm{C} / \mathrm{N}$ ratio $<8.8)$, high $\mathrm{P}$ content $(\mathrm{C} / \mathrm{P}<50)$ and low in total ammonia nitrogen (TAN) $(<20 \mathrm{~g} \mathrm{~N} / \mathrm{kg})$ gave the highest growth rates and vital worms without signs of mortality. Besides the $\mathrm{C} / \mathrm{P}$ ratio of the diet, worm conditions related with the difference between test and pre-culture conditions. The starting weight of the worms seemed to have an effect on the total fatty acid content of the worms. The growth potential of a diet rich in proteins and $\mathrm{P}$ depends on how much TAN is associated with the diet. By blending different food sources these factors to a certain extent can be manipulated. Lv seemed to have a distinct and very stable FA composition, irrespective of the diet's FA composition. The worms were rich in poly unsaturated FAs (PUFAs), including several $\omega 3$ and $\omega 6$ FAs, and contained relatively high levels of C18 and C20 PUFAs. This makes them suitable as fish feed, in particular for freshwater fish.

In order to serve aquaculture feed markets with an attractive alternative to fish meal, such as aquatic worm biomass, a continuous and secure bulk production needs to be realized. In Chapter 6 the performance parameters established in chapter 4 (worm growth rate, density and biomass production rate) were used as the input for a feasibility assessment of large scale worm production on secondary sludge from the potato industry. In addition, in chapter 6 future value chains and lines of research were discussed.

A hypothetical worm production system treating the surplus secondary sludge from a potato processing factory can reduce excess sludge production by $50 \%$ in solids and $62 \%$ in volume. This is accompanied by a daily production of 1.6 metric ton of fresh worm biomass. With a very conservative estimation of the worm density of $1.6 \mathrm{~kg} \mathrm{ww} / \mathrm{m}^{2}$ carrier material a footprint of the system of $217 \mathrm{~m}^{2}$ can be realized, which is at least two times smaller than with a previous reactor design without a gravel layer. With reduced sludge processing costs and a conservative market price of $1.4 € / \mathrm{kg}$ dry worm biomass, worm production can already be realized at an annual rate of return of 3 years. However, the costs are highly sensitive for worm biomass stocking, reactor construction and operation. A more accurate economic assessment should be based on the results of pilot-scale research. 
Two general product types, whole biomass (as fish feed) and refined products can be distinguished and applied in two application areas (feed and non-food), depending on the quality of the organic (waste) sludge that the worms have been produced from. Valorisation for potential bulk markets needs further refinery of crude worm biomass into a lipid (worm oil) and a protein fraction (protein isolate). This can result in several new and unique business models in aquaculture, feed, chemical and agriculture sectors. Obviously, an assessment of economical and legislative boundary conditions needs to be part of such business models.

Worm biomass is a potential high quality fishmeal replacer, with a similar or even better potential than other waste based alternatives such as single cell biomass and insects. A comparison between Lv and fishmeal with respect to crude composition, essential amino acids and FAs learns that $L v$ is a highly suitable fish feed source. It can provide essential amino acids at sufficiently high levels. Based on its FA composition and (relatively low) fat content, LV can best be considered a protein source. Still, worm biomass is rich in PUFA, which could be a potential high value product for feed applications. Compared to black soldier fly and bacterial production systems, Lv shows intermediate production efficiencies, while biomass harvesting and processing probably is more easy.

Additional advantages of Lv worm biomass to replace fishmeal are: 1) Lv acts as a strong natural fish attractant, 2) the growth efficiency of fish on worms is high in comparison to regular feeds, 3) the nutritional profile of worms matches that of fishmeal, 4) the worms are a natural feed source for freshwater fish and 5) the worms allow a secure and stable feed production that is independent of natural resources.

Further recommendations for future research as outlined and discussed in chapter 6 are mostly related to the technical upscaling of the reactor technology and obtaining more detailed insight in controlled worm growth in response to food characteristics, reactor design and operational conditions. 
Acknowledgements

About the author

List of publications 


\section{Acknowledgements}

Between start and finish of this $\mathrm{PhD}$ studentship, many things have changed for me personally and professionally. A marriage, father of two beautiful daughters, owner of two funny dogs and a start-up business which is slowly turning into something viable is keeping me happy and busy at the same time. Although daily life can be exhausting from time to time, I feel truly blessed. Within all those years many other people and animals played a significant role which I would like to thank hereby.

Thanks to the management, technical and analytical staff of Wetsus. Their support allowed me to execute the research in such a way that creativity and freedom of operation where respected. Special thanks to Jan Tuinstra, Wim Borgonje, Harm van der Kooi and Harrie Bos to make all things work like they should work! Thanks for allowing me to act as 'Bob the builder'.

Thanks to all my colleagues from Wetsus for just being there when needed for mental support, questions, practical help or inspiration. Special thanks to Martina Sammer for her cooperation. Thanks to Lena \& Daniel Bergmair, Petra \& Jos van Dalfsen, Jan Willem Schoonen and Dries Parmentier for their ongoing friendship.

The research wouldn't be the same without the help of many students and the use and sacrifices of many blackworms. I therefore thank Tailtec b.v. and Australian Blackworm Ltd for their fresh supplies which were carefully fostered and used in all the growth and production tests that were executed by myself and students. Special thanks to all my students: Vaidotas Kisielius, Írisz Gergácz, Klaudia Straśko, Ede Bobák, Ernest Mejías Cumplido, Natalia Stanulewicz, Peter Rappoldt, Ramon Beimers, Tiago Marques and Tian Li. You are all big contributors to the work presented in this thesis. Some were lucky to be part of some major breakthroughs. These same breakthroughs were in many cases not possible without the patience and effort of others, a sincere 'thank you' for all of you. The supervision and cooperation has been a great experience in many ways.

I would like to thank Duynie and Tailtec for starting and funding the project at Wetsus. The theme meetings in which we reviewed and discussed the research together and the commercial view have been of high value for this work.

Thanks to all the companies that provided free samples of their industrial waste streams. Special thanks to Richard Mossel form Cargill, Carine van Vuure from Vion food, Ernst Zijlstra and Erik de Been from Lamb Weston. 
A special thanks to my friend Thomas Dijkstra. The yearly bike weekends allowed me to "escape from reality", blow of some steam and enjoy our beautiful country. Thanks for the cover design, all the fun bike moments we share and your ongoing friendship.

Thanks to Gert-Jan Euverink who hired me twice! The pre-postdoc year at Groningen University allowed me to combine my fresh experience and skills with others research topics. Working and discussing things with you were inspiring and fun.

To my promoter, Cees Buisman, thank you for your vision, advice and long-term interest in the aquatic worm theme. Thank you for allowing me to spend some serious time on acquisition for funding for future worm research, unfortunately this did not result in a continuation of the worm research at Wetsus. The meetings with you were always interesting and were causing a lot of self-reflection, in a good way.

To my co-promotor, Hardy Temmink, you were always supportive at all times. Thank you for being the devil's advocate and the critical supervisor, essential for the quality of the research. As we are both very passionate and direct in our expressions we never had a dull moment during our meetings. Although we approached almost every topic in a different way, I started to appreciate and respect your way of thinking over time. Your structured and clear view on things made the process from begin to end of a high standard, something we can be proud on as a team.

To my co-promotor and new partner in crime, Hellen Elissen, your love for this little fascinating creature is amazing. The research wouldn't be possible without your dedication and enormous amount of worm related knowledge and experience. You are a true worm specialist!

To my sisters and brother, thank you for being my family. Being a brother of two loving sisters and a wise and older brother is great. I wish I can spend more time with each of you in the near future.

Thank you my wife Irene for all your love and everlasting support. I know that my dedication and my second love for worms were and still are, driving you crazy from time to time. That you believe in me, makes me stronger and helped me finishing this demon called 'Thesis'.

To my hardworking parents, I am forever grateful for your unconditional love and support. The norms and values I grew up with made me how I am today. The hardworking attitude and your generosity are out of this world. 


\section{About the author}

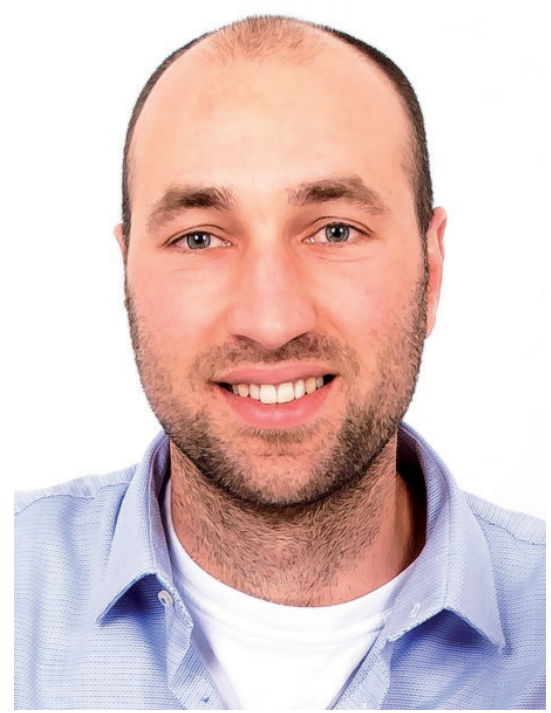

Bob Laarhoven was born on the $31^{\text {st }}$ of December in 1979 in Oud Gastel, a small town in the Dutch province, North Brabant. In 1998 he started to study Chemistry at the University of Professional Education in Etten-Leur, the Netherlands. In 1999 he started his MSc study Biology at the University Groningen with specialization in marine biology research. In 2006 he started a post master in education at the University of Groningen, Centre for learning \& teaching, resulting in a first degree for teaching biology. In the beginning of 2008, he started to work as a junior researcher at the Aquaculture and Fisheries department of Wageningen University. Here he worked within the European aquaculture project "SustainAqua" assisting and executing several experiments dealing with sustainable improvements in recirculating aquaculture systems. In 2009, he started to work as a research manager at Til-aqua International, working on the Improvement of Tilapia fry production in terms of better feeding and development. He also executed different feeding trials for external companies and research on temperature controlled sex reversal of Tilapia. From 2010 until present he is active for the Dutch society of Aquaculture (NGVA) as a member of the activity committee, organizing meetings and excursion about Aquaculture. In the summer of 2010, he started his work as a PhD student of the sub-department of Environmental Technology from Wageningen University. During his PhD, he was stationed at Wetsus, European Center of Excellence for Water Technology Research, in Leeuwarden in the Netherlands, where he performed the work presented in this thesis. In 2015, before finishing his $\mathrm{PhD}$, he started to work as a researcher at the research group; Products and Processes for Biotechnology at the University of Groningen. Here he executed research on the re-use and detection of tertiary cellulose, this within the CADOS project cooperation. He is currently exploring ways to set up a business aiming to produce blackworms for the European markets of ornamental and farmed fish feed. 


\section{List of publications}

Laarhoven B, Elissen H.J.H, Buisman C.J.N, Temmink H (2016). The carbon to nitrogen ratio in isoenergetic wheat based diets controls the growth rate of the aquatic worm Lumbriculus variegatus. Journal of Insects as Food and Feed 2(4): 225-231.

Laarhoven, B., Elissen, H., Temmink, H., Buisman, C. 2016. Agar sediment test for assesing the suitability of organic waste streams for recovering nutrients by the aquatic worm lumbriculus variegatus. Plos ONE

Serrano, A., Hendrickx, T., Elissen, H., Laarhoven, B., Buisman, C., Temmink, H. 2016. Can aquatic worms enhance methane production from waste activated sludge?. Bioresource Technology

Elissen, H., Hendrickx, T., Temmink, H., Laarhoven, B., Buisman, C. 2015. Worm-it:converting organic wastes into sustainable fish feed by using aquatic worms. Journal of Insects as Food and Feed.

Sammer, M., Laarhoven, B., Mejias, E., Yntema, D., Fuchs, E.C., Holler, G., Brasseur, G., Lankmayr, E.2014. Biomass measurement of living Lumbriculus variegatus with impedeance spectroscopy. Journal of Electrical Bioimpedance.

Neat, F.C., Lengkeek, W., Westerbeek, E.P., Laarhoven, B. \& Videler. J.J. 2003. Behavioural and morphological differences between lake and river populations of the freshwater blenny, Salaria fluviatilis. Journal of Fish Biology. 
"Het park"

Een plek mooi door stilte

Waar zon en schaduw weerspiegelen in het water

Gemoed en gedachten komen tot rust

En alles wordt helder als water

Bob Laarhoven 


\section{SENSE}

Netherlands Research School for the

Socio-Economic and Natural Sciences of the Environment

\section{I P L O M A}

For specialised PhD training

The Netherlands Research School for the Socio-Economic and Natural Sciences of the Environment

(SENSE) declares that

\section{Bob Laarhoven}

born on 31 December 1979 in Oud en Nieuw Gastel, The Netherlands

has successfully fulfilled all requirements of the

Educational Programme of SENSE.

Wageningen, 15 December 2017

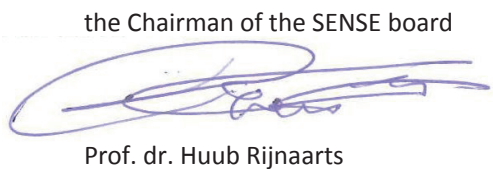

Prof. dr. Huub Rijnaarts the SENSE Director of Education



The SENSE Research School has been accredited by the Royal Netherlands Academy of Arts and Sciences (KNAW)

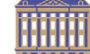

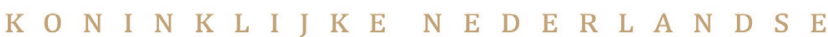

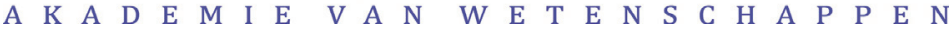




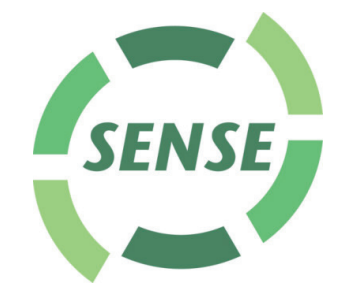

The SENSE Research School declares that Mr Bob Laarhoven has successfully fulfilled all requirements of the Educational PhD Programme of SENSE with a work load of $54 \mathrm{EC}$, including the following activities:

\section{SENSE PhD Courses}

Environmental research in context (2011)

- Research in context activity: 'Co-organizing scientific programme of Wetsus Water Challenge 2011'

- Masterclass biobased innovation (2013)

Other PhD and Advanced MSc Courses

- Advanced statistics course Design of experiments, Wageningen University (2010)

- Techniques for writing and presenting a scientific paper, Wageningen University (2011)

- Dynamic energy budgets, VU University Amsterdam (2011)

- Sustainability analysis in food production, Wageningen University (2011)

- Advanced course on environmental biotechnology, Delft University of Technology (2012)

\section{Management and Didactic Skills Training}

- Supervising MSc students with thesis entitled 'Growth and reproduction of L. variegatus fed with wheat raw products varying in COD/N ratios' (2012), 'A RAS integrated worm reactor to produce worm biomass on the basis of food industrial sludge (L. variegatus)' (2012) and 'Growth response of Lumbriculus variegatus fed on different by-products' (2013)

- PhD representative at Wetsus (2012-2013)

- Organising Organics \& Nutrients group meetings between sub-department of environmental technology (ETE), Wageningen University, and Wetsus Leeuwarden (2012-2013)

\section{Selection of Oral Presentations}

- An aquatic worm production concept for the valorization of food byproducts. Insects to feed the world conference 2014, 15-17 May 2014, Ede, The Netherlands

- An aquatic worm production concept for the valorization of food byproducts. Environmental Technology for Impact 2015 (ETEI2015) conference, 29-30 April 2015, Wageningen, The Netherlands

- From food waste products to worm biomass. SENSE science market 'Towards a biobased economy', 25 October 2012, The Hague, The Netherlands

\section{SENSE Coordinator PhD Education}

Dr. ing. Monique Gulickx

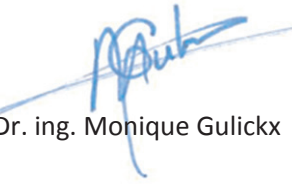


This work was performed in the cooperation framework of Wetsus, European Centre of Excellence for Sustainable Water Technology (www.wetsus.nl). Wetsus is co-funded by the Dutch Ministry of Economic Affairs and Ministry of Infrastructure and Environment, the European Union Regional Development Fund, the Province of Fryslân, and the Northern Netherlands Provinces. The authors would like to thank the participants of the research theme "Aquatic worms" for the fruitful discussions and their financial support.

Cover design: Thomas Dijkstra

Cover photo: Christina Kappel

Inside layout ProefschriftOntwerp.nl

Printed by Gildeprint — Enschede (Netherlands) 